Análise de cobertura de critérios de teste estruturais a partir de conjuntos derivados de especificações formais: um estudo comparativo no contexto de aplicações espaciais

Paula Fernanda Ramos Herculano 



\title{
Análise de cobertura de critérios de teste estruturais a partir de conjuntos derivados de especificações formais: um estudo comparativo no contexto de aplicações espaciais
}

\author{
Paula Fernanda Ramos Herculano
}

Orientador: Prof. Dr. Márcio Eduardo Delamaro

Dissertação apresentada ao Instituto de Ciências Matemáticas e de Computação - ICMC-USP, como parte dos requisitos para obtenção do título de Mestre em Ciências - Ciências de Computação e Matemática Computacional.

\section{“VERSÃO REVISADA APÓS A DEFESA"}

Data da Defesa:

$24 / 04 / 2007$

Visto do Orientador:

USP - São Carlos

Junho/ 2007 




\section{Agradecimentos}

Agradeço, primeiramente, a Deus, por ter colocado as duas pessoas mais importantes, especiais e que eu tenho o maior orgulho do mundo: Pedro e Joana, meus pais.

Agradeço aos meus pais por tudo. É até difícil descrever aqui tanto amor, carinho, apoio, amizade, enfim, tudo. Vocês me fazem entender o que é o amor incondicinal. Não consigo nem expressar tudo o que vocês são, fazem e fizeram por mim. Sem vocês eu não teria chegado até aqui.

Ao Leandro, meu irmão querido, por ser o melhor irmão do mundo. Pela sua calma nos meus momentos de desespero. À D. Sueli, por todo carinho que tem dedicado a nossa família, há mais de 10 anos.

À Debora, a melhor amiga que uma pessoa pode sonhar em ter.

Ao Taboca que tem sido muito importante na minha vida. Por todo amor, carinho, amizade e paciência em ouvir minhas reclamações/observações/comentários, também as minhas "choradeiras" e manhas.

Ao meu orientador, Delamaro, por todo apoio, incentivo e amizade. Obrigada por ter acreditado em mim sempre.

Ao Maldonado, obrigada também pelo apoio e amizade. Nunca vou esquecer o dia em que chorei na sua sala, por saudades de casa.

Ao Dino por ter acreditado em mim na época da Iniciação Científica e me apoiado sempre que possível.

Ao Ades, pelas conversas filosóficas nas viagens do Plavis e por estar sempre disposto a ajudar.

Às minhas amigas do coração: as amigas-irmãs Lu e Kelly; à "workaholic" Cacá, que eu estou com muita saudades e à Kémelli que sentirei saudades.

Aos meus amigos de sempre, que eu amo muito: Zappa, Jão, Rodrigo e Delane.

A toda a minha família, avós, tios, tias e primos que são muito importantes na minha vida. Em especial ao Ian e à Giovana que a cada sorriso fazem a minha vida um pouco melhor.

A todos os meus amigos e agregados da, inesquecível, PgCompUsp-04.

A todo o pessoal do LabES (e àqueles que são "praticamente" do LabES) por proporcionar sempre um ótimo ambiente de trabalho. Tento nomear todos, em ordem alfabética, mesmo com medo de esquecer de algum: Adenilso, Alessandra, André, Antonielly, Bira, Camila, Darley, Débora, Elisa, Erika, Ivan, Luciana (e Richard), Lúcio, Fabiano, Marcella, 
Marcelo, Marco, Masiero, Otávio, Paula, Ré, Rogério, Rosana, Rosely, Sandra, Sandro (KLB), Simone (e Paulo), Stanley, Valter e Viviane.

Um agradecimento especial ao Fabiano (tio) e ao André por mostrarem que eu estava inventando comandos no latex!

Aos professores e funcionários do ICMC, pela atenção, respeito e dedicação. Ao pessoal da portaria e ao pessoal da limpeza que fazem do ICMC um lugar sempre agradável. Um agradecimento especial à Ana Paula, Beth e Laura, sempre atenciosas e dispostas a ajudar. À Aurinha, sempre muito querida.

Ao Rudinei e à Elaine pelos longos e descontraídos "happy-hours".

Ao pessoal do Plavis.

À Capes, pelo apoio financeiro. 


\title{
Lista de Siglas e Acrônimos
}

\author{
AM - Análise de Mutantes \\ CPN - Coloured Petri Net \\ ES - Engenharia de Software \\ EXP - EXPerimento \\ FSM - Finite State Machine \\ HSI - Harmonized State Identification \\ INPE - Instituto Nacional de Pesquisas Espaciais \\ JaBUTi - Java Bytecode Understanding and Testing \\ MEF - Máquina de Estado Finito \\ OBDH - On-Board Data Handling \\ Plavis - PLAtaforma para Validação e Integração de Software \\ Proteum - Program Testing Using Mutants \\ Proteum/RS - Program Testing Using Mutants/Reactive Systems \\ RPC - Rede de Petri Colorida \\ RS - Reactive Systems \\ $\mathrm{SC}-$ State-Counting \\ SDL - Specification and Description Language \\ SR - Sistema Reativo \\ VV\&T - Validação, Verificação e Teste \\ UIO - Unique Input-Output
}



As técnicas de teste podem ser divididas, num primeiro nível, naquelas baseadas no código (caixa branca) e naquelas baseadas na especificação (caixa preta ou funcionais). Nenhuma delas é completa pois visam a identificar tipos diferentes de defeitos e a sua utilização em conjunto pode elevar o nível de confiabilidade das aplicações. Assim, tornam-se importantes estudos que contribuam para um melhor entendimento da relação existente entre técnicas funcionais e estruturais, como elas se complementam e como podem ser utilizadas em conjunto.

Este trabalho está inserido no contexto do projeto PLAVIS (Plataforma para Validação e Integração de Software em Aplicações Espaciais), e tem como objetivo realizar um estudo comparativo entre as técnicas de geração de casos de teste funcionais (baseadas nas especificações formais) e os critérios estruturais baseados em fluxo de controle e fluxo de dados, aplicados nas implementações. Num contexto específico, esse estudo deve fornecer dados de como se relacionam essas duas técnicas (funcional e estrutural) gerando subsídios para sua utilização em conjunto. Num contexto mais amplo - o do projeto PLAVIS - visa a estabelecer uma estratégia de teste baseada em critérios funcionais e estruturais e que possam, juntamente com as ferramentas que dão suporte a eles, compor um ambiente de teste disponível à utilização em aplicações espaciais dentro do INPE. 

Testing techniques can be divided, in high level, in code-based ones (white box) and specification based ones (black box). None of them are complete as they intend to identify different kinds of faults. The use of them together can increase the application confidence level. Thus, it is important to investigate the relationship between structural testing techniques and functional testing techniques, how they complete themselves and how they can be used together.

This paper was developed in the context of the Plavis (PLAtform of software Validation \& Integration on Space systems) project. This project provides comparative studies between functional generation testing techniques (based on formal specifications) and structural generation testing techniques, such as control-flow and data-flow criteria, applied in the implementation. In a specific context, this study provides data about the relationship between these techniques and how they can be used together. In the context of the Plavis project, the goal is to provide a testing strategy, based on functional and structural criteria, and a set of tools, composing a testing environment to be used in Space Applications projects, at INPE. 

1 Introdução 1

1.1 Considerações Iniciais . . . . . . . . . . . . . . . . . . . . 1

1.2 Contexto e Motivação . . . . . . . . . . . . . . . . . . . . 2

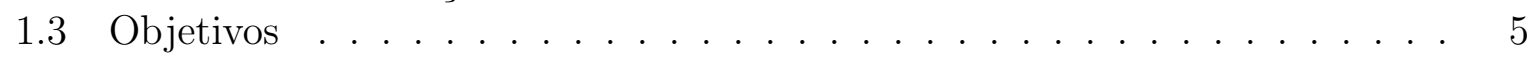

1.4 Organização do Trabalho . . . . . . . . . . . . . . . 6

2 Revisão Bibliográfica $\quad 7$

2.1 Considerações Iniciais . . . . . . . . . . . . . . . . . . . . . . . . . 7

2.2 Técnicas de Especificação de Sistemas Reativos . . . . . . . . . . . . 7

2.3 Máquinas de Estados Finitos . . . . . . . . . . . . . . . . . . . . 9

2.4 Redes de Petri Coloridas . . . . . . . . . . . . . . . . . . . . . . . . . . . . . . . . . . . . 12

2.5 Técnicas de Teste de Software . . . . . . . . . . . . . . . . 16

2.5.1 Técnica Funcional . . . . . . . . . . . . . . . . 18

2.5.2 Técnica Estrutural . . . . . . . . . . . . . . . . . . . . . 19

2.5.3 Técnica Baseada em Erros . . . . . . . . . . . . . . . . . 22

2.6 Teste e Validação de Especificações . . . . . . . . . . . . . . . . . . . . 25

2.6.1 Árvore de Alcançabilidade . . . . . . . . . . . . . . . 25

2.6 .2 Método $W \ldots \ldots \ldots \ldots \ldots \ldots$

2.6 .3 Unique Input-Output - UIO . . . . . . . . . . . . . . . . 27

2.6.4 Método State-Counting . . . . . . . . . . . . . . . 29

2.6.5 Análise de Mutantes . . . . . . . . . . . . . . . . . 30

2.6.5.1 Análise de Mutantes - MEF . . . . . . . . . . . . . . 31

2.6.5.2 Análise de Mutantes - RPC . . . . . . . . . . . . . . 32

2.7 Ferramentas de Teste . . . . . . . . . . . . . . . . . . 33

$2.7 .1 \mathrm{JaBUTi} \ldots \ldots \ldots \ldots \ldots \ldots \ldots$

2.7 .2 Plavis $/$ FSM . . . . . . . . . . . . . . . . . . . 36

2.7 .3 Proteum $/ \mathrm{CPN} \ldots \ldots \ldots \ldots \ldots \ldots$

2.8 Considerações Finais . . . . . . . . . . . . . . . . . . . . . . . . . . . . . . . . 39

3 Estudos de Caso $\quad 43$

3.1 Considerações Iniciais . . . . . . . . . . . . . . . . . . . . . . . . . . . . . 43

3.2 Estudo de Caso 1: Protocolo de Conferência . . . . . . . . . . . . . . . . . . 44

3.2.1 Descrição do Protocolo . . . . . . . . . . . . . . . . . . 44 
3.2.2 Definição do estudo de caso . . . . . . . . . . . . . . . . . . . . . . . . 49

3.2.3 Planejamento . . . . . . . . . . . . . . . . . . . . . 49

3.2 .4 Operação . . . . . . . . . . . . . . . . . . . . . . . . . . . . . . . . . . 50

3.2 .5 Coleta de Dados . . . . . . . . . . . . . . . . . . 51

3.2 .6 Análise e Interpretação . . . . . . . . . . . . . . . . . . . . . 52

3.2.6.1 Implementação derivada da especificação informal . . . . . 52

3.2.6.2 Implementação derivada da especificação em MEF . . . . 55

3.2.6.3 Análise Comparativa . . . . . . . . . . . . . . . 57

3.3 Estudo de Caso 2: Protocolo OBDH-EXP . . . . . . . . . . . . . . . 59

3.3.1 Descrição do Protocolo . . . . . . . . . . . . . . . . 59

3.3.2 Definição do estudo de caso . . . . . . . . . . . . . . . . . . 62

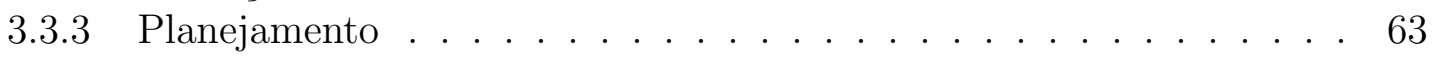

3.3 .4 Operação . . . . . . . . . . . . . . . . . . . . . 64

3.3.5 Coleta de Dados . . . . . . . . . . . . . . . . . . 65

3.3 .6 Análise e Interpretação . . . . . . . . . . . . . . . . . . . 65

3.4 Considerações Finais . . . . . . . . . . . . . . . . . . . . 67

$\begin{array}{llr}4 \text { Conclusão } & 69\end{array}$

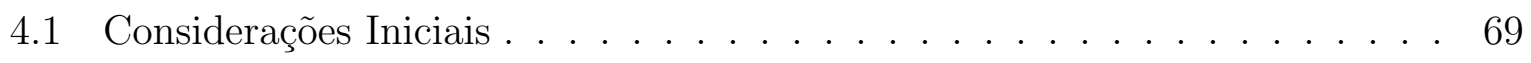

4.2 Contribuições . . . . . . . . . . . . . . . . . . . . . . 70

4.3 Trabalhos Futuros . . . . . . . . . . . . . . . . . . 70

$\begin{array}{ll}\text { Referências } & 81\end{array}$

A Rede de Petri Colorida - Protocolo de Conferência $\quad 83$ 
2.1 Representação por meio de um diagrama de transição de estados da Máquina de Estados Finitos $M_{1}($ Chow, 1978) . . . . . . . . . . . . . . . 11

2.2 Operações sobre multi-conjuntos de elementos, adaptada de Jensen (1996) 14

2.3 Programa Exemplo; identifier, que contém ao menos um defeito (adaptado de (Barbosa et al., 2000)) . . . . . . . . . . . . . . . . . 18

2.4 Grafo de fluxo de controle do programa identifier (extraído de Barbosa et

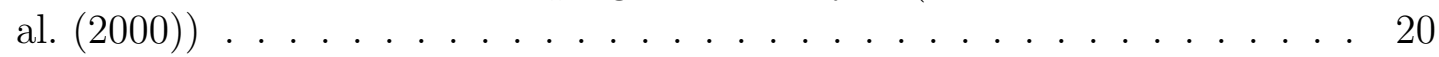

2.5 Grafo de fluxo de dados do programa identifier (extraído de (Barbosa et al., 2000)) . . . . . . . . . . . . . . . . . . 22

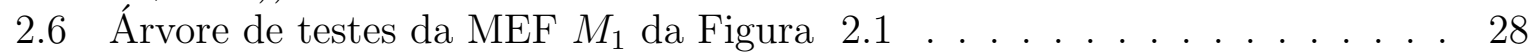

2.7 Seqüência de teste gerada pelo Método $W \ldots \ldots \ldots \ldots$. . . . . . . 28

2.8 Tela da JaBUTi, considerando o critério ativo todos-nós $s_{e i}$ : bytecode inicial 36

2.9 Tela para edição e/ou criação na MEF na Plavis/FSM . . . . . . . . . . . 38

2.10 Tela para a geração de seqüências de teste, na Plavis/FSM . . . . . . . . . 38

2.11 Tela da Proteum/CPN para escolha dos operadores de mutação . . . . . . 40

2.12 Tela da Proteum/CPN - Mutantes de uma sessão . . . . . . . . . . . . . . 40

3.1 Serviço de Conferência . . . . . . . . . . . . . . . . . . 45

3.2 Máquina de Estado Finito do Protocolo de Conferência . . . . . . . . . . . 48

3.3 Arquitetura do Protocolo de Conferência sem a interface do usuário . . . . 51

3.4 Processo de operação do estudo de caso utilizando o ConfCase . . . . . . . 52

3.5 Arquitetura do protocolo OBDH-EXP . . . . . . . . . . . . . . . 59

3.6 Formato do comando enviado pelo $\mathrm{OBDH} \ldots \ldots$. . . . . . . . . 60

3.7 MEF do protocolo OBDH-EXP, visão macro . . . . . . . . . . . . . . 61

3.8 MEF do protocolo OBDH-EXP, visão detalhada . . . . . . . . . . . . . . 61

3.9 Processo de operação do estudo de caso utilizando o OBDH-EXP . . . . . 64

A.1 RPC do Protocolo de Conferência - Página CPE . . . . . . . . . . . . 83

A.2 RPC do Protocolo de Conferência - Página CSAP . . . . . . . . . . . . 84

A.3 RPC do Protocolo de Conferência - Página Send . . . . . . . . . . . . . . 84

A.4 RPC do Protocolo de Conferência - Página Leave . . . . . . . . . . . . . . 85

A.5 RPC do Protocolo de Conferência - Página Receive . . . . . . . . . . . . . 85

A.6 RPC do Protocolo de Conferência - Página JoinAnswer . . . . . . . . . . . 86 



\section{Lista de Tabelas}

2.1 Tabela de transição de estados da máquina $M_{1} \quad \ldots \ldots$. . . . . . . . . . . 10

2.2 Operações da Máquina de Estados Finito $M_{1} \ldots \ldots \ldots$. . . . . . . . 11

2.3 Classes de equivalência para o programa identifier . . . . . . . . . . . . . . 19

2.4 Operadores de Mutação para Máquinas de Estados Finitos. . . . . . . . . . . 32

2.5 Operadores de Mutação para Redes de Petri Coloridas, extraído de Simão (2004) . . . . . . . . . . . . . . . . . . . . 33

3.1 Cobertura em \% referente aos critérios estruturais - implementação baseada na especificação informal . . . . . . . . . . . . . . . . . . 53

3.2 Custo de aplicação - implementação baseada na especificação informal . . . 54

3.3 Cobertura em \% referente aos critérios estruturais - implementação baseada na especificação formal . . . . . . . . . . . . . . . . . . 56

3.4 Custo de aplicação - implementação baseada na especificação formal . . . . 57

3.5 Descrição dos comandos enviados pelo OBDH . . . . . . . . . . . . . . 62

3.6 Cobertura em \% referente aos critérios estruturais . . . . . . . . . . . . 66

3.7 Custo de aplicação, em número de casos de teste efetivos . . . . . . . . . 67 



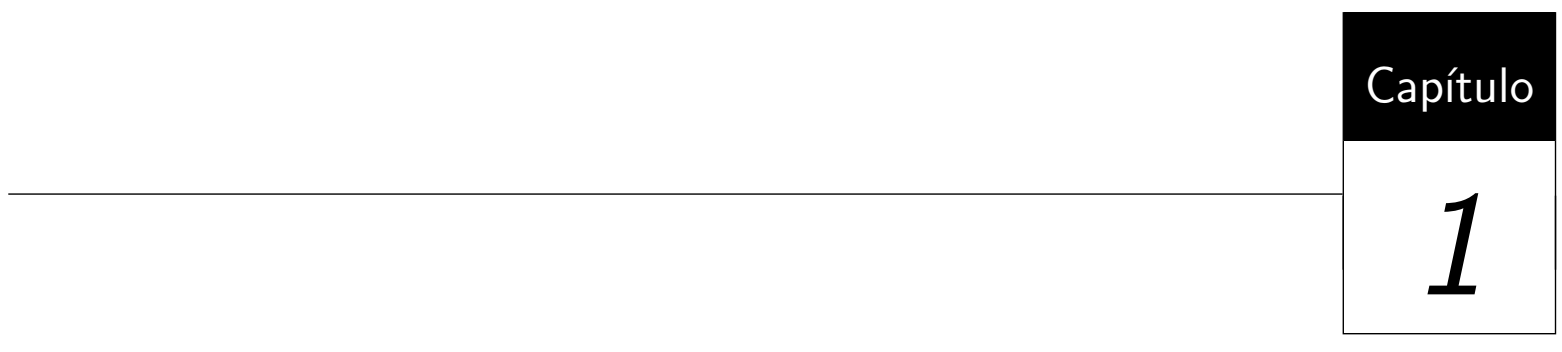

Introdução

\subsection{Considerações Iniciais}

Sistemas baseados em computação têm sido utilizados em todas as áreas da atividade humana e, como conseqüência, aspectos de qualidade e produtividade somam-se à inerente dificuldade e complexidade da atividade de desenvolvimento de software (Maldonado, 1991). Nesse sentido, a Engenharia de Software, disciplina que aplica os princípios de engenharia com o objetivo de produzir software de alta qualidade a baixo custo (Pressman, 2005), evoluiu significativamente nas últimas décadas procurando estabelecer técnicas, critérios, métodos e ferramentas para a produção de software.

Para que a engenharia de software possa ser aplicada de forma apropriada, necessita-se conhecer o contexto no qual o software a ser produzido está inserido. De acordo com Pressman (2005), o software pode ser dividido em várias categorias, tais como: software básico, sistemas de informação, sistemas científicos, sistemas pessoais, sistemas de inteligência artificial e Sistemas Reativos (SR). Os Sistemas Reativos, contexto no qual se insere este trabalho, caracterizam-se por interagirem continuamente com o meio externo respondendo a estímulos, de forma a produzir resultados corretos dentro de intervalos de tempo previamente especificados (Harel, 1987). Exemplos desses sistemas são: controle de tráfego aéreo, sistemas de monitoramento hospitalar, controle metroviário, protocolos de comunicação, entre outros. A correção nessa classe de sistemas exerce um papel fundamental, até mesmo obrigatório, já que esses sistemas controlam atividades essenciais 
a vidas humanas e de grande movimentação financeira, tais como, sistemas bancários e de telecomunicações. Sendo assim, a ocorrência de falhas pode causar grandes perdas financeiras e, até mesmo, perda de vidas humanas.

Para a especificação de tais sistemas são utilizados métodos e técnicas rigorosos, já que a linguagem natural, em geral, pode ser ambígua (Wing, 1990). Os métodos são chamados de métodos formais, pois possuem rigor matemático, de forma a tentar eliminar ambigüidades. Como exemplo de modelos formais pode-se citar: Máquinas de Estados Finitos, Redes de Petri, Statecharts, Estelle, SDL, entre outras. No entanto, mesmo com todo o rigor dessas técnicas, defeitos ainda podem ser inseridos e as especificações também devem ser validadas de alguma forma.

O processo de desenvolvimento de software envolve uma série de atividades nas quais, apesar das técnicas, métodos e ferramentas empregadas, erros no produto ainda podem ocorrer. Quando trata-se de sistemas reativos, as atividades de validação, verificação e teste tornam-se ainda mais importante, devido às características inerentes desses sistemas. O teste consiste em uma análise dinâmica do produto, sendo relevante para a identificação e eliminação dos erros que persistem, representando a última revisão da especificação, projeto e codificação (Harrold, 2000; Maldonado, 1991; Pressman, 2005; Zhu, 1996).

Num nível mais geral, para que o produto de software atinja um grau de qualidade aceitável, atividades agregadas sob o nome de Garantia de Qualidade de Software, entre elas atividades de VV\&T (Verificação, Validação e Teste), têm sido introduzidas ao longo de todo o processo de desenvolvimento de software. Dentre as técnicas de verificação e validação, o teste de software é uma das mais utilizadas, constituindo um dos elementos para fornecer evidências da confiabilidade do software em complemento a outras atividades como, por exemplo, o uso de revisões e de técnicas formais e rigorosas de especificação e de verificação (Maldonado, 1991).

\subsection{Contexto e Motivação}

O uso de modelos para teste de software tem sido proposto por décadas. Como exemplo cita-se os trabalhos de Chow (1978) e Fujiwara et al. (1991). O teste baseado em modelos consiste em derivar casos de teste a partir de um modelo que representa o comportamento do software. Esse tipo de teste apresenta várias vantagens, dentre elas está o fato de que os modelos comportamentais são desenvolvidos nas fases iniciais do ciclo de desenvolvimento, o que permite que as atividades de teste comecem antes da fase de codificação. Por meio da modelagem é possível revelar omissões ou ambigüidades na especificação ou no projeto de software, as quais podem ser corrigidas nas fases iniciais do ciclo de vida do software. 
A modelagem permite, também, gerar casos de teste para serem aplicados na própria implementação.

De maneira geral, as técnicas de teste podem ser divididas naquelas baseadas no código (caixa branca) e naquelas baseadas na especificação (caixa preta ou funcionais). Nenhuma delas é completa pois visam a identificar tipos diferentes de defeitos e a sua utilização em conjunto pode elevar o nível de confiabilidade das aplicações.

Além disso, ressalta-se que as técnicas de teste devem ser vistas como complementares e a questão que se coloca está em como utilizá-las de forma que as vantagens de cada uma sejam melhor exploradas em uma estratégia que leve a um teste de boa qualidade, ou seja, eficaz em revelar a presença de erros e de baixo custo (Maldonado, 1991).

Assim, tornam-se importantes estudos que contribuam para um melhor entendimento da relação existente entre técnicas baseadas em especificação e técnicas baseadas em código, como elas se complementam e como podem ser utilizadas em conjunto.

Estudos teóricos e empíricos visando à comparação de critérios de teste bem como o estabelecimento de estratégias para sua aplicação têm sido conduzidos nessa direção (Barbosa et al., 2001; Briand et al., 2004; Frankl e Weyuker, 1993; Harrold, 2000; Jorge et al., 2001; Maldonado et al., 2000a; Mathur e Wong, 1993; Mresa e Bottaci, 1999; Ntafos, 1988; Offutt et al., 1996; Rapps e Weyuker, 1982, 1985; Vincenzi et al., 2001; Wong et al., 1994; Zhu, 1996).

Outro aspecto fundamental associado ao teste de software refere-se ao desenvolvimento de ferramentas que automatizem a aplicação das técnicas e critérios de teste. De fato, sem a utilização de ferramentas automatizadas como mecanismos de apoio, a atividade de teste tende a ser extremamente trabalhosa, propensa a erros e limitada a programas muito simples (Horgan e Mathur, 1992). Além de contribuírem para qualidade e produtividade da atividade de teste, ferramentas de teste também são de fundamental relevância no apoio à condução de estudos empíricos, possibilitando avaliar o aspecto complementar das técnicas e critérios de teste.

Dentre as ferramentas de teste desenvolvidas pelo Grupo de Engenharia de Software do ICMC/USP cita-se:

- MGASet (Candolo et al., 2001; Nakazato, 1995): auxilia a edição, validação e simulação de Máquina de Estados Finitos;

- Proteum - Program Testing Using Mutants - (Delamaro, 1993; Delamaro e Maldonado, 1996): apóia a aplicação do critério Análise de Mutantes (DeMillo, 1978), em nível de unidade, no teste de programas C;

- Proteum/IM (Delamaro et al., 2001): apóia a aplicação do critério Mutação de Interface (Delamaro et al., 2001) no teste de programas C, em nível de integração. 
A ferramenta Proteum/IM é uma extensão da Proteum, possuindo arquitetura e implementação similares a esta. O que diferencia ambas as ferramentas é o conjunto de operadores de mutação utilizados em cada uma e o fato de que a Proteum/IM oferece características para testar a conexão entre as unidades do software;

- Proteum/IM 2.0 (Maldonado et al., 2000b): ambiente de teste integrado que viabiliza a aplicação do teste de mutação tanto de unidade como de integração. A Proteum/IM 2.0 é resultante da integração das ferramentas Proteum e Proteum/IM;

- Proteum-RS/FSM (Fabbri, 1996): apóia a aplicação do teste de mutação para Máquinas de Estados Finitos pela aplicação de 9 operadores de mutação;

- Proteum-RS/ST (Sugeta, 1999): apóia a aplicação do teste de mutação para especificações baseadas em Statecharts. Utiliza 37 operadores de mutação e define ainda três estratégias de abstração dos componentes do Statechart em diferentes níveis hierárquicos;

- Proteum-RS/PN (Simão, 2000): apóia a aplicação do teste de mutação para Redes de Petri. Além dos 11 operadores de mutação, possui facilidades para identificação de mutantes equivalentes e geração automática de casos de teste;

- Poke-Tool - Potential Uses Criteria Tool for Program Testing - (Chaim, 1991): desenvolvida na FEEC/UNICAMP em colaboração com o ICMC/USP, apóia a aplicação dos critérios Potenciais-Usos (Maldonado, 1991) e também outros critérios estruturais como Todos-Nós e Todos-Arcos;

São destacadas três ferramenta, utilizadas nesta dissertação de mestrado:

- JaBUTi - Java Bytecode Understanding and Testing - (Vincenzi, 2004; Vincenzi et al., 2003): Basicamente, a ferramenta apóia a aplicação de critérios baseados em fluxo de controle (Todos-Nós e Todas-Arestas) e em fluxo de dados (Todos-Usos e Todos-Pot-Usos) no teste de programas e componentes escritos em Java. Uma das principais vantagens associadas à JaBUTi está no fato da ferramenta não requerer código-fonte na condução da atividade de teste. Ela realiza toda a análise estática e de cobertura diretamente no código objeto Java (bytecode). Isso permite, por exemplo, que componentes desenvolvidos por terceiros possam ser integrados e testados, mesmo que não se tenha acesso a seu código fonte;

- Proteum/CPN (Simão, 2004) apóia o teste de mutação para Redes de Petri Coloridas; 
- Plavis/FSM (Simão et al., 2005) plataforma de teste para especificações baseadas em Máquinas de Estados Finitos;

Ressalta-se que a disponibilidade de ferramentas de teste permite a transferência tecnológica entre universidade e indústria, fator indispensável para a produção de software de alta qualidade. Além disso, a existência de ferramentas auxilia pesquisadores e alunos de Engenharia de Software a adquirirem os conceitos básicos e experiência na comparação, seleção e estabelecimento de estratégias de teste. Tais ferramentas desempenham um papel importante no processo de ensino, aprendizado e treinamento dos conceitos de teste, contribuindo para a formação e capacitação de pessoal (Barbosa et al., 2001).

Este trabalho está inserido no contexto do projeto PLAVIS (Plataforma para Validação e Integração de Software em Aplicações Espaciais) patrocinado pelo CNPq. O projeto (http://www.labes.icmc.usp.br/plavis) reúne cientistas das seguintes universidades e centros de pesquisas: USP, UNICAMP, UFSCar, INPE e UNIVEM. Há também uma cooperação com a França, por meio do projeto Capes-Cofecub. O objetivo global do projeto PLAVIS é verificar a aplicabilidade dos métodos, técnicas e ferramentas desenvolvidos no âmbito acadêmico para Testes de Software (geração, seleção, execução e análise automatizada de testes) em aplicações espaciais fornecidas pelo INPE. É enfocada também a qualidade dos testes, tanto do ponto de vista da cobertura (seja do código, seja da especificação), quanto do ponto de vista da eficácia para encontrar falhas.

Os objetivos específicos do projeto Plavis:

- Adaptação e aplicação de ferramentas existentes, desenvolvidas em meio acadêmico pelos grupos envolvidos, em estudos de casos reais disponibilizados pelo INPE;

- Transferência de tecnologia

- Criação de plataforma no INPE contendo as ferramentas de modelagem, testes e análise de desempenho citadas no primeiro item;

- Capacitação da equipe de Engenharia Espacial do INPE no uso das ferramentas;

- Avaliação dos resultados obtidos com o uso das ferramentas em estudos de casos reais.

O objetivo específico deste trabalho está descrito na seção seguinte.

\subsection{Objetivos}

O objetivo deste trabalho é realizar um estudo comparativo entre as técnicas de geração de casos de teste baseados nas especificações formais e os critérios estruturais de fluxo de 
dados e de fluxo de controle a fim de analisar qual o relacionamento entre essas técnicas e como podem ser utilizadas em conjunto. São analisados o custo e a eficácia (em termos de cobertura estrutural) de se aplicar um conjunto de teste derivado de uma especificação formal em uma implementação do problema.

As técnicas de especificação formal utilizadas neste trabalho são: Máquinas de Estados Finitos e Redes de Petri Coloridas (RPC). Os métodos de geração de casos de teste analisados são: Método W (Chow, 1978), State-Counting (Petrenko e Yevtushenko, 2005) e Unique Input-Output - UIO (Sabnari e Dahbura, 1988), e o critério Análise de Mutantes (DeMillo, 1978), sendo os três primeiros baseados em Máquina de Estado Finito e o último sendo aplicado tanto a Máquinas de Estados Finitos quanto a Redes de Petri Coloridas.

Para compor esse estudo foram selecionados, como estudo de caso, dois protocolos, o On-Board Data Handling (OBDH) e o ConfCase (Côte de Resyste Project, 1999). O primeiro, é um protocolo de comunicação fornecido pelo Instituto Nacional de Pesquisas (INPE). Foi escolhido por pertencer ao domínio alvo que deseja-se explorar, que são as aplicações espaciais. O segundo, é um protocolo de conferência, foi selecionado por tratar-se de um protocolo simples, formalmente especificado e que apresenta características semelhantes ao domínio que se deseja abordar. Os estudos de caso são compostos da especificação e implementação dos problemas. Os conjuntos de casos de teste são derivados a partir das especificações e dos requisitos estruturais e, posteriormente, aplicados nas implementações para análise e avaliação.

\subsection{Organização do Trabalho}

Este trabalho está organizado da seguinte maneira: neste Capítulo foram apresentados o contexto no qual esta dissertação de mestrado está inserida juntamente com a motivação e os objetivos. No Capítulo 2 é feita uma revisão bibliográfica do trabalho, relacionando os temas pertinentes ao desenvolvimento do trabalho como as técnicas de especificação de sistemas reativos, as técnicas de teste de software e por fim o uso de ferramentas de auxílio ao teste, destacando as ferramentas JaBUTi, Plavis/FSM e Proteum/CPN, que são utilizadas no contexto desta dissertação. No Capítulo 3 são apresentados, de forma detalhada, os dois estudos de caso realizados, contendo desde a descrição de cada um a análise dos resultados obtidos. Por fim, no Capítulo 4 são apresentadas as conclusões e os trabalhos futuros. 


\subsection{Considerações Iniciais}

Neste capítulo são apresentados os principais conceitos utilizados no desenvolvimento deste trabalho. Na Seção 2.2 é feita uma contextualização referente a especificações de Sistemas Reativos e em seguida, nas Seções 2.3 e 2.4 são descritas as duas técnicas utilizadas neste trabalho que são as Máquinas de Estados Finitos e as Redes de Petri Coloridas. Na seqüência são abordados os conceitos de teste de software e suas principais técnicas (funcional, estrutural e baseada em erros) e técnicas de teste e validação de especificações, nas Seções 2.6.1 a 2.6.5. É mostrada a importância do desenvolvimento e utilização de ferramentas de apoio ao teste e é dado destaque, nas Seções 2.7.1, 2.7.2 e 2.7.3 às ferramentas utilizadas neste trabalho.

\subsection{Técnicas de Especificação de Sistemas Reativos}

De acordo com Pressman (2005) a especificação de um sistema é um documento essencial para o correto desenvolvimento do produto e serve de base para a engenharia de hardware, engenharia de software, engenharia de banco de dados e engenharia humana. Ela descreve a função e o desempenho de um sistema baseado em computador e as restrições que orientarão seu desenvolvimento, assim como as informações que entram e saem do sistema. 
Para representar essas informações e apoiar o trabalho do engenheiro de software existem métodos ou linguagens técnicas apropriadas. Classificam-se esses métodos como formais e informais, sendo que a principal diferença está no fato de que os métodos informais não possuem embasamento matemático, enquanto que os métodos formais possuem (Sugeta, 1999).

Os métodos informais são representações em linguagem natural que servem para descrever objetivos, metas e requisitos. Esses métodos, apesar de serem de fácil compreensão, não conseguem capturar e definir, de forma precisa, os requisitos do sistema, podendo sempre deixar margem a interpretações ambíguas. Assim, têm sido empregadas técnicas de especificação formal para especificar sistemas complexos, tais como, os Sistemas Reativos (SR).

Os SR possuem como característica fundamental a interação contínua com o ambiente, reagindo a eventos internos e externos, o que faz com que seu aspecto comportamental seja de fundamental importância para definir os requisitos do sistema. Fazem parte dessa classe, por exemplo, sistemas de controle de tráfego aéreo e de telefonia. Tais sistemas são sistemas críticos com relação à segurança pois podem colocar em risco vidas humanas e/ou grandes valores financeiros. Visto isso, para o desenvolvimento desses sistemas é necessário o emprego de métodos adequados e rigorosos com relação à forma de representação, tais como os métodos formais de especificação.

Sommerville (2003) afirma que os métodos de especificação formal completam as técnicas de especificação informal. Eles podem ser usados para refinar um requisito do sistema detalhado, mas informal.

Algumas técnicas formais são muito empregadas por possuírem uma representação gráfica, facilitando a interpretação do aspecto comportamental do sistema. Dentre as técnicas formais estão aquelas baseadas em modelo de Máquina de Transição de Estados, tais como, Redes de Petri (Peterson, 1981), Máquinas de Estados Finitos (Gill, 1962) e Statecharts (Harel, 1987). De acordo com Barroca e McDermid (1992) apud Simão (2004), os métodos formais podem ser divididos em 5 classes:

- Orientados a Modelo: Fornecem uma definição explícita e abstrata do estado do sistema e operações que transformam esses estados, porém, sem representar explicitamente a concorrência. São exemplos dessa classe: VDM - Vienna Development Method, Z e Máquina de Estados Finitos;

- Algébricos: Fornecem uma definição implícita das operações do sistema por meio do relacionamento do comportamento de diferentes operações, sem definir os estados do sistema. Novamente, nenhuma representação explícita da concorrência é fornecida. São exemplos dessa classe: OBJ e Larch; 
- Baseados em Álgebra de Processos: Fornecem um modelo explícito de processos concorrentes e representam o comportamento por meio de restrições impostas à comunicação observável entre os processos. São exemplos dessa classe: CCS Calculus of Communicating Systems e CSP - Communicating Sequential Processes;

- Baseados em Lógica: Fornecem um modelo de comportamento usando lógica matemática para descrever as propriedades dos componentes do sistema. Um exemplo dessa classe é a lógica temporal;

- Baseados em Rede: Fornecem um modelo implícito da concorrência do sistema por meio do fluxo de dados e de controle através de uma rede. Exemplos dessa classe são as técnicas de Redes de Petri e Redes de Petri Coloridas;

De acordo com Wing (1990) alguns métodos formais podem ser representados graficamente, sendo divididos em métodos formais e semiformais. Entre os métodos semiformais visuais estão incluídos os trabalhos de Jackson (Jackson, 1983), HIPO - Hierarchy Input Processing Output - (Corporation IBM, 1974) e SD - Structured Design - (Gane e Sarson, 1979). Como vantagem, destaca-se que facilitam a comunicação entre o projetista e o cliente, já a desvantagem está no fato de que podem contribuir para a elaboração de especificações ambíguas pois combinam diagramas e textos. Como métodos formais visuais cita-se Statecharts, Máquinas de Estados Finitos e Redes de Petri. As técnicas Máquinas de Estados Finitos e Redes de Petri Coloridas (uma extensão das Redes de Petri) são descritas nas sessões seguintes.

\subsection{Máquinas de Estados Finitos}

A aplicação de Máquinas de Estados Finitos (MEF) não é limitada a uma determinada área científica e sim a praticamente todo campo de investigação. Sua teoria trata de modelos matemáticos que servem como aproximação de fenômenos físicos e abstratos (Gill, 1962). Essa técnica é muito utilizada na especificação do aspecto comportamental de Sistemas Reativos e, em particular, na especificação de protocolos de comunicação (Fabbri, 1996).

Uma Máquina de Estado Finito é uma máquina hipotética composta por estados e transições. A cada evento de entrada a máquina pode gerar um evento de saída e mudar de estado. O evento de saída gerado e o novo estado dependem unicamente do evento de entrada e do estado atual. A máquina pode estar apenas em um único estado, em um dado instante. Sua representação pode ser feita de duas formas: i) por meio de uma tabela de transição, na qual as colunas representam as possíveis entradas e as linhas os estados da máquina; ii) diagrama de transição de estados - que é um grafo direcionado, sendo 
cada estado representado por um vértice e cada transição representada por uma aresta direcionada, rotulada pelos eventos associados à transição. Esse rótulo é, geralmente, apresentado no formato entrada:saída.

Uma MEF pode ser representada por dois modelos: o modelo de Mealy (Mealy, 1955) e o modelo de Moore (Moore, 1956). No primeiro, a saída é baseada no estado atual e na entrada e no seu diagrama de estados cada transição é rotulada pela combinação da entrada e saída correspondentes. Já no modelo de Moore o rótulo da transição contém apenas a função de saída correspondente, sendo a função de transição dependente apenas do estado atual da máquina.

Formalmente uma máquina é representada por uma tupla $M=\left(X, Z, S, s_{0}, f_{z}, f_{s}\right)$, tal que:

- $X$ é um conjunto finito não vazio de símbolos de entrada;

- $Z$ é um conjunto finito de símbolos de saída;

- $S$ é um conjunto finito não vazio de estados;

- $s_{0} \in S$ é o estado inicial;

- $f_{z}:(S \times X) \rightarrow Z$ é a função de entrada;

- $f_{s}:(S \times X) \rightarrow S$ é a função de próximo estado.

Na Figura 2.1 está representada uma Máquina de Estado Finito $M_{1}$ (Chow, 1978) por meio de um diagrama de transição de estados e na Tabela 2.1, essa máquina está representada por meio de uma tabela de transição, de acordo com o modelo de Mealy. $M_{1}$ especifica o comportamento de um extrator de comentários, no qual o conjunto de entrada é composto por uma seqüência de símbolos "*", "/", "v", sendo "v" qualquer caracter diferente de "*” e "/". A entrada é uma cadeia de caracteres e os comentários são impressos. Um comentário é uma seqüência de caracteres iniciada por "/*" e terminada por "*/". Como saídas, têm-se as operações representadas na Tabela 2.2. O estado 1 é o estado inicial da máquina.

Tabela 2.1: Tabela de transição de estados da máquina $M_{1}$

\begin{tabular}{|c|c|c|c|}
\hline & $*$ & $/$ & $\mathbf{v}$ \\
\hline \hline 1 & $1 /$ ignore & $2 /$ ignore & 1/ignore \\
\hline 2 & $3 /$ empty-bf & $2 /$ ignore & $1 /$ ignore \\
\hline 3 & $4 /$ acc-bf & $3 /$ acc-bf & $3 /$ acc-bf \\
\hline 4 & $4 /$ acc-bf & 1/deacc-bf & $3 /$ acc-bf \\
\hline \hline
\end{tabular}

As propriedades e as principais características de uma MEF são: 


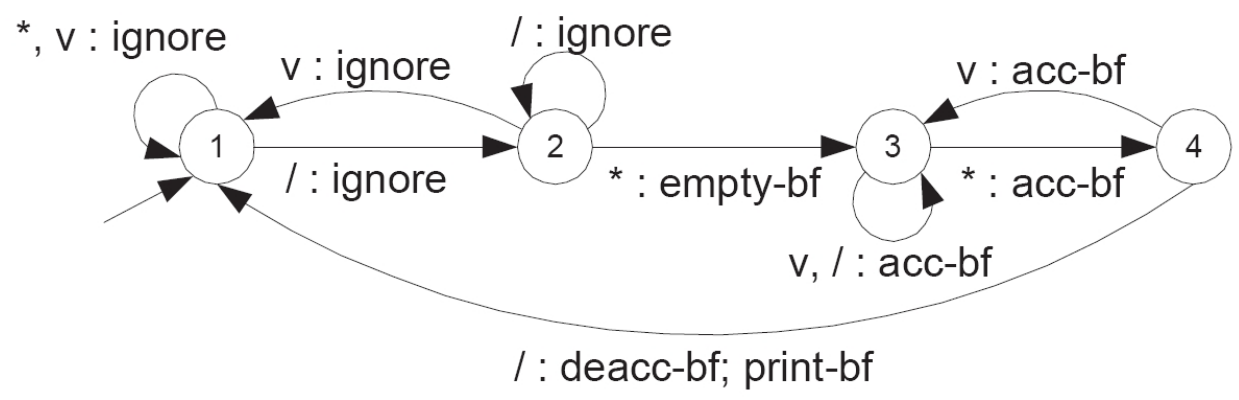

Figura 2.1: Representação por meio de um diagrama de transição de estados da Máquina de Estados Finitos $M_{1}$ (Chow, 1978)

Tabela 2.2: Operações da Máquina de Estados Finito $M_{1}$

\begin{tabular}{|l|l|}
\hline Operadores & ação \\
\hline \hline ignore & ação nula \\
\hline empty-bf & buffer $:=$ vazio \\
\hline acc-bf & buffer $:=$ buffer concatenado com o caracter corrente \\
\hline deacc-bf & buffer $:=$ buffer com o caracter truncado mais à direita \\
\hline print-bf & imprime o conteúdo do buffer \\
\hline \hline
\end{tabular}

- estados equivalentes: os estados $s_{1}$ de uma MEF $M_{1}$ e $s_{2}$ de uma MEF $M_{2}$ são ditos equivalentes se, quando são exercitados por qualquer seqüência de entrada produzem a mesma saída. Caso essas saídas sejam diferentes, os estados são ditos estados distinguíveis. $M_{1}$ e $M_{2}$ podem ser a mesma máquina.

- especificação completa: uma MEF é dita completamente especificada se, para cada estado existe uma transição para cada símbolo de entrada.

- minimalidade: uma máquina é dita minimal se não existe nenhum par de estados equivalentes.

- determinismo: uma máquina é dita determinística se, para cada entrada existe, no máximo, uma transição definida em cada estado.

- conectividade forte: uma máquina é dita ser fortemente conexa se, para todo par de estados $\left(s_{1}, s_{2}\right)$ existe uma seqüência de símbolos de entrada tal que essa seqüência leva a máquina do estado $s_{1}$ para o estado $s_{2}$.

Outro conceito importante nesse contexto é o de seqüência. Existem algumas seqüências básicas, que são pertinentes ao estabelecimento de critérios de geração de seqüência de teste baseados em MEF (Nakazato et al., 1994a,b,c). São elas:

- seqüência de identificação: é uma seqüência de símbolos de entrada que tem por objetivo identificar, de maneira única, cada um dos estados da máquina. 
- seqüência de sincronização: é uma seqüência de símbolos de entrada que leva a máquina $M$ a um estado final especificado, independente da saída gerada ou do estado inicial.

- seqüência distinguível: é uma seqüência de identificação que produz seqüências de saída diferentes para cada um dos estados da máquina $M$.

- seqüência única de entrada e saída (UIO): é uma seqüência de identificação que relaciona um símbolo de entrada e um símbolo de saída e que é única para cada estado da máquina $M$.

- conjunto de caracterização $(W)$ : é um conjunto de seqüências de identificação tal que os símbolos de saída observados após a aplicação dessas seqüências (numa ordem fixada), sobre cada um dos estados, são diferentes.

Para a validação de especificações baseadas em Máquinas de Estados Finitos, vários métodos de geração de seqüências de teste têm sido propostos na literatura, como os métodos W (Chow, 1978), Wp - Partial W-Method (Fujiwara et al., 1991), DS - Distinguishing Sequences (Gönenç, 1970) e UIO - Unique Input-Output (Sabnari e Dahbura, 1988). No entanto, para que esses sejam aplicados, é necessário que a máquina satisfaça algumas propriedades e restrições. Um método para geração de seqüências que merece destaque é o State-Counting (Petrenko e Yevtushenko, 2005). A aplicação desse método não requer que a máquina satisfaça algumas propriedades que os métodos citados anteriormente requerem como, por exemplo, a máquina ser completamente especificada e minimal.

O principal objetivo desses métodos, segundo Fujiwara et al. (1991), é oferecer a possibilidade de executar as atividades de teste e validação em sistemas construídos de acordo com alguma técnica de modelagem, de forma sistemática, através de procedimentos bem definidos para a geração dessas seqüências, fazendo com que os produtos se apresentem de forma mais segura e com maior qualidade. Esses critérios são apresentados na Seção 2.6 .

\subsection{Redes de Petri Coloridas}

As Redes de Petri (RP) são uma ferramenta gráfica e matemática de modelagem, sendo uma linguagem formal ideal para a representação de sistemas que enfatizam a comunicação e sincronização entre processos e o compartilhamento de recursos. Segundo Murata (1989), as Redes de Petri foram propostas inicialmente por Carl A. Petri, em sua tese de doutoramento, em 1962, e, originalmente, os sistemas eram organizados por meio de suas condições e eventos e da inter-relação entre tais condições e eventos. Posteriormente, essa 
definição foi ampliada de forma que as condições pudessem conter uma ou mais marcas, passando as condições a serem chamadas de lugares da rede e os eventos de transições (Simão, 2004). Essa nova definição deu origem às redes chamadas Lugar/Transição e as anteriores passaram a ser denominadas Condição/Evento. Pelo fato das Redes Lugar/ Transição serem mais estudadas e utilizadas, essas são genericamente denominadas de Redes de Petri. Uma Rede Condição/Evento é uma Rede de Petri Lugar/Transição na qual os lugares contêm, no máximo, uma marca.

Com o objetivo de enriquecer o poder de modelagem das redes, várias extensões e/ou restrições têm sido propostas, no entanto, o poder de decisão sobre as propriedades do modelo pode ser reduzido. Como exemplo, têm-se as Redes de Petri Temporais e as Estocásticas, que associam tempo às transições e aos lugares, respectivamente. As Redes de Escolha Livre e as Redes Elementares que, por um lado, têm maior poder de decisão sobre as propriedades do modelo, por outro, têm a expressividade reduzida, limitando o número de sistemas que podem ser modelados. Para lidar com o conceito de tipo abstrato de dados foram propostas as Redes de Petri Coloridas e para o conceito de orientação a objetos, têm-se as Redes de Petri Orientadas a Objetos, nas quais as marcas representam os objetos.

Nas Redes de Petri não há o conceito de dados fazendo com que a manipulação desses dados tenha que ser representada diretamente na estrutura da rede, o que torna os modelos excessivamente grandes. Para suprir essa deficiência, foram criadas as Redes de Petri Coloridas, nas quais foram adicionados os recursos de definição e manipulação de tipos de dados. Por razões históricas, as marcas em uma Rede de Petri Colorida são representadas por meio de cores, diferentemente das Redes de Petri originais, nas quais as marcas são "pretas", não sendo distinguíveis (Jensen, 1994).

\section{Multi-Conjunto de Elementos}

Para a definição de Redes de Petri Coloridas é necessária a definição de multi-conjunto de elementos. Um multi-conjunto de elementos é semelhante a um conjunto, exceto pelo fato de que em um multi-conjunto um elemento pode aparecer mais de uma vez. A representação de elementos repetidos é feita por um número inteiro, denominado de coeficiente. Quando o elemento aparece apenas uma vez no multi-conjunto seu coeficiente pode ser omitido. Já quando há mais de uma ocorrência do mesmo elemento, por exemplo, quando o elemento $a$ aparece 3 vezes dentro do multi-conjunto ele é representado por 3(a). As operações definidas sobre multi-conjuntos são adição, multiplicação por escalar, comparações, tamanho e subtração, que estão representadas na Figura 2.2, adaptada de Jensen (1996). 
Adição

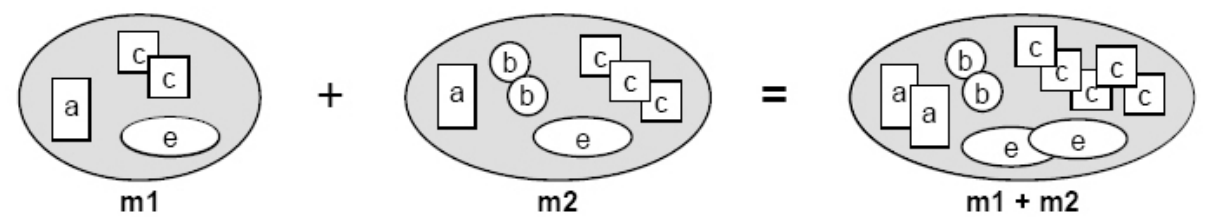

Multiplicação por Escalar

3
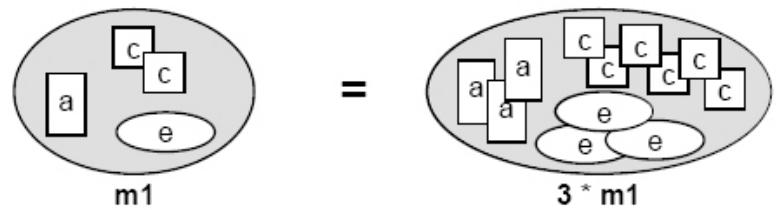

Comparação

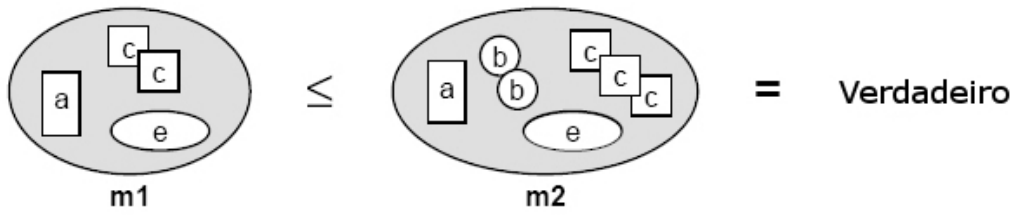

Tamanho (número de elementos)

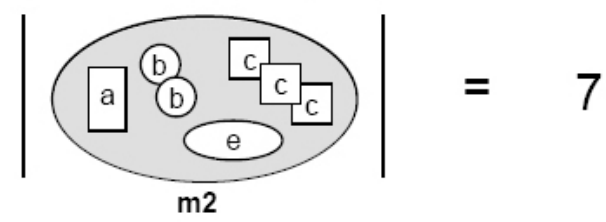

Subtração (somente se $\mathrm{m} 2>=\mathrm{m} 1$ )

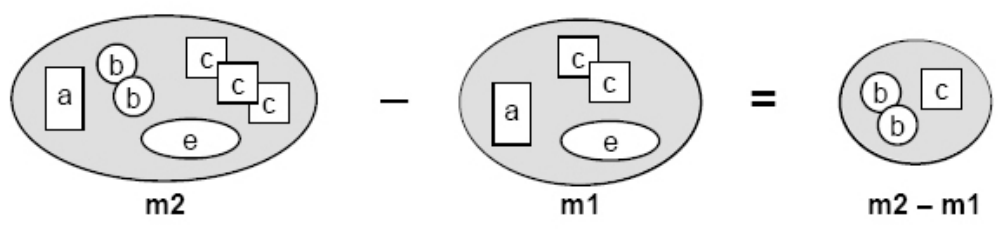

Figura 2.2: Operações sobre multi-conjuntos de elementos, adaptada de Jensen (1996)

\section{Definição Formal}

Uma rede de Petri Colorida é definida formalmente por uma tupla sendo $R P C=$ $(\Sigma, P, T, A, N, C, G, E, I)$ tal que:

- $\Sigma$ é um conjunto finito não vazio de tipos, chamado de conjunto de cores

- $P$ é um conjunto finito de lugares

- $T$ é um conjunto finito de transições, tal que: $P \cap T=\emptyset$

- $A$ é um conjunto finito de arcos, tal que: $P \cap A=T \cap A=\emptyset$

- $N$ é uma função de nós, tal que: $N: A \rightarrow P \times T \cup T \times P$

- $C$ é uma função de coloração, tal que: $C: P \rightarrow \Sigma$ 
- $G$ é uma expressão de guarda que associa a cada $t \in T$ uma expressão do tipo booleano

- E é uma expressão de anotação dos arcos que associa a cada $a \in A$ uma expressão do tipo lugar relacionado

- I é uma expressão de inicialização que associa a cada $p \in P$ uma expressão do tipo $C(p)$

As definições dos termos a seguir foram baseadas em Simão (2004).

\section{Cores}

Em RPC o termo cor é usado como sinônimo de tipo de dados. Uma cor $C$ é um conjunto não vazio, possivelmente com infinitos elementos. Uma RPC possui um conjunto não vazio de cores $\Sigma$.

\section{Linguagem de Anotação de Arcos}

Assim como ocorre nas linguagens de programação para a definição das cores de uma especificação e para a manipulação de seus elementos é necessário utilizar uma linguagem concreta. A escolha dessa linguagem não altera a semântica e a expressividade da técnica. No entanto, uma linguagem que não possui a semântica bem definida pode prejudicar o desempenho das técnicas de análise.

\section{Elementos Estruturais}

Em uma RPC há aqueles elementos que definem o comportamento estático do sistema, chamados de elementos estruturais e aqueles que definem o comportamento dinâmico, chamados de elementos dinâmicos. Os elementos estruturais são os lugares, as transições e os arcos.

Os lugares representam os estados da rede. Eles são representados por uma elipse com seus nomes escritos dentro da elipse. Para cada lugar é associado um tipo de dado (isto é, uma cor) que determina o tipo que esse lugare pode conter (por convenção, a informação de tipos é colocada em itálico e próxima ao lugar). As ações da rede são representadas por meio das transições que graficamente são apresentadas na forma de retângulos. Os arcos representam os relacionamentos entre os elementos do sistema. Um arco pode relacionar um lugar a uma transição (arco de entrada) ou uma transição a um lugar (arco de saída). No primeiro caso ele indica que uma transição pode remover marcas do lugar correspondente, enquanto no segundo indica que a transição pode adicionar marcas ao lugar. O número exato de marcas e os valores de seus dados é determinado pelas anotações dos arcos (que são posicionadas próximas aos arcos) (Jensen, 1994). 


\section{Elementos Dinâmicos}

Os elementos dinâmicos referem-se às características de execução da rede, por exemplo, se uma dada marcação é alcançável (Jensen, 1994). Os elementos dinâmicos são as anotações de arcos, expressões de guarda e expressões de inicialização.

Uma anotação de arco é posicionada próxima ao respectivo arco. A anotação de arco indica que transições podem ocorrer de diferentes maneiras, quantificando e qualificando a relação entre os lugares e as transições. Uma anotação de arco mapeia um multi-conjunto de elementos da cor do lugar associado a esse arco.

Uma expressão de guarda é uma expressão booleana, chamada de guarda, (com variáveis) relacionadas a cada transição. A condição, dada pela expressão booleana, especifica que a transição só é habilitada se a expressão for avaliada como verdadeira.

Uma expressão de inicialização refere-se ao conteúdo de um lugar quando o sistema é inicializado, ou seja, é o estado inicial do lugar. Ela é um valor associado ao lugar que representa um multi-conjunto de elementos da cor do respectivo lugar. Quando não especificada, o valor assumido é o multi-conjunto vazio de elementos.

No Apêndice A pode ser vista uma RPC. Essa RPC corresponde ao ConfCase, um protocolo de comunicação que foi usado como estudo de caso deste trabalho e está descrito no Capítulo 3, na Seção 3.2.1.

\subsection{Técnicas de Teste de Software}

Embora a Engenharia de Software proporcione métodos, técnicas e ferramentas para auxiliar na garantia da qualidade do produto desenvolvido, defeitos podem ser introduzidos. Em vista disso, a atividade de teste é de fundamental importância para a eliminação desses defeitos que ainda persistem. O teste é uma das atividades que devem ser realizadas durante o desenvolvimento de software que visam a garantir a qualidade desse processo assim como do produto (Harrold, 2000), consistindo em executar um programa com o objetivo de revelar (ao menos) um defeito (Myers et al., 2004). Geralmente, o teste está associado à execução de um programa resultante da fase de implementação e análise de conformidade com os requisitos do sistema que podem ser representadas pela especificação.

É importante ressaltar a diferença entre os termos defeito, engano, erro e falha. De acordo com o padrão IEEE 610.12-1990 (IEEE, 1990), defeito (fault) é um passo, processo ou definição de dados incorretos; engano (mistake) é uma ação humana que produz um resultado incorreto; erro (error) é a diferença entre o valor obtido e o valor esperado; falha (failure) consiste na produção de uma saída incorreta com relação à especificação. A execução de um programa $P$, com um caso de teste $t \in T$ pode ser responsável por "revelar 
um defeito" ou expor uma falha e não "encontrar um defeito". Essa última afirmação caracteriza a etapa de depuração.

A atividade de teste envolve quatro etapas: planejamento de testes, projeto de casos de teste, execução e avaliação dos resultados de teste (Pressman, 2005), que podem ser conduzidas em três fases:

- Teste de unidade: consiste em testar a menor unidade de projeto de software que pode ser um procedimento, um método ou uma classe. Nessa fase, procura-se identificar defeitos na lógica e na implementação de cada módulo do programa.

- Teste de integração: nessa fase procura-se descobrir defeitos na interface entre os módulos e na integração da estrutura do programa.

- Teste de sistemas: essa fase consiste em verificar se as funções estão de acordo com a especificação, se todos os elementos combinam-se adequadamente assim como se as características de desempenho e robustez estão sendo satisfeitas.

Um ponto muito importante que deve ser analisado é o projeto e/ou a avaliação de um determinado conjunto de testes. Idealmente, um programa $P$ deveria ser testado com um conjunto de testes $T$ formado pelo conjunto completo do domínio de entrada $D$. Entretanto, sabe-se que isso é impraticável pois o domínio de entrada pode ser infinito ou possuir um número muito grande de elementos. Sendo assim, por questões de produtividade e tempo o objetivo é utilizar casos de teste que tenham alta probabilidade de revelar um defeito com o mínimo de tempo e esforço (Maldonado, 1997). Para isso, diversos critérios, métodos e técnicas têm sido propostos de forma a oferecer ao testador uma abordagem sistemática e teoricamente fundamentada na condução e na avaliação da atividade de teste (DeMillo, 1980; Rapps e Weyuker, 1985). Esses critérios particionam o domínio de entrada de forma que o conjunto de teste seja eficiente em revelar defeitos. Um caso de teste é um par ordenado $(d, S(d))$ no qual $d \in D$ e $S(d)$ é a respectiva saída esperada. Os critérios de teste podem ser usados tanto para geração de um conjunto de casos de teste quanto para a avaliação da adequação desse conjunto, evidenciando a suficiência do teste (Frankl e Weyuker, 2000).

De forma geral, os critérios de teste estão agrupados em três técnicas, que distinguem-se pela origem da informação necessária para derivar os requisitos de teste, são elas: funcional (ou caixa preta) - os requisitos de teste são derivados a partir da especificação; estrutural (ou caixa branca) - casos de teste são criados a partir do código do programa; e baseada em erros - os requisitos de teste são derivados a partir de informações sobre os defeitos mais freqüentes encontrados no desenvolvimento de software. É importante ressaltar que essas três técnicas são vistas como complementares e o uso em conjunto 
proporciona maior qualidade e confiança na atividade de teste (Maldonado, 1991). As técnicas Funcional, Estrutural e Baseada em Erros estão descritas nas próximas seções. Para ilustrar alguns conceitos, são usados exemplos extraídos de Barbosa et al. (2000). Tais exemplos são baseados no programa identifier.

O Identifier.c é um programa que deve determinar se um identificador é válido ou não, em "Silly Pascal" (uma variante de Pascal). Um identificador válido deve começar com uma letra e conter apenas letras ou dígitos. Além disso, deve ter no mínimo 1 caractere e no máximo 6 caracteres de comprimento. Na Figura 2.3 é mostrado o código do programa.

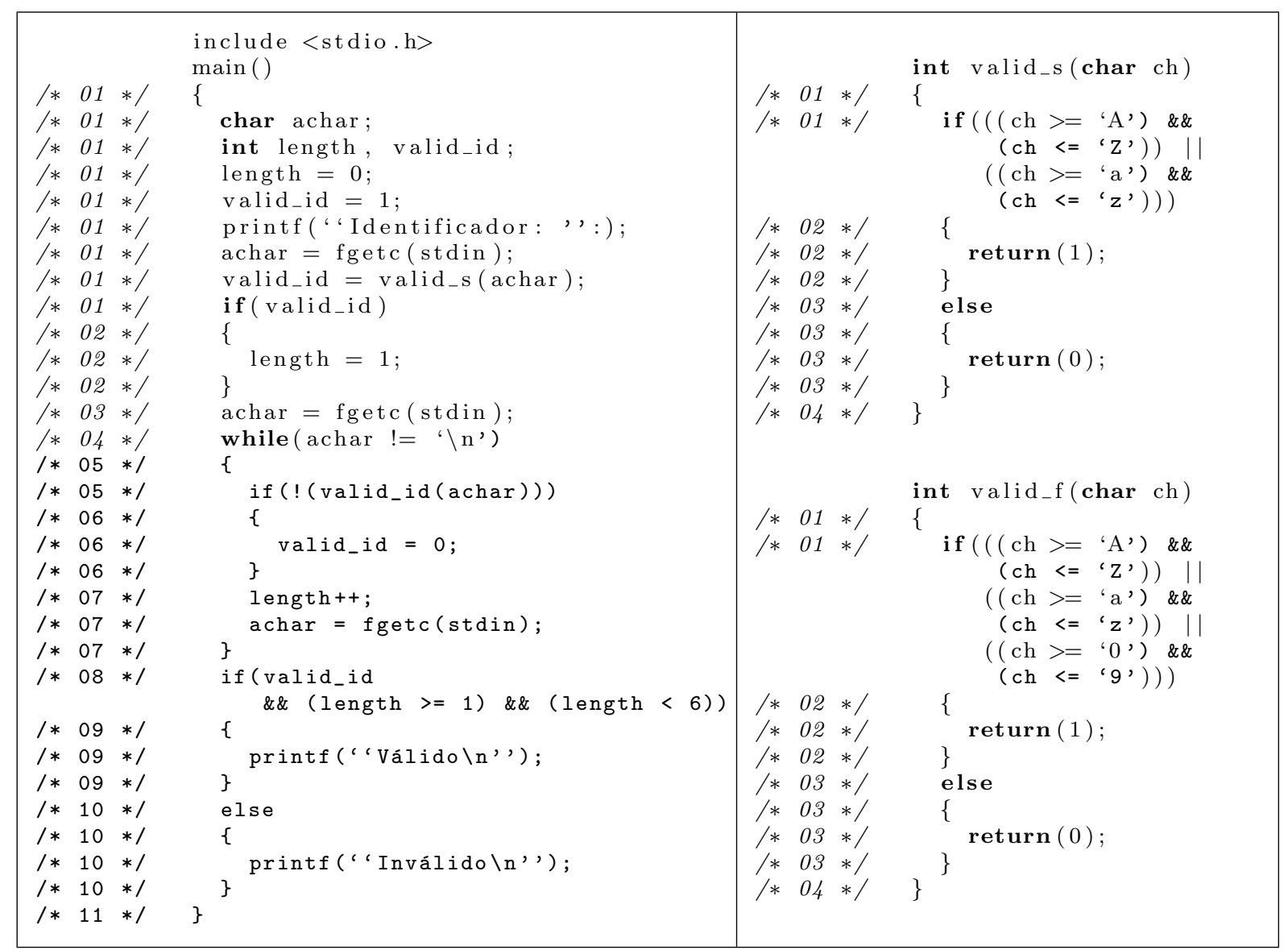

Figura 2.3: Programa Exemplo; identifier, que contém ao menos um defeito (adaptado de (Barbosa et al., 2000))

\subsubsection{Técnica Funcional}

Na técnica funcional, também conhecida como "caixa-preta", o software é tratado como bloco no qual o seu conteúdo interno é desconhecido, tendo como informações disponíveis (ou acessíveis) apenas os valores de entrada e de saída. Os requisitos de teste são derivados a partir da especificação do sistema. Sendo assim, é muito importante que a especificação 
esteja de acordo com os requisitos do usuário (Pressman, 2005). Como exemplo de critérios dessa técnica, cita-se:

- Teste exaustivo: considera cada condição de entrada como um caso de teste. Geralmente é considerado impraticável, já que o domínio de entrada pode ser infinito ou possuir um número extremamente grande de valores (Myers et al., 2004).

- Particionamento em classes de equivalência: consiste em dividir os elementos do domínio de entrada em classes, de forma que as funcionalidades similares pertençam a uma mesma classe. Essas classes podem ser válidas ou inválidas e, a partir delas, os casos de teste são derivados. A título de ilustração, na Tabela 2.3 são mostradas as classes de equivalência (válidas e inválidas) para o programa identifier.

Tabela 2.3: Classes de equivalência para o programa identifier

\begin{tabular}{|l|c|c|}
\hline Restrições de Entrada & Classes Válidas & Classes Inválidas \\
\hline \hline Tamanho $(t)$ do identificador & $1 \leq t \leq 6$ & $t>6$ \\
\hline Primeiro caracter $(c)$ é uma letra & Sim & Não \\
\hline Contém somente caracteres válidos & Sim & Não \\
\hline
\end{tabular}

- Análise do valor limite: esse critério complementa o critério de particionamento em classes de equivalência buscando selecionar elementos pertencentes aos "limites" das classes. De acordo com Pressman (2005) esses elementos são escolhidos, pois, empiricamente, tem-se constatado que a maior incidência de erros ocorre nos limites das classes e não no interior delas.

- Grafo de causa-efeito: esse critério busca verificar a combinação das condições de entrada (causa) com as ações (efeito) do programa, relacionando-as em um grafo. Esse grafo é convertido em uma tabela de decisão, que é utilizada na geração dos casos de teste.

Um problema relacionado à técnica funcional está no fato de não ser possível quantificar a atividade de teste, pois não há informações disponíveis para garantir que as partes críticas do sistema foram executadas. Como os requisitos de teste são obtidos a partir da especificação, pode haver inconsistências na atividade, pois essa, parte do princípio que a especificação esteja correta, no entanto, tal afirmação não é garantida.

\subsubsection{Técnica Estrutural}

Na técnica estrutural, também conhecida como teste de "caixa-branca" a estrutura interna do programa é examinada para derivar os requisitos de teste. Os critérios dessa técnica 
são baseados no tipo da estrutura para determinar quais elementos serão requeridos na execução do programa. Em geral, são utilizados grafos orientados para representar o controle lógico do programa. Esses grafos contêm um único nó de entrada, nos quais cada vértice representa um bloco indivisível de comandos e as arestas indicam um possível desvio de fluxo de controle (Myers et al., 2004). Os grafos são conhecidos como grafo de fluxo de controle ou grafo de programa.

Um programa $P$ pode ser decomposto em um conjunto de blocos disjuntos de comandos. Todos os comandos do bloco têm um único predecessor (possivelmente com exceção do primeiro) e um único sucessor (possivelmente com exceção do último). Um bloco é um conjuntos de instruções que são executadas dentro de um programa, onde não há desvio de controle. Quando o primeiro comando do bloco é executado, todos os outros comando que compõe aquele bloco também são executados seqüencialmente.

\section{Critérios Baseados em Fluxo de Controle}

Um grafo de fluxo de controle $G=(N, E, s)$ é um grafo orientado com um único nó de entrada $s \in N$, sendo $N$ o conjunto de nós e $E$ é o conjunto de arcos. Cada vértice do grafo representa um bloco indivisível de comandos dentro do programa e cada aresta do grafo representa um possível desvio de controle de um bloco para outro.

O grafo de fluxo de controle do programa identifier está ilustrado na Figura 2.4.

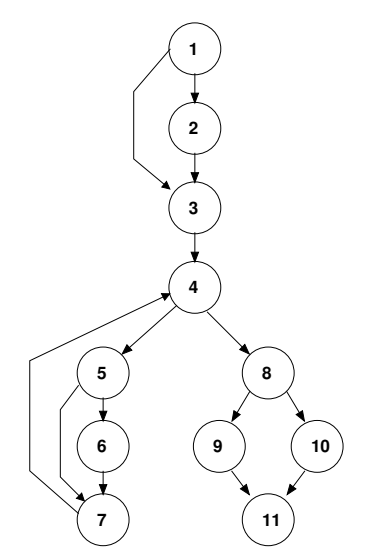

Figura 2.4: Grafo de fluxo de controle do programa identifier (extraído de Barbosa et al. (2000))

Um caminho é uma seqüência finita de nós $\left(n_{1}, n_{2}, \ldots, n_{k}\right) k \geq 2$ tal que existe um arco que liga os nós de $n_{i}$ para $n_{i}+1$ para $i=1,2, \ldots, k-1$. Um caminho simples é um caminho em que os nós que o compõem, exceto, possivelmente, o primeiro e o último, são distintos. Um caminho simples é dito ser um caminho livre de laços. Um caminho completo é um caminho no qual o primeiro é o último nós são, respectivamente, o nó de entrada e o nó de saída do grafo. Um caminho simples do programa identifier é o caminho $(2,3,4,5,6,7)$, um caminho livre de laços é, por exemplo, o caminho $(1,2,3,4,5,7,4,8,9,11)$ é um ca- 
minho completo. O caminho $(6,7,4,5,7,4,8,9)$ não é executável e qualquer caminho completo que o inclua também não é executável, isto é, não existe nenhum dado de entrada que leve o programa a executar esse caminho (Barbosa et al., 2000).

Os principais critérios são dessa técnica são:

- Todos-nós: exige que a execução do programa exercite, pelo menos uma vez, cada vértice do grafo de programa.

- Todas-arestas: exige que a execução do programa passe, pelo menos uma vez, por cada aresta do grafo de programa.

- Todos-caminhos: exige que todos os possíveis caminhos do grafo de programa sejam, pelo menos uma vez, executados. Em geral, esse critério é impraticável, pois o número de caminhos é infinito na presença de laços.

\section{Critérios Baseados em Fluxo de Dados}

Nesses critérios os requisitos de teste são derivados a partir das informações referentes ao fluxo de dados do programa. Para isso, são adicionadas ao grafo de programa informações sobre o fluxo dos dados, caracterizando o grafo Def-Uso definido por Rapps e Weyuker (1982, 1985). Nesse contexto são utilizados dois conceitos importantes, o de definição e o de uso de uma variável. A definição de uma variável ocorre no momento em que um valor lhe é atribuído. Um uso expressa uma referência ao valor daquela variável. Esse uso caracteriza-se como uso computacional (c-uso) ou uso predicativo ( $p$-uso). No primeiro a variável é usada em um comando de computação, no segundo, ela é usada em uma expressão de decisão. Os caminhos a serem exercitados são definidos em função das associações definição-uso das variáveis do programa. A partir dessas informações é construído o grafo Def-Uso, do qual deriva-se o conceito de par def-uso, que se refere a uma definição e subseqüente uso daquela variável (podendo ser um c-uso ou p-uso). O grafo Def-Uso do programa identifier está apresentado na Figura 2.5.

Outro conceito importante é o de caminho livre de definição. Um caminho $\left(n_{1}, \ldots, n_{m}\right), m \geq 1$, é um caminho livre de definição para uma variável $x$ se não contém nenhuma definição de $x$ nos nós $n_{1}, \ldots, n_{m}+1$ (Rapps e Weyuker, 1982).

Como exemplos desse tipo de critério citam-se os critérios definidos por Rapps e Weyuker (1982, 1985) e os critérios Potenciais-Usos (Maldonado, 1991):

- Todas-definições: esse critério requer que, para cada definição de uma variável, exista pelo menos um caso de teste que alcance um uso daquela variável, por meio de um caminho livre de definição (Rapps e Weyuker, 1982). Isto é, exige-se um uso qualquer (c-uso ou p-uso), de um tipo qualquer, para todas definições existentes 


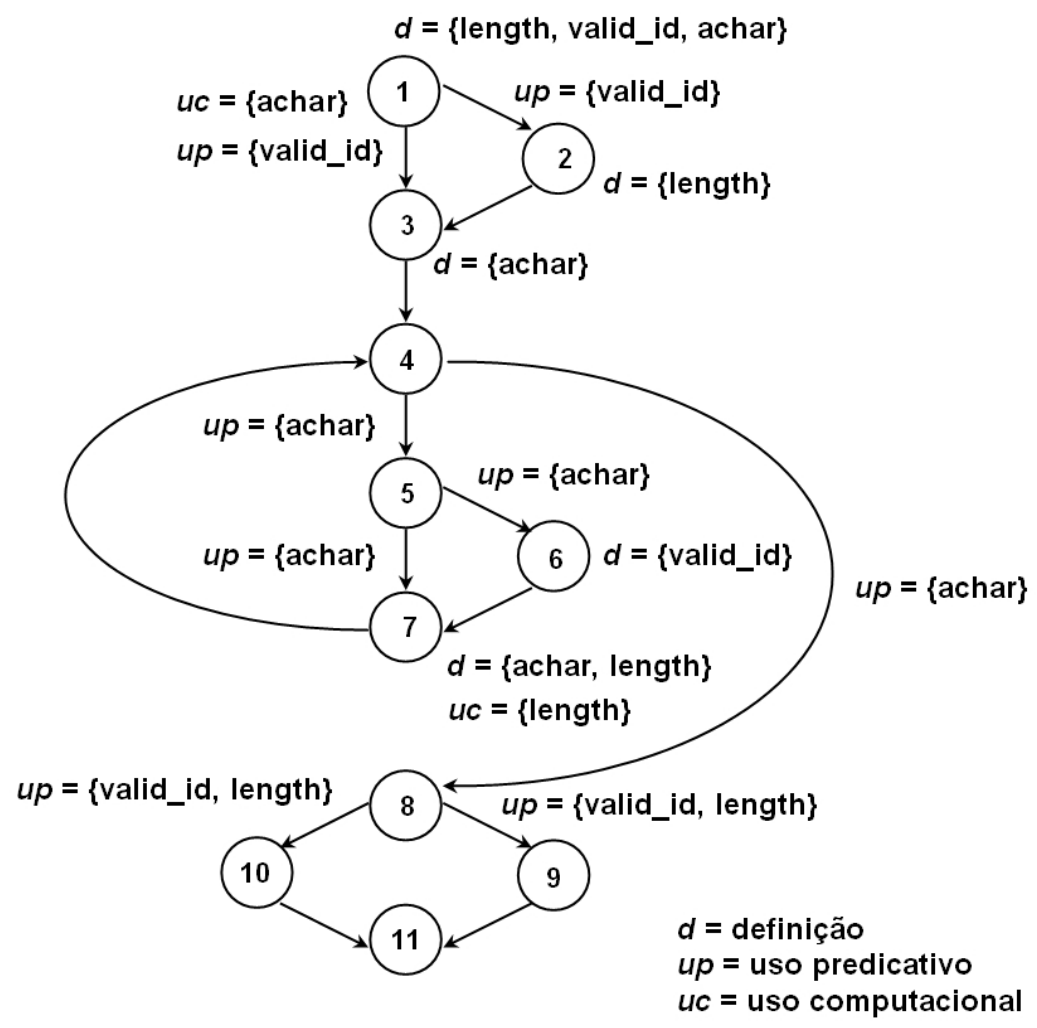

Figura 2.5: Grafo de fluxo de dados do programa identifier (extraído de (Barbosa et al., 2000))

no programa, sendo assim, todas definições de variáveis serão utilizadas pelo menos uma vez.

- Todos-usos: esse critério requer que, para cada definição de uma variável, exista pelo menos um caso de teste que alcance cada uso daquela variável, por meio de um caminho livre de definição. Isto é, para cada definição de variável, todos os usos de valores atribuídos nessa definição devem ser executados (independentemente do tipo de uso).

- Todos-potenciais-usos: esse critério requer associações que são caracterizadas independente de uma referência (um uso) explícito de uma determinada definição. Assim, é necessário que sejam exercitados, a partir da definição de uma determinada variável, caminhos livres de definição, independente de ocorrer uma referência explícita dessa variável no caminho (Maldonado, 1991).

\subsubsection{Técnica Baseada em Erros}

Essa técnica baseia-se em utilizar os defeitos mais freqüentes introduzidos durante o processo de desenvolvimento do software, assim como os tipos específicos de defeitos que se 
deseja revelar, para derivar os requisitos de teste. O critério mais conhecido dessa técnica é o Critério Análise de Mutantes (DeMillo, 1978).

\section{Critério Análise de Mutantes}

O critério Análise de Mutantes foi desenvolvido na Yale University e no Georgia Institute of Technology, na década de 70, possuindo um forte relacionamento com o método para detecção de defeitos lógicos em circuitos digitais (Vincenzi, 2004). O princípio desse critério é, a partir de um programa original que deseja-se testar, inserir algumas alterações sintáticas. Dessa forma, tem-se o programa original e vários programas mutantes. Em seguida, elaboram-se os casos de teste e comparam-se os resultados obtidos entre o programa original e pelo programa mutante, de forma a encontrar disparidades. Os mutantes são gerados a partir de operadores de mutação que estão relacionados a um tipo ou classe de erros que pretende-se revelar.

Um operador de mutação é uma função que, a partir de um programa $P$, resulta em um conjunto de programas semelhantes, no entanto, com um defeito inserido. Como um mesmo tipo de defeito pode ocorrer em diversas partes do programa, o operador gera um conjunto de programas mutantes. Cada programa mutante corresponde à aplicação da função em um único ponto do programa.

Esse critério permite que a adequação dos casos de teste seja avaliada, por meio do escore de mutação. Tal escore é definido por meio da relação entre o número de mutantes gerados e o número de mutantes mortos, ignorando os mutantes equivalentes. Um mutante é considerado como mutante morto quando o resultado produzido por sua execução difere daquele produzido na execução do programa original, com o mesmo conjunto de casos de teste. Por outro lado, um mutante vivo é aquele que apresenta os mesmos resultados do programa original para todo o conjunto de teste. Isso pode acontecer, simplesmente, porque o conjunto não possui nenhum caso de teste capaz de revelar a diferença do mutante ou porque o mutante é equivalente ao programa original, ou seja, apresenta, para qualquer dado do domínio de entrada, os mesmos resultados do programa original.

O escore de mutação é definido pela seguinte expressão:

$$
m s(P, T)=\frac{D M(P, T)}{M(P)-E M(P)}
$$

Sendo:

$P=$ programa original

$T=$ conjunto de casos de teste

$m s=$ escore de mutação 
$D M(P, T)=$ número de mutantes mortos pelos casos de teste em $T$

$M(P)=$ número total de mutantes gerados

$E M(P)=$ número de mutantes gerados equivalentes a $P$

Um dos problemas relacionados a esse critério refere-se ao número de mutantes gerados e, conseqüentemente, ao alto custo computacional exigido na execução desses mutantes. Para amenizar esse problema, algumas abordagens têm sido propostas, tais como, Mutação Aleatória (Acree, 1980) e Mutação Restritiva (Mathur e Wong, 1993).

Ambas as abordagens procuram reduzir o número de mutantes utilizados. Na Mutação Aleatória seleciona-se apenas uma percentagem dos mutantes gerados pelos operadores. Mesmo utilizando uma pequena percentagem do total de mutantes, é possível gerar bons casos de teste. Na Mutação Restritiva examinam-se apenas alguns tipos específicos de mutantes e os demais são ignorados (DeMillo, 1987).

Dado um programa $P$ e um conjunto de casos de teste $T$, cuja qualidade deve-se avaliar, deve-se seguir os seguintes passos para aplicar o critério Análise de Mutantes (Simão, 2004):

1. Geração do conjunto de mutantes $M$ : Constrói-se um conjunto de programas obtidos pela inserção de algumas alterações sintáticas. Cada produto é denominado de mutante e o conjunto de mutantes é denominado vizinhança. Essa etapa é muito importante pois o sucesso da aplicação desse critério depende da escolha adequada da vizinhança. Tal vizinhança deve ser escolhida de modo que o conjunto de casos de teste aplicado consiga revelar a maior parte dos defeitos do produto e deve ter cardinalidade pequena para que o problema da geração e verificação do comportamento dos mutantes seja tratável.

2. Execução de $P$ com $T$ : Executa-se o programa original $P$ com o conjunto de casos de teste $T$ e verifica-se se o programa produz os resultados desejados. Caso esses resultados não sejam os esperados, o programa deve ser corrigido e a atividade de teste deve ser retomada.

3. Execução dos mutantes $M$ com $T$ : Todos os mutantes gerados devem ser executados com o mesmo conjunto de testes utilizados na etapa anterior. Os resultados dessa etapa são comparados com os da etapa anterior com o objetivo de encontrar disparidades. Caso essas sejam encontradas, os mutantes são considerados mortos, significando que o conjunto de testes conseguiu revelar diferenças entre o programa original e os programas mutantes. Porém, se ambas execuções apresentarem resultados idênticos, o mutante continua vivo e deve ser analisado pois pode tratar-se 
de um mutante equivalente (que deve ser apenas descartado) ou pode expressar que o conjunto de testes escolhido não é adequado. Caso ocorra essa última situação, novos casos de teste devem ser adicionados.

4. Análise dos mutantes: Essa é a etapa que exige maior intervenção humana. Nessa etapa deve-se optar por continuar o teste ou não. Essa decisão pode ser tomada pela análise do escore de mutação obtido. Caso a decisão seja a de continuar, avaliam-se os mutantes vivos na tentativa de criar um novo (e mais adequado) conjunto de casos de teste, retomando os passos 2, 3 e 4, e/ou avaliá-los quanto a sua equivalência. Essa última análise geralmente necessita da intervenção do testador, já que é sabido que a decisão da igualdade entre programas é um problema indecidível. Os mutantes identificados como equivalentes são descartados.

\subsection{Teste e Validação de Especificações}

Como já citado, a ocorrência de falhas em sistemas reativos pode ocasionar grandes perdas financeiras ou colocar em risco vidas humanas e, num nível de maior conseqüência, acarretar perda dessas vidas. Para tentar garantir a segurança, correção e completude desses sistemas, são usados métodos formais para sua especificação. Existem várias técnicas de especificação formal que se adequam a diferentes características exigidas por esses sistemas, como por exemplo Máquinas de Estados Finitos, Statecharts, Redes de Petri, Estelle e SDL. No entanto, o uso dessas técnicas não garante a correção e completude das especificações e, para tentar aumentar a confiança das especificações, é necessário que atividades de teste sejam conduzidas. A seguir, são descritas algumas técnicas, relevantes para o contexto deste trabalho, referentes ao teste e a validação de especificações, como: método $W$, Unique Input-Output, State-Counting e o critério análise de mutantes nos contextos de Máquina de Estados Finitos e Redes de Petri Coloridas.

\subsection{1 Árvore de Alcançabilidade}

Uma árvore de alcançabilidade consiste em gerar todos os possíveis estados (configurações) de um sistema a partir de uma configuração inicial. Esse método tem sido utilizado em Máquina de Estados Finitos, Statecharts, Estelle e Redes de Petri (Murata, 1989).

$\mathrm{Na}$ árvore de alcançabilidade os nós representam os estados do modelo e as arestas são rotuladas com os eventos. A raiz da árvore corresponde ao estado inicial da máquina. Se em uma máquina $M$, o nó $n_{1}$ está ligado ao nó $n_{2}$ por meio de uma aresta rotulada com o evento $e$, significa que a ocorrência desse evento $e$ leva a máquina da configuração $n_{1}$ para a configuração $n_{2}$. Dessa forma, tem-se essa ligação representada na árvore como um nó 
$n_{1}$ ligado por uma aresta $e$ a um nó $n_{2}$. A seguir é apresentado um algoritmo genérico para a criação de uma árvore de alcançabilidade, extraído de (Simão, 2004).

Faça do estado inicial o nó da raiz e marque-o como novo

Enquanto houver nós marcados como novos

Selecione um nó $n_{1}$, tal que $n_{1}$ está marcado como novo

Marque $n_{1}$ como velho

Para todo evento $e$ que pode ocorrer em $n_{1}$, faça:

Seja $n_{2}$ o estado obtido após a ocorrência do evento $e$ em $n_{1}$

Inclua na árvore o nó $n_{2}$ e uma aresta que liga $n_{1}$ a $n_{2}$ com o rótulo $e$

Marque $n_{2}$ como novo

A partir de uma Árvore de Alcançabilidade é possível verificar algumas propriedades dinâmicas de um sistema, tais como: i) validade de uma seqüência de eventos - quando cada evento causa o disparo de uma transição de forma a alterar a configuração do sistema; ii) alcançabilidade de estados - quando, a partir de um determinado estado $e_{1}$, existe uma seqüência $s_{q}$ válida de estados que leva a máquina ao estado $e_{2}$; iii) reiniciabilidade - quando, para cada estado, existe uma sequiência valida de eventos que leva ao estado inicial; iv) existência de deadlocks - quando o modelo alcança um estado a partir do qual o sistema não evolui; e v) uso de transições - quando uma transição aparece em pelo menos um caminho da árvore de alcançabilidade.

Um problema relacionado à Árvore de Alcançabilidade é o número de possíveis configurações, que é infinito, a não ser que a especificação sempre leve a uma configuração final, na qual nenhum outro estado pode ocorrer. Esse problema é conhecido como problema da explosão de estados. Para isso é definida uma subárvore da Árvore de Alcançabilidade, projetada para manter algumas características, mas reduzindo o tamanho da árvore. Essa subárvore perde algumas informações importantes contidas na Árvore de Alcançabilidade. Portanto, deve ser definida de forma a satisfazer as necessidades e a manter as informações importantes referentes à aplicação à qual é destinada. Uma subárvore de Alcançabilidade pode ser definida de forma que os caminhos entre a raiz e algum nó não possuam nós ou eventos repetidos.

\subsubsection{Método $W$}

Esse método foi proposto por Chow em 1978 e é adequado para estruturas de controle que possam ser modeladas com Máquinas de Estados Finitos. O método baseia-se nas propriedades seqüenciais da máquina para a determinação de um conjunto de casos de teste que seja finito e, ao mesmo tempo, consiga a cobertura do maior número possível de erros contidos na máquina (Simão, 2002). 
Segundo Fabbri et al. (1993), as Máquinas de Estados Finitos devem possuir algumas características nas quais a saída e o próximo estado dependam somente do estado corrente e da entrada, ou seja, não existem variáveis de controle ou contadores manipulados pelas operações que possam influenciar o seqüenciamento das operações. Assume-se, ainda, que as máquinas tenham as seguintes propriedades:

- Minimalidade;

- Determinismo;

- Sejam Máquinas de Mealy;

- Especificação Completa;

- Estado inicial fixo;

- Todo estado seja alcançável a partir do estado inicial.

A MEF ainda deve apresentar um Conjunto de Caracterização $W$. Esse método pode ser descrito por meio do seguinte procedimento:

1. geração do Conjunto de Caracterização $W$;

2. geração da Árvore de Testes;

3. geração das seqüências de teste.

A Árvore de Testes é uma subárvore da Árvore de Alcançabilidade das Máquinas de Estados Finitos tal que todos os rótulos dos nós terminais, e somente os rótulos dos nós terminais, apareçam duas vezes no caminho que liga a raiz a esses nós. Nas Figuras 2.6 e 2.7 são representados, respectivamente, a Árvore de Testes para a MEF $M_{1}$ da Figura 2.1 e a seqüência de testes gerada pelo Método $W$.

O Método $W$ gera uma grande quantidade de seqüências de casos de teste. Para tentar reduzir esta quantidade de seqüências geradas, foi desenvolvido o Método $W_{p}$ (Partial $W$ Method - (Fujiwara et al., 1991)), que, de acordo com (Simão, 2002), consegue obter a mesma cobertura que o Método $W$ com um conjunto de casos de teste reduzido.

\subsubsection{Unique Input-Output - UIO}

Proposto por Sabnari e Dahbura (1988), este critério teve como principal motivação a checagem de conformidade de especificações de protocolos de comunicação de redes de computadores. Para Sabnari uma seqüência de teste é uma seqüência de símbolos de 


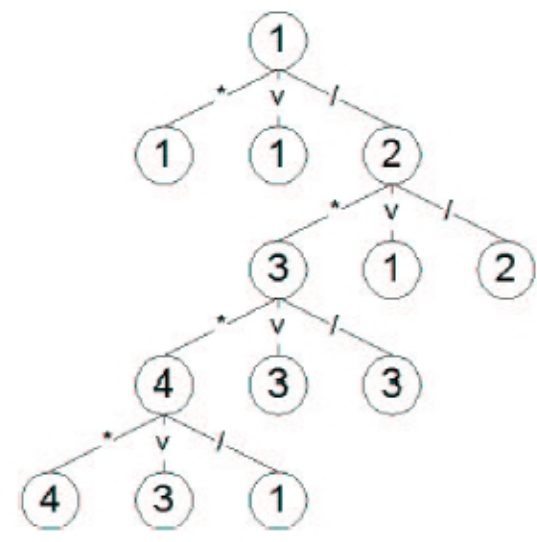

Figura 2.6: Árvore de testes da MEF $M_{1}$ da Figura 2.1
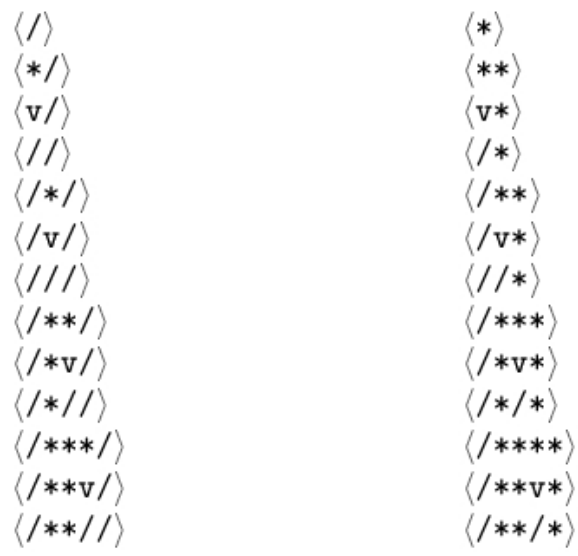

Figura 2.7: Seqüência de teste gerada pelo Método $W$

entrada e saída. Assim, a checagem de conformidade consiste em verificar se os símbolos de saída gerados são idênticos aos das saídas esperadas (Nakazato et al., 1994a,b,c).

Uma seqüência única de entrada e saída, como o próprio nome diz, é única para cada estado e é também chamada de assinatura do estado. Isso quer dizer que essa seqüência pode distinguir um estado $s_{i}$ de qualquer outro estado $s \in S$. Nem todo estado de uma máquina possui uma seqüência UIO, entretanto, se existe uma seqüência UIO para cada estado $s_{i}$, então, cada estado da Máquina $M$ pode ser identificado por essa seqüência. $\mathrm{O}$ método UIO constrói um conjunto de seqüência de entrada que visita cada transição de $s_{i}$ a $s_{j}$ aplicando um conjunto de cobertura de transições $P$ e então verifica o estado final $s_{j}$ aplicando sua seqüência única de entrada e saída.

Apesar de usado na prática, o método UIO não garante que defeitos na implementação sejam revelados, pois a unicidade dessa seqüência pode não ser mantida em uma implementação incorreta. Uma implementação incorreta possui um estado $s^{\prime}$ que, devido a algum defeito, possui a mesma seqüência UIO de um estado $s$ e uma transição incorreta que termina em $s^{\prime}$ em vez de terminar em $s$ pode ser testada como correta (Gargantini, 
2004). Isto quer dizer que o método não garante a cobertura total dos erros, pois a seqüência de entrada leva a uma única saída na especificação correta, mas isso não é garantido para as implementações com erro.

A aplicação desse critério requer que as seguintes características da MEF:

- Minimalidade;

- Determinismo;

- Fortemente Conexa;

- Especificação Completa;

- Sejam Máquinas de Mealy;

- Estado inicial fixo.

\subsubsection{Método State-Counting}

A maioria dos métodos de geração de seqüência de teste propostos na literatura requerem que a MEF seja complemente especificada e minimal. Uma MEF completamente especificada possui uma transição para cada combinação estado-entrada e uma máquina reduzida é aquela que não possui estados equivalentes. No entanto, na prática, a maioria das MEFs são parcialmente especificadas pois, muitas vezes, representam apenas pedaços do sistema ou um ambiente restrito (Petrenko e Yevtushenko, 2005).

O que os métodos de geração de seqüências fazem é completar a máquina artificialmente (hipótese de completude). Uma maneira de se assumir essa completude é, para as combinações estado-entrada que não existem, considerar uma transição que tem saída nula e permanece no mesmo estado. Outra maneira é fazer com que a transição vá para um estado de erro com uma saída que representa um símbolo de erro.

Entretanto, Petrenko e Yevtushenko (2005) argumentam que, muitas vezes, uma hipótese de completude pode ser inútil pois há casos em que as transições que foram adicionadas artificialmente nunca serão executadas.

O método State-Conting (SC) (Petrenko e Yevtushenko, 2000, 2005) considera a geração de conjuntos de casos de teste a partir de MEFs que podem ser parcialmente especificadas e não reduzidas. Ele identifica os estados quase-equivalentes e determina um conjunto dos estados "core", do qual fazem parte somente estados que podem ser distinguidos entre si. Em seguida analisa as seqüências de entrada eliminando os prefixos daquelas que são referentes às transições entre os estados quase-equivalentes. Entretanto, o problema clássico da identificação de estados no qual afirma-se que nem sempre os estados podem ser distinguidos usando apenas as combinações core, ainda permanece. 
O Método SC para a derivação de um conjunto de teste $m$-completo, sendo $m$ o número mínimo de estados de uma máquina, consiste:

- Entrada: MEF $A=\left(S, s_{0}, X, Y, D_{A}, \delta, \lambda\right)$, todos os pares de estados distintos e um inteiro $m$;

- Saída: um conjunto de teste $m$-completo para a máquina $A$;

- Passo 1: determinar o conjunto $K$ das transições core de $A$. Esse conjunto pode ser obtido por meio da árvore de alcançabilidade;

- Passo 2: Para cada $\alpha_{i} \in K$ : construir um conjunto de seqüências "transversais", que também são usadas em métodos como o $W, W_{p}$ e HSI. Esse passo começa com uma seqüência de entrada vazia e estende-a de todas as possíveis formas (obtendo as seqüências definidas) até que uma (atual) seqüência de entrada alcance um estado onde nenhuma entrada é definida;

- Passo 3: para cada par de estados distintos escolher uma seqüência de entrada $\gamma$ que os distingue. Esse passo é executado somente quando a MEF possui estados distinguíveis. Nesse passo uma seqüência de separação é concatenada à seqüência "transversal".

O tamanho total de um conjunto de teste $m$-completo para uma especificação MEF com estados distintos gerada pelo SC depende da escolha do conjunto de separação, constituindo um conjunto de caracterização $W$, uma vez que essas seqüências são partes de entrada do método. Uma seqüência de separação "ótima" deve produzir um conjunto com a mínima complexidade. O problema de determinar essa seqüência permanece aberto para todos os métodos de geração de teste com cobertura de defeitos (Petrenko e Yevtushenko, 2005).

\subsubsection{Análise de Mutantes}

O critério análise de mutantes, inicialmente desenvolvido para o teste de programas, tem sido investigado para o teste de especificações, devido à sua flexibilidade de aplicação em diferentes contextos. No contexto de especificação de Sistemas Reativos, a Análise de Mutantes pode facilitar a atividade de teste pois esse critério é baseado em um modelo de erros que pode ser definido de forma que possa explorar tipos de erros referentes a essas técnicas. Assim, a especificação é a base para a geração dos mutantes, que têm como objetivo retratar os erros típicos relacionados à técnica de especificação utilizada. 
Petrenko et al. (1996) usam um conceito semelhante à Análise de Mutantes no teste e validação de protocolos de comunicação baseando-se em um modelo de erros correspondente a um conjunto restrito e pré-estabelecido dos erros a serem explorados durante essa atividade. Os autores discutem aspectos de cobertura no teste de especificações de modelos de protocolos baseadas em Máquina de Estados Finitos fazendo um estudo em relação à conformidade dessas especificações com relação a sua implementação.

Souza (1996) explorou a Análise de Mutantes no contexto de especificações baseadas em Estelle. Em seu trabalho foi definido um conjunto de operadores de mutação com base nas características do modelo tais como: hierarquia e comunicação entre os módulos, arquitetura do sistema, interface entre os módulos e paralelismo da especificação. Fabbri (1996) também explorou o conceitode Análise de Mutantes na validação de especificações de Sistemas Reativos baseadas nas técnicas Máquina de Estados Finitos, Statecharts e Redes de Petri. Em seu trabalho foi definido um conjunto de operadores de mutação, para cada uma dessas técnicas, e conduzido manualmente um estudo que mostrou evidências do aspecto complementar do critério Análise de Mutantes na validação do aspecto comportamental de Sistemas Reativos. Mais tarde, os operadores de mutação desenvolvidos para RP dos trabalhos de Fabbri et al. (1994) e Simão (2000) foram estendidos por Simão (2004) para RPC. Por estarem diretamente relacionadas a este trabalho, detalhes sobre a aplicação das técnicas referentes às Máquinas de Estados Finitos e às Redes de Petri Coloridas são discutidas nas Seções seguintes.

\subsubsection{Análise de Mutantes - MEF}

Segundo Chow (1978), um dos maiores problemas do teste é determinar um critério de seleção de casos de teste que seja válido e confiável. Considerando $M$ uma máquina correta e $M^{\prime}$ uma máquina que deseja-se avaliar, ambas minimais, com o mesmo alfabeto de entrada, Chow classifica os erros de seqüenciamento em três tipos:

- erros de transferência: quando $M^{\prime}$ não equivale a $M$, mas pode tornar-se equivalente mudando-se apenas a função do próximo estado de $M^{\prime}$

- erros de operação: quando $M^{\prime}$ não equivale a $M$, mas pode tornar-se equivalente mudando-se apenas a função de saída de $M^{\prime}$

- estados extras ou ausentes: quando o número de estados de $M^{\prime}$ deve ser reduzido ou aumentado, com o objetivo de tornar $M^{\prime}$ equivalente a $M$. Como $M$ e $M^{\prime}$ são minimais, um número diferente de estados implica que $M$ e $M^{\prime}$ não são equivalentes

Baseada nessa classificação, Fabbri (1996) definiu os operadores de mutação mostrados

na Tabela 2.4. Esses operadores foram implementados, primeiramente, na ferramenta 


\section{CAPÍTULO 2. REVISÃO BIBLIOGRÁFICA}

Proteum-RS/FSM, e mais recentemente, na ferramenta Plavis/FSM que está descrita na Seção 2.7.2. As siglas dos operadores são compostas por partes que abreviam a ação realizada pelo operador de mutação.

Um conjunto de teste gerado pelo método $W$, no qual todas as condições para sua aplicação são satisfeitas, em teoria, teria escore de mutação 1 quando aplicado aos mutantes apresentados na Tabela 2.4, gerados para uma MEF. Isso porque todos os erros de seqüenciamento do projeto seriam revelados e, conseqüentemente, todos os mutantes deveriam ser distinguidos da máquina $M$ original, por refletirem as classes de erros citadas anteriormente.

Tabela 2.4: Operadores de Mutação para Máquinas de Estados Finitos.

\begin{tabular}{|l|l|}
\hline Operador & Tipo da Alteração \\
\hline \hline Transition Initial State Alteration & alteração do estado inicial \\
\hline Transition Arc Deletion & arco faltando \\
\hline Transition Event Deletion & evento faltanto \\
\hline Transition Event Insertion & evento extra \\
\hline Transition Event Alteration & evento trocado \\
\hline Transiotion Destination State Alteration & destino trocado \\
\hline Output Deletion & saída faltando \\
\hline Output Alteration & saída trocada \\
\hline State Deletion & estado faltando \\
\hline State Insertion Output Separation & isola saída relevante \\
\hline State Insertion Transition Separation & $\begin{array}{l}\text { desmembra transição com mais de um } \\
\text { evento }\end{array}$ \\
\hline $\begin{array}{l}\text { State Insertion Transition Output Separa- } \\
\text { tion }\end{array}$ & $\begin{array}{l}\text { separa eventos com mesma saída de uma } \\
\text { transição }\end{array}$ \\
\hline State Insertion Transition Combination & combina transições \\
\hline
\end{tabular}

\subsubsection{Análise de Mutantes - RPC}

Para a definição dos operadores de mutação para Redes de Petri Coloridas, Simão (2004) baseou-se nas particularidades dessa técnica, bem como na análise (e posterior adaptação) de trabalhos anteriores (como (Fabbri et al., 1994; Simão, 2000)) referentes à definição de operadores de mutação para Redes de Petri. Os operadores de mutação estão divididos em 7 categorias: Marcação Inicial (3 operadores), Arcos (10 operadores), Variáveis (2 operadores), Constantes (1 operador), Condições de Guarda (3 operadores) e Operadores (com 6 operadores de mutação), sendo, ao todo, 27 operadores de mutação. Na Tabela 2.5, extraída de Simão (2004), é apresentado um resumo de todos os operadores. 
Tabela 2.5: Operadores de Mutação para Redes de Petri Coloridas, extraído de Simão (2004).

\begin{tabular}{|c|c|}
\hline \multicolumn{2}{|r|}{ Marcação Inicial } \\
\hline$\overline{\text { InitMarkDel }}$ & "Remoção de Marcação Inicial \\
\hline InitMarkIns & Inserção de Marcação Inicial \\
\hline InitMarkExchange & Troca de Marcação Inicial \\
\hline \multicolumn{2}{|r|}{ Arcos } \\
\hline InputArcInversion & Inversão de Arco de Entrada \\
\hline OutputArcInversion & Inversão de Arco de Saída \\
\hline InputArcDel & Remoção de Arco de Entrada \\
\hline OutputArcDel & Remoção de Arco de Saída \\
\hline InputArcIns & Inserção de Arco de Entrada \\
\hline OutputArcIns & Inserção de Arco de Saída \\
\hline InputArcExchange & Troca de Arco de Entrada \\
\hline OutputArcExchange & Troca de Arco de Saída \\
\hline InputArcShift & Deslocamento de Arco de Entrada \\
\hline OutputArcShift & Deslocamento de Arco de Saída \\
\hline \multicolumn{2}{|r|}{ Variáveis } \\
\hline VarExchange & Substituição de Variáveis \\
\hline VarSmall & Substituição de Variáveis por Constantes \\
\hline \multicolumn{2}{|r|}{ Constantes } \\
\hline ConstExchange & Substituição de Constantes \\
\hline \multicolumn{2}{|r|}{ Anotações } \\
\hline AnnotExchange & Substituição de Anotações dos Arcos \\
\hline AnnotSmall & Substituição de Anotações dos Arcos por Constante \\
\hline \multicolumn{2}{|r|}{ Condições de Guarda } \\
\hline GuardIns & Inserção de Condições de Guarda \\
\hline GuardExchange & Troca de Condições de Guarda \\
\hline GuardInv & Inversão de Condições de Guarda \\
\hline \multicolumn{2}{|r|}{ Operadores } \\
\hline OpRelRel & Troca de Operadores Relacionais \\
\hline OpMultRelRel & Troca de Operadores Relacionais para Multi-Conjuntos \\
\hline OpArithArith & Troca de Operadores Aritméticos \\
\hline OpLogLog & Troca de Operadores Lógicos \\
\hline OpIfInv & Troca de Expressões if-then-else \\
\hline OpMultArithArith & Troca de Operadores Aritméticos para Multi-Conjuntos \\
\hline
\end{tabular}

\subsection{Ferramentas de Teste}

Como toda atividade humana, a atividade de teste também está sujeita a erros e, geralmente, quando conduzida manualmente, tende a ser improdutiva, dada a sua complexi- 
dade. A qualidade da atividade de teste depende da utilização dos critérios. Como a quantidade de informações produzidas por esses critérios é, em geral, grande, a automatização da aplicação de tais critérios torna-se um fator determinante para a produtividade da atividade de teste e, conseqüentemente, de sua qualidade.

Pensando nisso, foram desenvolvidas ferramentas que automatizam a aplicação de técnicas e critérios de teste, pois a aplicação manual tende a ser trabalhosa, propensa a erros e limitada a programas extremamente simples. Com a utilização de ferramentas de teste é possível realizar estudos empíricos que visam a avaliar e comparar as técnicas e critérios de teste. Destaca-se, também, a possibilidade de transferência de tecnologia para as indústrias, o que contribui para a evolução contínua de tais ambientes e o auxílio a pesquisadores e alunos de Engenharia de Software na aquisição de conceitos básicos e experiência na comparação, seleção e estabelecimento de estratégias de teste. Para o uso de especificações formais, a disponibilidade de ferramentas facilita a edição, análise de propriedades e simulação dessas especificações.

Pode-se encontrar diversas ferramentas de apoio ao teste de programas e ao teste de especificações formais. Como ferramentas de apoio ao teste de especificações em Máquina de Estados Finitos pode-se citar a MGASet (Candolo et al., 2001; Nakazato, 1995), a ITIS (BLRC, 2005) e a TAG (Tan et al., 1996). MGASet - desenvolvida pelo Grupo de Engenharia de Software do ICMC/USP, auxilia na edição, simulação, verificação de propriedades, geração de seqüências e validação da especificação. A ITIS (Interoperability Testing Intelligent System) - desenvolvida pelo BLRC (Bell Labs Research China), possibilita a geração de casos de teste pela aplicação de critérios de cobertura de caminho para especificações em Máquinas de Estados Finitos e Máquinas de Estados Finitos Estendidas. A ferramenta TAG (Test Automatic Generation) é genérica para o desenvolvimento de conjunto de casos de teste para especificações em MEF e pode gerar casos de teste na forma de esqueletos SDL.

Várias ferramentas foram propostas para dar apoio à edição, simulação e análise de propriedades das Redes de Petri e Redes de Petri Coloridas. Como exemplo citam-se: a INA (Roch e Stark, 1999), a PED (Heiner, 2005), a PEP (Grahlmann, 1997) e a PROD (Varpaaniemi et al., 1995) para RP e a Design/CPN (Design/CPN, 2006; Jensen, 1997) e a Proteum/CPN para a Redes de Petri Coloridas.

Para o teste de programas, várias ferramentas foram propostas para a aplicação dos critérios de análise de fluxo de dados e fluxo de controle, dentre elas pode-se citar a Asset (Frankl e Weyuker, 1985), ATAC (Horgan e Mathur, 1992), ATACOBOL (Sze e Lyu, 2000) e as ferramentas desenvolvidas pelo Grupo de Engenharia de Software do ICMC/USP como a POKETOOL (Chaim, 1991) (desenvolvida em parceria com a Unicamp) e a JaBUTi (Vincenzi et al., 2003). Com relação ao apoio ao teste de mutação, 
destacam-se as ferramentas da família Proteum (Program Testing Using Mutants), desenvolvidas no ICMC/USP, composta pelas ferramentas Proteum/C (Delamaro, 1993), Proteum/IM (Delamaro, 1997), Proteum-RS/FSM (Fabbri, 1996), Proteum-RS/ST (Sugeta, 1999), Proteum-RS/PN (Simão, 2000), Proteum/SML (Yano, 2004) e Proteum/CPN (Simão, 2004).

As ferramentas Plavis/FSM, Proteum/CPN e JaBUTi são descritas nas seções seguintes, pois são utilizadas no contexto deste trabalho.

\subsubsection{JaBUTi}

Como uma das contribuições de grupo do Engenharia de Software do ICMC/USP no contexto de orientação a objetos, foi desenvolvida a ferramenta JaBUTi (Java Bytecode Understanding and Testing) (Vincenzi, 2004; Vincenzi et al., 2003). A JaBUTi tem como objetivo ser um ambiente completo para o entendimento e teste de programas escritos em Java. Ela fornece ao testador diferentes critérios de teste estruturais - os critérios baseados em fluxo de controle (todos-nós e todas-arestas) e em fluxo de dados (todos-usos e todos-pot-usos) - para a análise de cobertura. Fornece também um conjunto de métricas estáticas para avaliar a complexidade das classes que compõem o programa/componente e implementa ainda heurísticas de particionamento de programas que visam auxiliar a localização de defeitos.

Uma das principais vantagens associadas à JaBUTi está no fato de a ferramenta não requerer código-fonte na condução da atividade de teste. Ela realiza toda a análise estática e de cobertura diretamente no código objeto Java (bytecode). Isso permite, por exemplo, que componentes desenvolvidos por terceiros possam ser integrados e testados, mesmo que não se tenha acesso a seu código fonte.

A ferramenta implementa oito critérios, sendo quatro critérios de fluxo de controle e quatro critérios de fluxo de dados. Esses critérios estão divididos em virtude da distinção entre partes de códigos relacionadas a execução "normal" daquelas relacionadas ao tratamento de exceções. Tal distinção permite ao testador concentrar-se em características diferentes do programa, um de cada vez, realizando a atividade de teste de modo incremental e respeitando as restrições de tempo e custo que lhe são impostas (Vincenzi et al., 2003). A distinção dessas características reflete-se nos critérios de fluxo de dados todos-nós $_{e i}$, todos-nós ${ }_{e d}$, todas-arestas ${ }_{e i}$, todas-arestas ${ }_{e d}$ e no critério baseado em fluxo

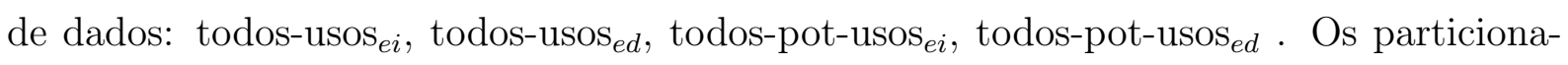
mento em ei e ed referem-se, respectivamente, às execuções independentes de exceção

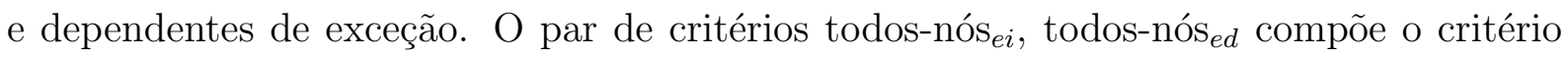
todos-nós. Essa definição é análoga para os outros critérios. 
As principais funções realizadas pela ferramenta para a análise de cobertura são: a instrumentação do arquivo .class, a coleta de informações de cobertura durante a execução do programa e a determinação da suficiência do teste de cada um dos métodos de acordo com os critérios de teste disponíveis.

Para facilitar a geração de casos de teste de modo a aumentar a cobertura em relação aos critérios de teste, a ferramenta atribui diferentes pesos aos requisitos de teste indicando qual o requisito de teste, se coberto, aumentaria a cobertura em relação ao critério. Para avaliar o andamento da atividade de teste, relatórios de teste com diferentes níveis de granularidade (por projeto, por classe, por método, por caso de teste) podem ser gerados para auxiliar o testador na decisão de quando parar os testes e determinar quais partes ainda não foram suficientemente testadas.

A JaBUTi permite que uma sessão de teste já iniciada, seja interrompida e retomada posteriormente, essa sessão é chamada de projeto de testes. Quando um projeto de testes é criado, a ferramenta constrói um grafo definição-uso para cada método da classe a ser testada, deriva os requisitos de teste de cada critério e apresenta na tela o bytecode de uma das classes sendo testadas, como é mostrado na Figura 2.8.

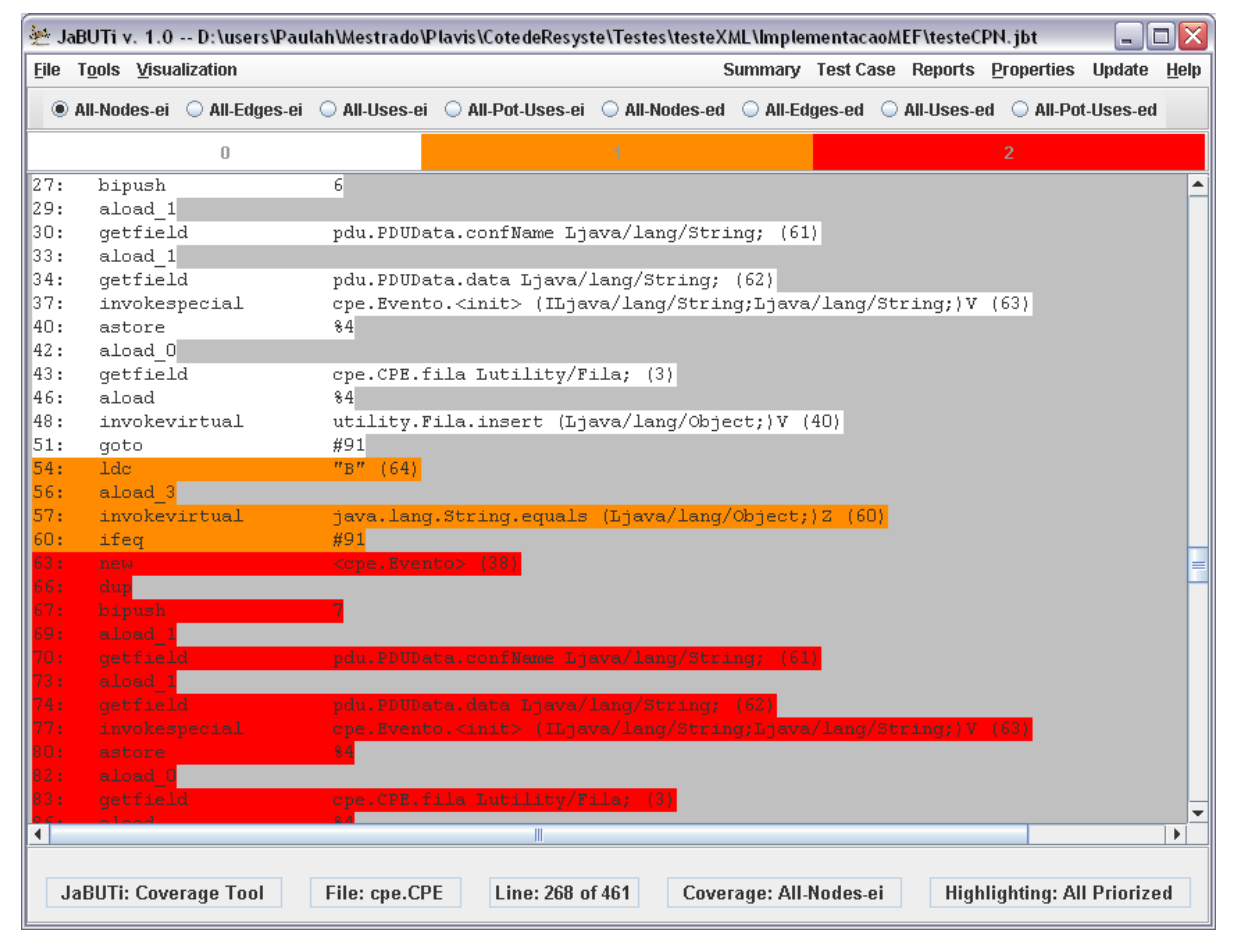

Figura 2.8: Tela da JaBUTi, considerando o critério ativo todos-nós $s_{e i}$ : bytecode inicial

\subsubsection{Plavis/FSM}

A Plavis/FSM, como o próprio nome diz, foi desenvolvida no contexto do projeto Plavis, sendo uma plataforma de apoio ao teste de especificações baseadas em Máquinas de Es- 
tados Finitos. Ela é uma ferramenta web que foi originada pela integração de três outras ferramentas, desenvolvidas por diferentes pesquisadores, e em diferentes épocas, sendo, cada uma delas, projetadas para a aplicação e uso de técnicas de teste diferentes. Uma delas, a Proteum/FSM (Fabbri et al., 1994, 1999) é adequada para o critério Análise de Mutantes, outra, a Condado (Martins et al., 1999) se baseia no critério de cobertura Switch Cover, desenvolvido por Chow (1978) e descrito por Binder (Binder, 1999) é semelhante ao transition tour, que tem como objetivo executar todas as combinações de transição pelo menos uma vez (Simão et al., 2005). A terceira ferramenta é a MGASet (Candolo et al., 2001), a qual implementa o Método $W$.

A Ferramenta permite a criação de um projeto e de sessões de teste dentro desse projeto. Após a criação de uma sessão, o projeto pode ser interrompido e retomado em um outro momento.

Para a obtenção da MEF a Plavis/FSM possui duas maneiras, uma é a ferramenta gráfica para a criação e/ou edição e a outra é importar de um arquivo uma MEF já existente. Após a obtenção da MEF é possível gerar os mutantes, escolhendo os operadores de mutação desejados. Os operados de mutação implementados na ferramenta são os descritos na Tabela 2.4. Além dos métodos de geração de seqüências de teste que já estavam implementados nas ferramentas que foram integradas na Plavis/FSM, também estão implementados os métodos State Counting, Unique Input-Output (UIO) e Harmonized State Identification - (HSI) (Luo et al., 1994). Nas Figura 2.9 e 2.10 estão ilustradas a ferramenta de edição da MEF e a tela com os métodos de geração de seqüências de teste.

\subsubsection{Proteum/CPN}

A Proteum/CPN foi desenvolvida por Simão (2004) e, de acordo com o autor, visa a apoiar a aplicação do critério Análise de Mutantes para especificações baseadas em RPCs. A ferramenta oferece um conjunto mínimo de operações que satisfaz os requisitos básicos de uma ferramenta de teste baseada em mutação, os quais são (Delamaro, 1993):

- Tratamento de casos de teste: execução, inclusão/exclusão e habilitação/desabilitação;

- Tratamento de mutantes: geração, seleção, execução e análise; e

- Análise de adequação: escore de mutação e relatórios.

Para utilizar a ferramenta é necessário que um projeto seja criado. Cada projeto deve possuir uma RPC e também é escolhido o conjunto de operadores de mutação a ser utilizado. Dentro do projeto podem ser criadas uma ou mais sessões de teste. Essas sessões podem importar subconjuntos dos operadores de mutação do projeto a qual pertencem. Os 


\section{CAPÍTULO 2. REVISÃO BIBLIOGRÁFICA}

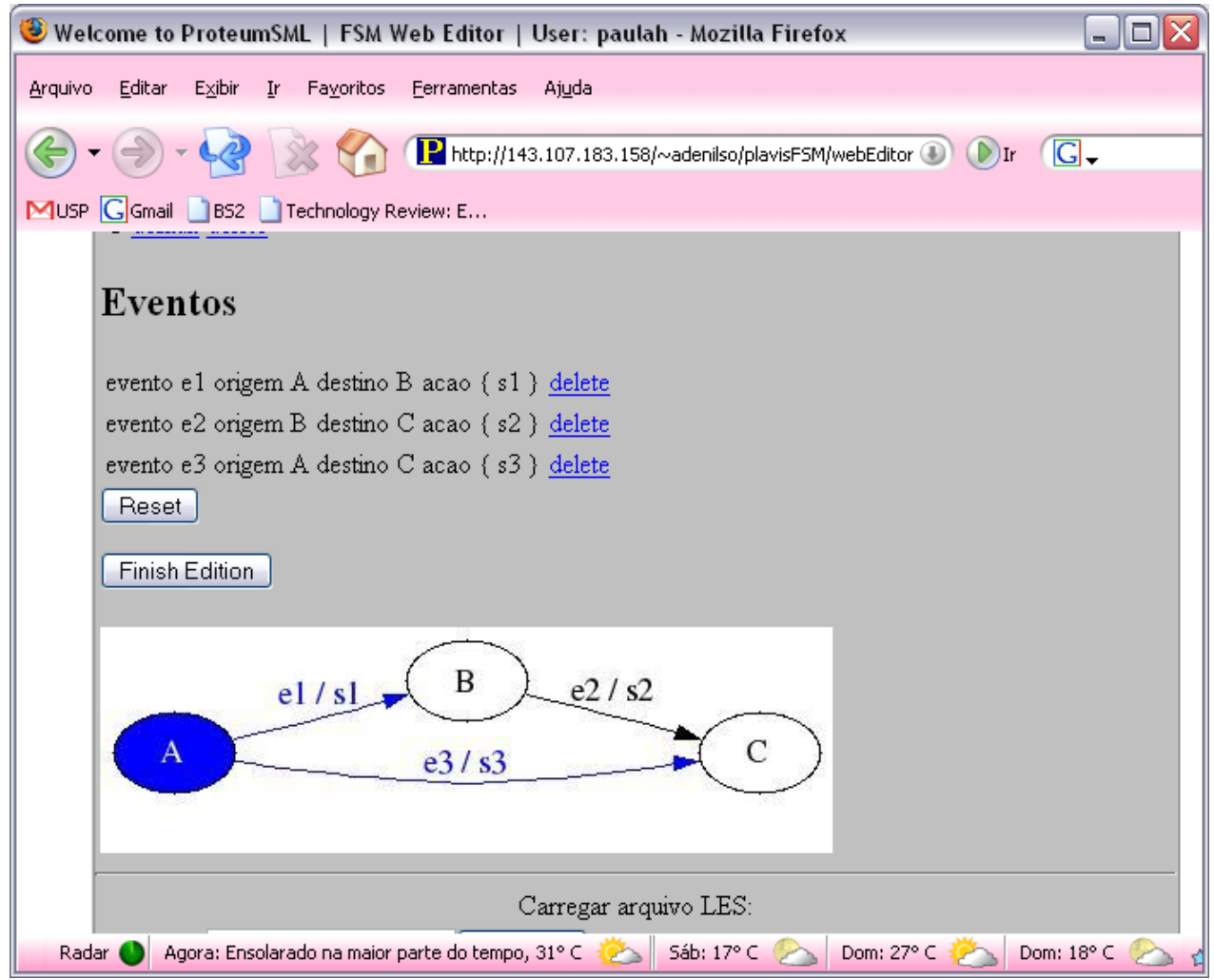

Figura 2.9: Tela para edição e/ou criação na MEF na Plavis/FSM

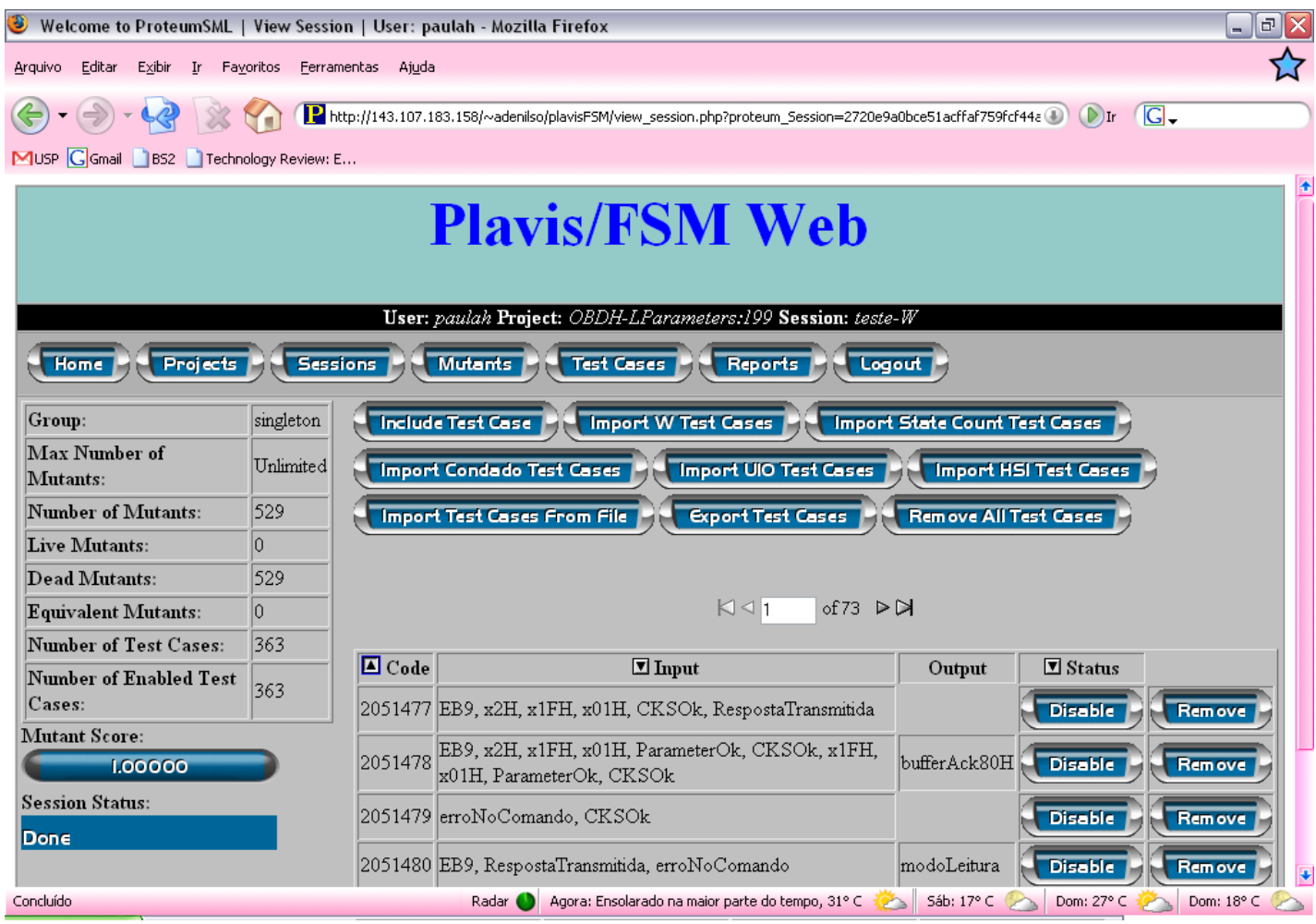

Figura 2.10: Tela para a geração de seqüências de teste, na Plavis/FSM 
operadores de mutação implementados nessa ferramenta são aqueles descritos em 2.6.5.2 Também podem existir grupos de sessões, que facilitam o trabalho cooperativo. Um grupo é composto por usuários de várias sessões de um mesmo projeto e os mutantes são particionados entre as sessões do grupo, conforme o numero máximo de mutantes que cada um pode possuir.

Em uma sessão de teste, antes de se incluir um caso de teste, a RPC original é simulada para verificar se o resultado obtido está correto. Caso afirmativo, pode-se incluir o caso de teste para executar os mutantes. Como um caso de teste pode ser inserido em outra sessão do projeto e a fim de se evitar a execução dos mutantes com o mesmo caso de teste, todos os casos de teste pertencem ao projeto e todos os mutantes são executados. Assim, quando um caso de teste já existente em projeto for inserido em outra sessão, apenas é necessário consultar as informações sobre sua execução (Simão, 2004).

Para que as informações de uma sessão de teste possam ser analisadas, a ferramenta disponibiliza dois tipos de relatório sendo um por operador e outro por caso de teste. No relatório por operador é possível visualizar o número de mutantes que foram mortos, os que estão vivos e os equivalentes. No outro relatório, são exibidas as informações sobre a execução de cada caso de teste.

Nas Figuras 2.11 e 2.12 estão apresentadas as telas para inclusão dos operadores de mutação e alguns mutantes gerados em uma sessão de teste, respectivamente. Ambas figuras foram extraídas do trabalho de Simão (2004).

\subsection{Considerações Finais}

Neste capítulo foram apresentados os conceitos relativos ao contexto no qual este trabalho está inserido. Foi discutida a importância de se utilizar métodos de especificação formal para a construção de sistemas em que a correção é mandatória, que é o caso dos sistemas reativos. Nessa classe de sistemas uma falha pode causar grandes prejuízos financeiros e, o que é mais grave, a perda de vidas humanas. Como exemplo de técnicas de especificação formal foram abordadas as técnicas de Máquinas de Estados Finitos e Redes de Petri Coloridas.

Foi discutido também que, apesar do rigor dessas técnicas, erros ainda podem ocorrer, por isso a atividade de teste faz-se necessária. Com relação a essa atividade foram descritos os conceitos relevantes, juntamente com métodos e critérios da literatura e que são referentes ao contexto desta dissertação. Ressaltou-se que, apesar de existirem várias técnicas que podem ser usadas na atividade de teste, o uso dessas em conjunto garante maior confiabilidade ao teste já que elas podem ser vistas como complementares. 


\section{CAPÍTULO 2. REVISÃO BIBLIOGRÁFICA}

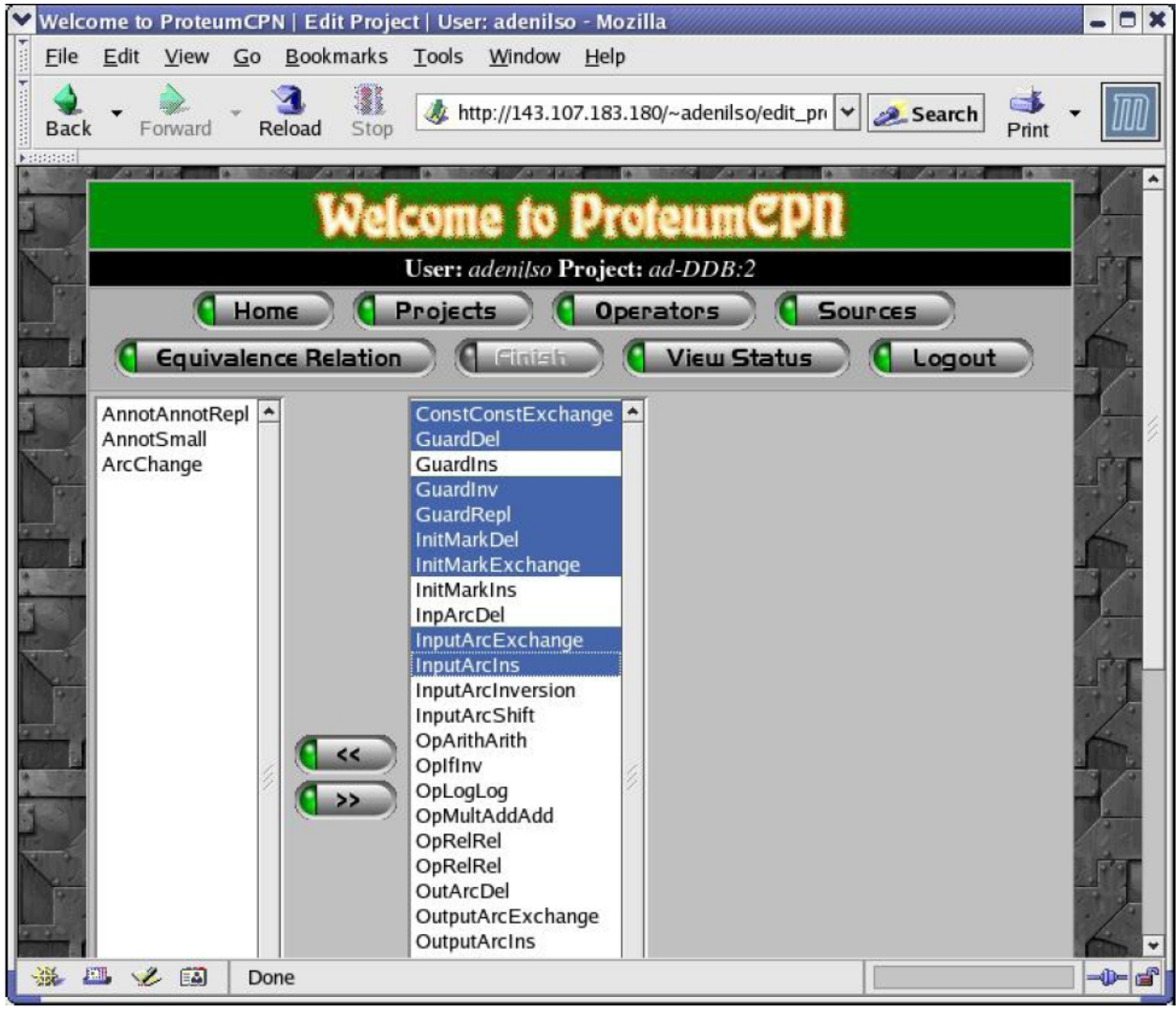

Figura 2.11: Tela da Proteum/CPN para escolha dos operadores de mutação

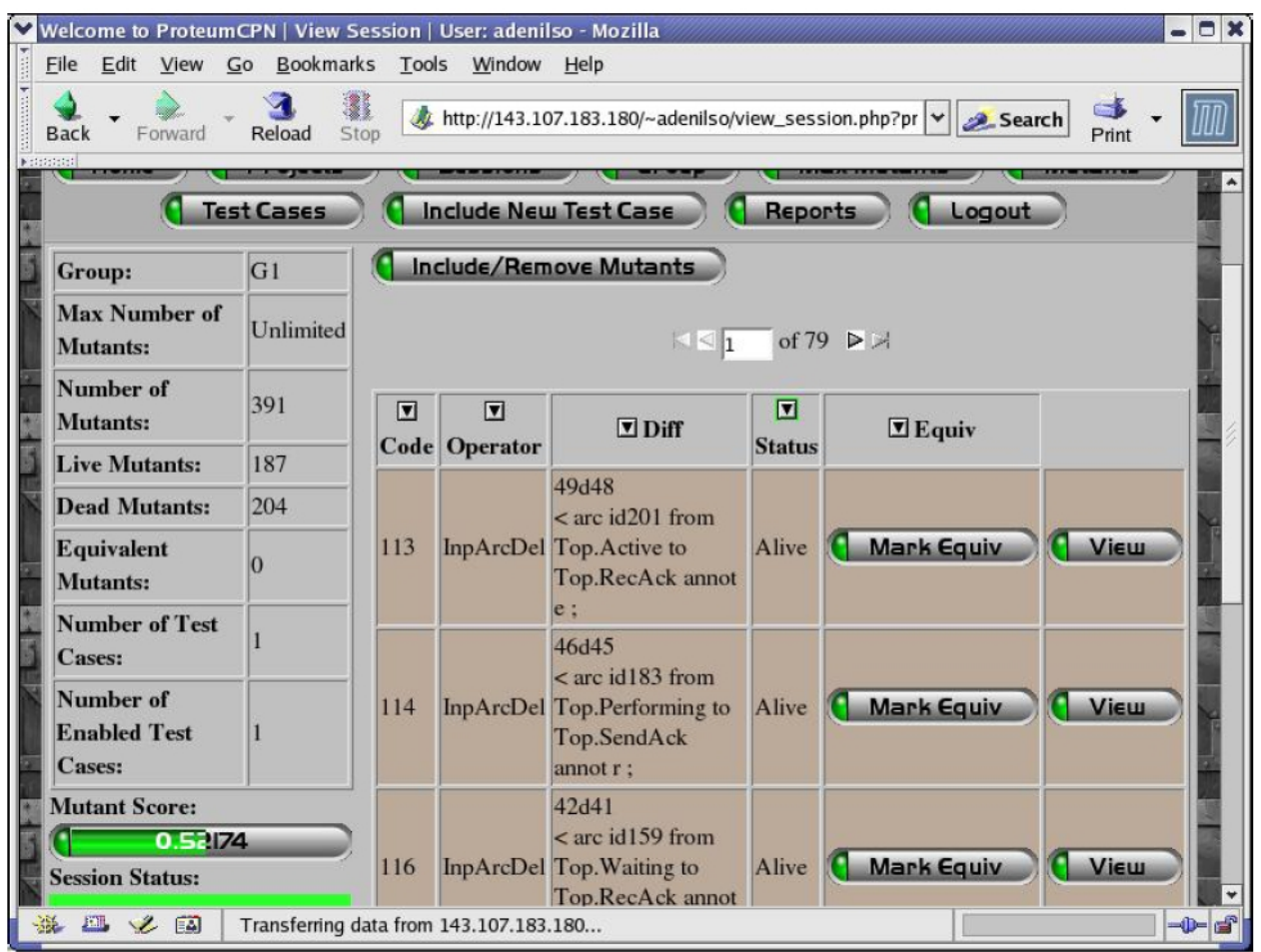

Figura 2.12: Tela da Proteum/CPN - Mutantes de uma sessão 


\section{CAPÍTULO 2. REVISÃO BIBLIOGRÁFICA}

Com base nisso inserem-se o contexto e objetivo deste trabalho, tem o intuito de investigar a relação entre conjuntos de teste derivados de métodos formais e os critérios estruturais de forma a analisar como eles se relacionam e como podem ser utilizados em conjunto. Foi ressaltado, também, que para que essa análise seja possível é necessário a disponibilidade de ferramentas de apoio à geração de casos de teste bem como de análise de cobertura.

No próximo Capítulo são mostrados os estudos de caso realizados durante este trabalho de mestrado. 



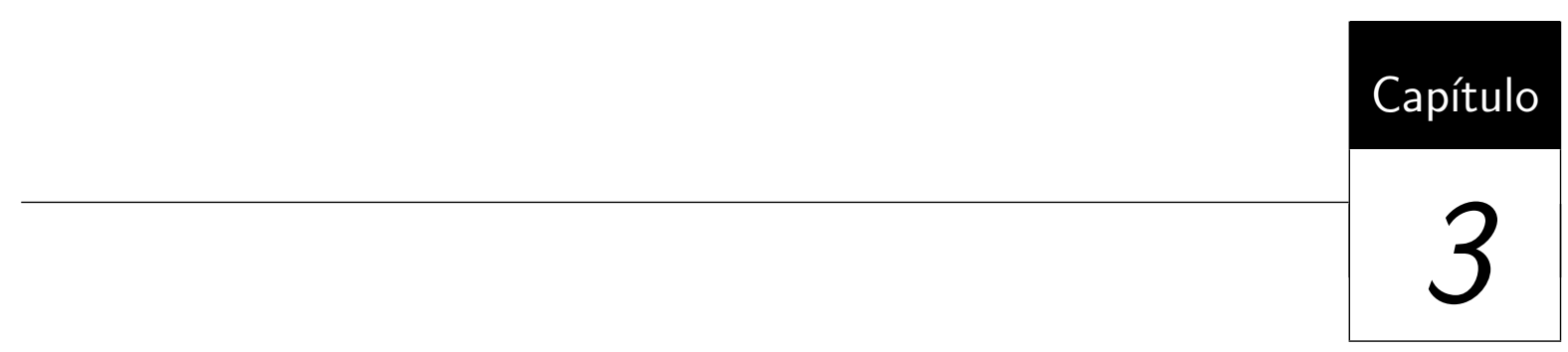

\section{Estudos de Caso}

\subsection{Considerações Iniciais}

Neste capítulo são descritos os dois estudos de caso conduzidos neste trabalho. Os dois estudos de caso construídos são sobre protocolos de comunicação; o primeiro é um protocolo de conferência, denominado ConfCase, um protocolo simples, formalmente especificado; o segundo é um protocolo, denominado OBDH-EXP fornecido pelo Instituto Nacional de Pesquisas Espaciais (INPE).

Os estudos de caso são compostos da especificação e implementação dos problemas. Conjuntos de casos de teste são derivados a partir das especificações e dos requisitos estruturais e, posteriormente, aplicados nas implementações para análise e avaliação com o objetivo de verificar qual o custo e a eficiência, em termos de cobertura estrutural, de aplicar conjuntos de teste derivados de especificações formais em implementações em Java.

Nas Seções 3.2 e 3.3 são apresentados os estudos de caso. Eles foram descritos e caracterizados com base no trabalho de Wohlin et al. (2000). Para a contextualização, faz-se uma breve descrição de cada um dos protocolos e, em seguida, são apresentados o propósito do estudo, o contexto de aplicação, a forma pela qual os estudos de caso foram conduzidos, a apresentação dos resultados obtidos e posterior análise dos resultados. Por fim, na Seção 3.4, apresentam-se as considerações finais deste capítulo. 


\subsection{Estudo de Caso 1: Protocolo de Conferência}

Este estudo de caso consiste na comparação de conjuntos de caso de teste derivados de métodos de especificação formal com critérios estruturais. Esta comparação é feita verificando a efetividade e o custo de se aplicar conjuntos de casos de teste derivados de especificações formais em implementações em Java. As técnicas de especificação formal utilizadas são Máquina de Estado Finito (MEF) e Rede de Petri Colorida (RPC), utilizando os métodos de geração de seqüência: $W$, State-Counting (SC), Unique Input-Output (UIO) e Análise de Mutantes (referentes à primeira técnica) e o critério Análise de $\mathrm{Mu}$ tantes, para RPC. Os critérios de teste estrutural utilizados são os critérios de fluxo de controle (todos-nós e todas-arestas) e de fluxo de dados (todos-usos). São utilizadas duas implementações distintas do protocolo de conferência, uma baseada na especificação informal e a outra baseada na especificação formal em Máquina de Estado Finito. A seguir tem-se uma descrição do Protocolo de Conferência (extraída de Côte de Resyste Project (1999)).

\subsubsection{Descrição do Protocolo}

O Protocolo de Conferência ${ }^{1}$ fornece um serviço semelhante a um chat, no qual os usuários podem participar de uma conferência, trocar mensagem e sair da conferência. Uma conferência é formada por um grupo de usuários, podendo existir várias conferências ao mesmo tempo mas cada usuário pode participar de apenas uma por vez. Caso o usuário queira participar de outra conferência, é necessário que ele saia daquela para, em seguida, conectar-se à desejada. A troca de mensagens é feita entre todos os participantes de uma mesma conferência, ou seja, cada usuário pode enviar mensagens e todos os outros participantes daquela conferência a recebem.

O serviço de conferência é executado no Conference Service Access Points(CSAP). É composto pelas seguintes primitivas (com seus parâmetros):

- join(nickname, identificador da conferência): um usuário entra em uma conferência e escolhe o seu nickname. É o nickname que identifica o usuário em uma conferência.

- datareq(mensagem): um usuário envia uma mensagem a todos os participantes da mesma conferência.

\footnotetext{
${ }^{1}$ O Protocolo de Conferência pertence ao projeto Côte de Resyste (COnformance TEsting OF REactive SYSTEms) no qual o objetivo é melhorar o processo de teste usando métodos formais. O projeto é uma cooperação entre várias instituições (Belinfante et al., 2001). Mais detalhes em http://fmt.cs .utwente. nl/ConfCase
} 
- dataind(nickname, mensagem): um usuário recebe uma mensagem, identificada pelo nickname de um participante da conferência.

- leave(): um usuário deixa de participar de uma conferência. Como um usuário pode participar de apenas uma conferência por vez, essa primitiva não requer identificação.

Na Figura 3.1, adaptada de Terpstra et al. (1996) é mostrado o serviço de conferência e a interação dos usuários.

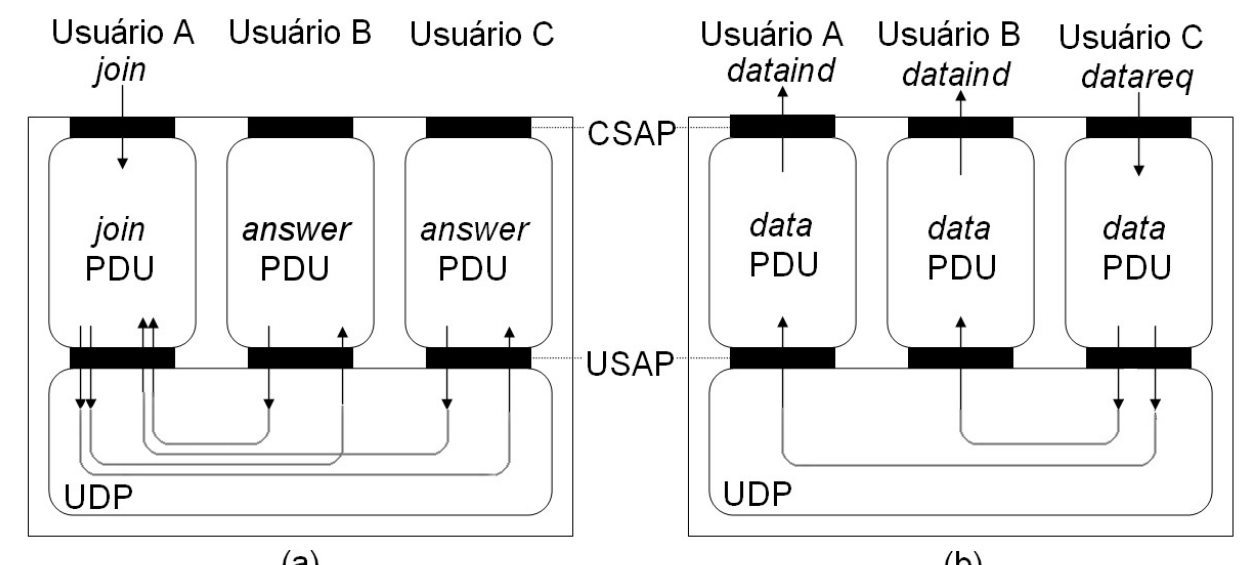

(a)

(b)

Figura 3.1: Serviço de Conferência

As primitivas join e leave são usadas para controle da conferência e as primitivas datareq e dataind são usadas para transferência de dados.

A seguir são descritas algumas características importantes para controle do serviço de conferência:

- Inicialmente, um usuário pode, apenas, entrar em uma conferência (join);

- Após entrar em uma conferência um usuário pode enviar mensagens (por meio da primitiva datareq), ou receber mensagens (por meio da primitiva dataind);

- A partir do momento em que um usuário entrou em uma conferência ele pode executar a primitiva leave, com o objetivo de deixar de participar daquela conferência. Assim que o leave foi executado o usuário pode entrar em outra conferência (ou na mesma), por meio de um novo join;

- Cada datareq causa um dataind para todos os outros participantes da conferência, isto é, todos os usuários que entraram na conferência (join) e não saíram (leave) até o momento do envio do datareq. 
Quem fornece os serviços de conferência é a CPE (Conference Protocol Entity). Ela usa as primitivas de serviço para construir os PDUs (Protocol Data Unit). Os PDUs são responsáveis pela troca de mensagens por meio do underlying layer. O Underlying Service Access Point - (USAP), serviço pelo qual as CPEs se comunicam, é um serviço sem conexão e não confiável, no qual as mensagens podem ser perdidas ou entregues fora de ordem mas nunca corrompidas ou entregues erradas. Esse serviço é fornecido usando-se o UDP (User Datagram Protocol).

Os Usuários A, B e C representam a interface do usuário e os PDUs estão contidos na camada que representa a CPE de cada usuário.

O PDUs são:

- join-PDU: informa a todos os potenciais parceiros da conferência que um usuário, em uma certa conferência, enviou um join;

- answer-PDU: os usuários que receberam o join-PDU respondem ao usuário que enviou a mensagem, com o objetivo de confirmar o recebimento e sinalizar que ambos participam da mesma conferência;

- data-PDU: informa a todos os participantes da conferência a mensagem contida no data-PDU;

- leave-PDU: informa a todos os participantes da conferência que um certo usuário saiu da conferência.

\section{Comportamento do Protocolo}

São as CPEs que administram os usuários da conferência e as transferências de dados entre eles. Cada CPE contém um conjunto de configuração, no qual estão contidos os potenciais parceiros da conferência. Nesse conjunto existe uma lista dos endereços do CSAP e do UDP correspondentes, fazendo com que seja possível que pares de CPEs se comuniquem. Cada CPE também tem um conjunto de parceiros da conferência que mantém atualizada uma lista de parceiros que estão ativos na conferência no momento. Quando uma CPE inicia sua operação, o conjunto de parceiros da conferência ainda está vazio.

\section{Comportamento normal da CPE}

O comportamento normal da CPE é definido (informalmente) em termos das seguintes regras:

1. Cada CPE que executa um join envia join-PDUs para todos os potenciais parceiros da conferência. 
2. Uma CPE que recebe um join-PDU e participa da mesma conferência do usuário que enviou o PDU envia, como resposta, um answer-PDU para o usuário que enviou o join. A CPE apenas inclui o usuário no conjunto de parceiros da conferência se este é membro de seu conjunto de potenciais parceiros da conferência.

3. Uma CPE que recebe um join-PDU e não participa da mesma conferência, ignora o PDU recebido.

4. Uma CPE que recebe um answer-PDU apenas inclui o usuário no conjunto de parceiros da conferência se este é membro de seu conjunto de potenciais parceiros da conferência; caso contrário, o PDU é ignorado.

5. Uma CPE que executa um datareq envia um data-PDU correspondente a todos os participantes da conferência.

6. Uma CPE que recebe um data-PDU entrega a mensagem contendo esse data-PDU para os usuários por meio de um dataind.

7. Uma CPE que executa um leave envia um leave-PDU para todas as CPEs do seu conjunto de parceiros da conferência e limpa o seu conjunto de parceiros da conferência.

8. Uma CPE que recebe um leave-PDU remove do seu conjunto de parceiros da conferência o parceiro que enviou o leave-PDU.

9. A perda de um answer-PDU faz com que seja possível que um data-PDU vindo de um usuário que não está no seu conjunto de parceiros da conferência chegue. Assim, para compensar a perda do answer-PDU, um join-PDU é enviado como resposta ao data-PDU. Se um answer-PDU chegar como resposta do join-PDU enviado, o conjunto de parceiros da conferência é atualizado.

Na Figura 3.2 é mostrada a especificação do protocolo de conferência representada por uma Máquina de Estado Finito. Essa máquina foi desenvolvida e revisada pelos membros do projeto Plavis. A elaboração da MEF é baseada na interpretação da especificação informal do protocolo. Nessa interpretação, toma-se um usuário como sendo o principal e todo o modelo é desenvolvido sob o ponto de vista ou o conhecimento desse usuário, que possui uma lista de potenciais parceiros e que pertence a uma única conferência. Os usuários são denominados Usuário A, Usuário B e Usuário C. É sob o ponto de vista do primeiro que a MEF é modelada. Os outros dois usuários são os potenciais parceiros. A conferência, denominada Ci, é uma conferência genérica, na qual os usuários podem ou não estar conectados. Os estados que compõem a MEF são: 
- IDLE: Momento em que o Usuário A ainda não está conectado na conferência;

- Aconnected: Quando o Usuário A executa a primitiva join, na conferência Ci e nenhum de seus potenciais parceiros participam da mesma conferência naquele momento;

- ABconnected: Quando os Usuários A e B estão conectados na conferência Ci;

- ACconnected: Quando os Usuários A e C estão conectados na conferência Ci;

- ABCconnected: Quando os Usuários A, B e C estão conectados na conferência Ci.

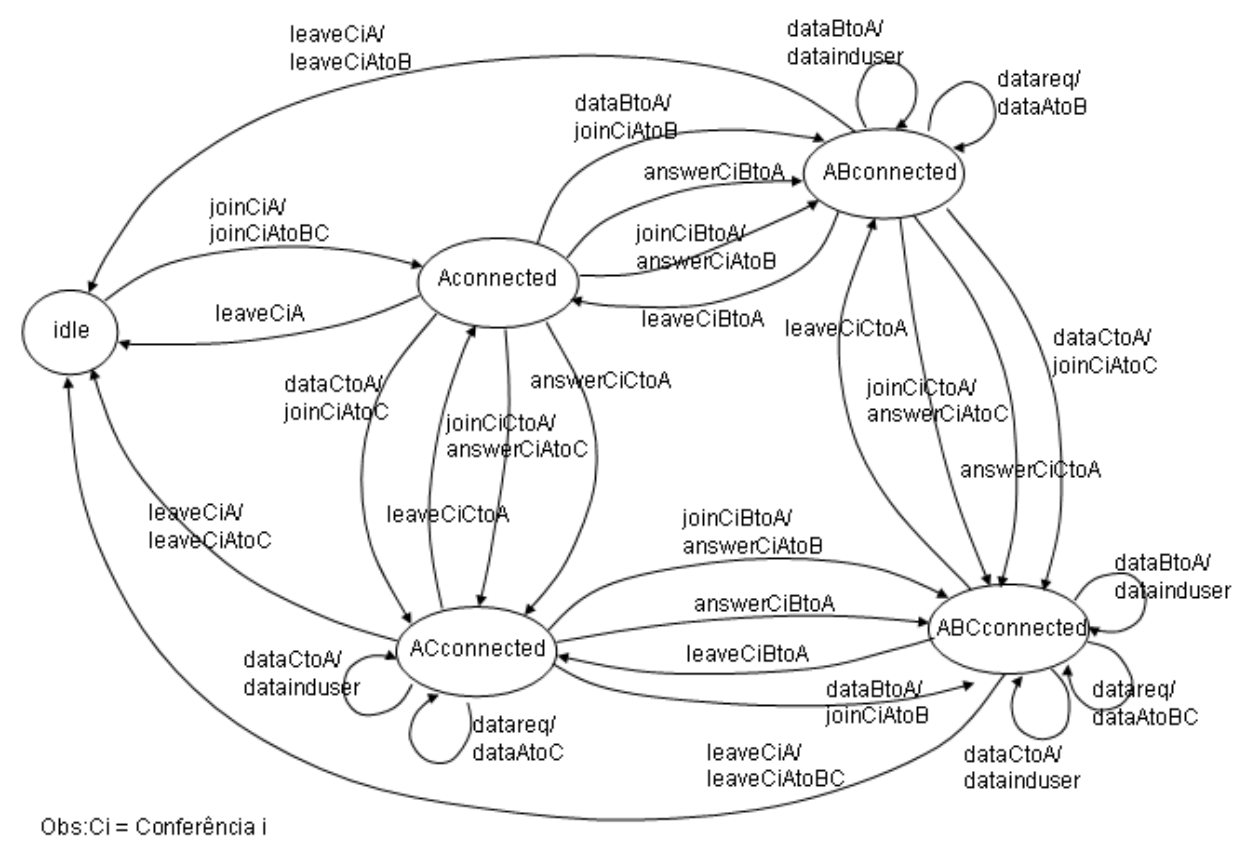

Figura 3.2: Máquina de Estado Finito do Protocolo de Conferência

As transições são rotuladas na forma entrada/saída. Quando a saída não é explícita, considera-se que seja nula. O rótulo das transições representa uma combinação entre as primitivas, o nome do usuário e o nome da conferência. Por exemplo: joinCiA/joinCiAtoBC significa que a primitiva join $(\mathrm{A}, \mathrm{Ci})$ foi executada como entrada e que resultou, como saída (um PDU), no envio de uma mensagem aos Usuários B e C informando que o Usuário A conectou-se à conferência. As outras transições são rotuladas analogamente.

A Rede de Petri Colorida do protocolo de conferência pode ser vista no apêndice A 


\subsubsection{Definição do estudo de caso}

Em seguida é feita uma breve definição do estudo de caso, seguindo o modelo proposto por Wohlin et al. (2000). Este modelo é composto de cinco etapas, descritas aqui como: Definição, Planejamento, Operação, Coleta de Dados e Análise e Interpretação.

- Analisar cinco conjuntos de casos de teste, sendo quatro deles derivados de uma especificação em Máquina de Estado Finito e um de uma Rede de Petri Colorida, aplicados em duas implementações, em Java, de um mesmo problema.

- Para o propósito de avaliar o quanto um conjunto de teste gerado baseado em uma especificação formal consegue cobrir os requisitos exigidos pelos critérios estruturais e qual é o custo de se aplicar, na implementação, esse conjunto de teste.

- Com respeito à efetividade e custo

- Do ponto de vista da cobertura dos requisitos de teste estrutural

- No contexto da exploração do uso de conjuntos de teste derivados de especificações formais aplicados em duas implementações Java, do ConfCase.

\subsubsection{Planejamento}

O estudo de caso está inserido no contexto do projeto Plavis, o qual envolve universidades e centros de pesquisa, tendo profissionais, pesquisadores e estudantes trabalhando nas áreas de especificação de requisitos e de teste de software. O objeto de estudo escolhido é um protocolo de conferência (descrito na Seção 3.2.1), denominado ConfCase. A escolha desse protocolo deu-se por ser um exemplo simples, formalmente especificado.

O intuito do procedimento descrito a seguir é verificar o guau de adequação dos conjuntos de teste gerados baseados em especificações formais são sempre adequados em relação aos critérios estruturais e se há diferença de custo na aplicação dos conjuntos de teste derivados de especificações formais e conjuntos de testes derivados de requisitos estruturais. Para isso são gerados conjuntos de teste derivados de 2 especificações formais (uma MEF e uma RPC) e outros 2 conjuntos derivados diretamente dos requisitos estruturais (de uma implementação que é baseada na especificação informal e de outra que é baseada na especificação em MEF).

O estudo de caso é composto dos seguintes materiais:

- Uma especificação informal (em linguagem natural), do ConfCase;

- Duas especificações formais do ConfCase, sendo uma representada por uma Máquina de Estado Finito e a outra por uma Rede de Petri Colorida. Essas especificações 
foram desenvolvidas, pelos membros do projeto Plavis, com base na especificação informal do problema.

- Duas implementações, do ConfCase, em Java, sendo uma derivada da especificação informal e a outra da especificação formal em Máquina de Estado Finito. Assim como as especificações, as implementações foram desenvolvidas no contexto do projeto Plavis.

- Uma ferramenta de apoio para a geração dos casos de teste baseados na especificação em MEF (Plavis/FSM);

- Uma ferramenta de apoio para a geração dos casos de teste baseados na especificação em RPC (Proteum/CPN);

- Uma ferramenta de apoio para análise de cobertura, de implementações Java, dos critérios estruturais alvo deste trabalho (JaBUTi);

- Um driver para interpretar e alimentar as implementações com as seqüências de teste geradas com o auxílio das ferramentas.

É importante destacar um ponto que coloca em risco a validade do estudo de caso. Esse risco refere-se a haver duas implementações de um mesmo problema sendo que estas não foram concebidas de forma sistemática, ou seja, não foi usada nenhuma técnica específica para derivá-las das especificações, representando, apenas, implementações do problema. Por outro lado essa é uma situação comum, mesmo quando são usados modelos formais.

\subsubsection{Operação}

Nesta Seção é mostrado como o estudo de caso foi conduzido. Com base nas especificações formais são criados os conjuntos de teste. Com a ajuda da ferramenta Plavis/FSM (Simão et al., 2005) são criados os 4 conjuntos de teste referentes aos métodos $W$, State-Counting, Unique Input-Output e Análise de Mutantes. A ferramenta Proteum/CPN (Simão, 2004) é usada para auxiliar na elaboração dos casos de teste do critério Análise de Mutantes para RPC. Também elaboram-se 2 conjuntos de teste com base nos requisitos estruturais das duas implementações.

Tendo todos os conjuntos de teste elaborados, cada um deles é aplicado em cada uma das implementações. O driver desenvolvido foi utilizado nessa etapa para interpretar as sequiências de teste, fazendo com que elas sejam as entradas para cada uma das implementações. As seqüências de teste são descritas em formato $\mathrm{XML}^{2}$ de forma a facilitar a criação e posterior uso do driver.

\footnotetext{
${ }^{2}$ eXtensible Markup Language
} 
Na Figura 3.3 é mostrada a arquitetura montada para o teste do protocolo. Nela, a interface do usuário é substituída pelo driver, por meio do qual são inseridas as seqüências de teste.

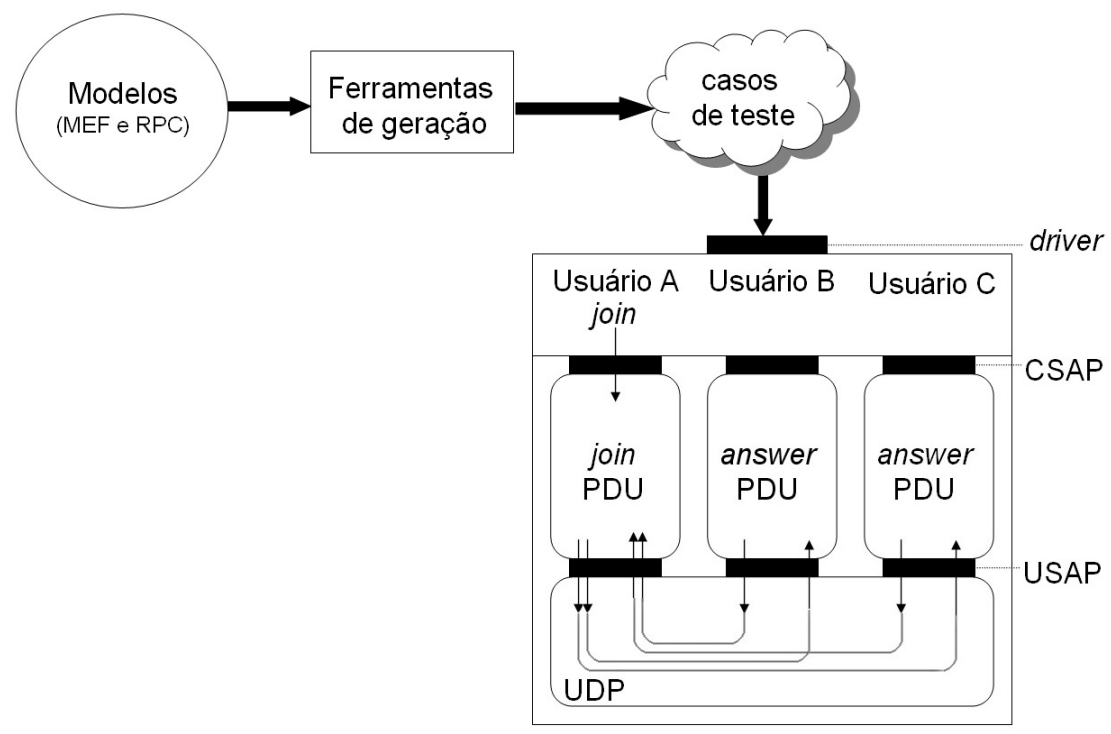

Figura 3.3: Arquitetura do Protocolo de Conferência sem a interface do usuário

Cada um dos conjuntos de teste é aplicado em cada uma das implementações e, com a ajuda da ferramenta JaBUTi (Vincenzi et al., 2003) é verificada a cobertura estrutural obtida com a aplicação dos conjuntos de teste e o número de casos de teste que influenciaram na cobertura dos requisitos estruturais. Na Figura 3.4 está ilustrado esse processo. Para garantir a validade dos dados, a execução dos testes é monitorada certificando que todos os casos de teste que compõem os conjuntos são executados.

\subsubsection{Coleta de Dados}

Os dados coletados nesse estudo de caso foram:

- A cobertura dos elementos requeridos pelos critérios estruturais todos-nós, todas-arestas e todos-usos com a aplicação dos conjuntos de teste referentes a:

- Método $W$;

- State-Counting;

- Unique Input-Output;

- Análise de Mutantes (MEF);

- Análise de Mutantes (RPC).

- O custo, em termos do número de casos de teste utilizados, de aplicar cada um dos conjuntos de teste, citados acima, nas implementações: 


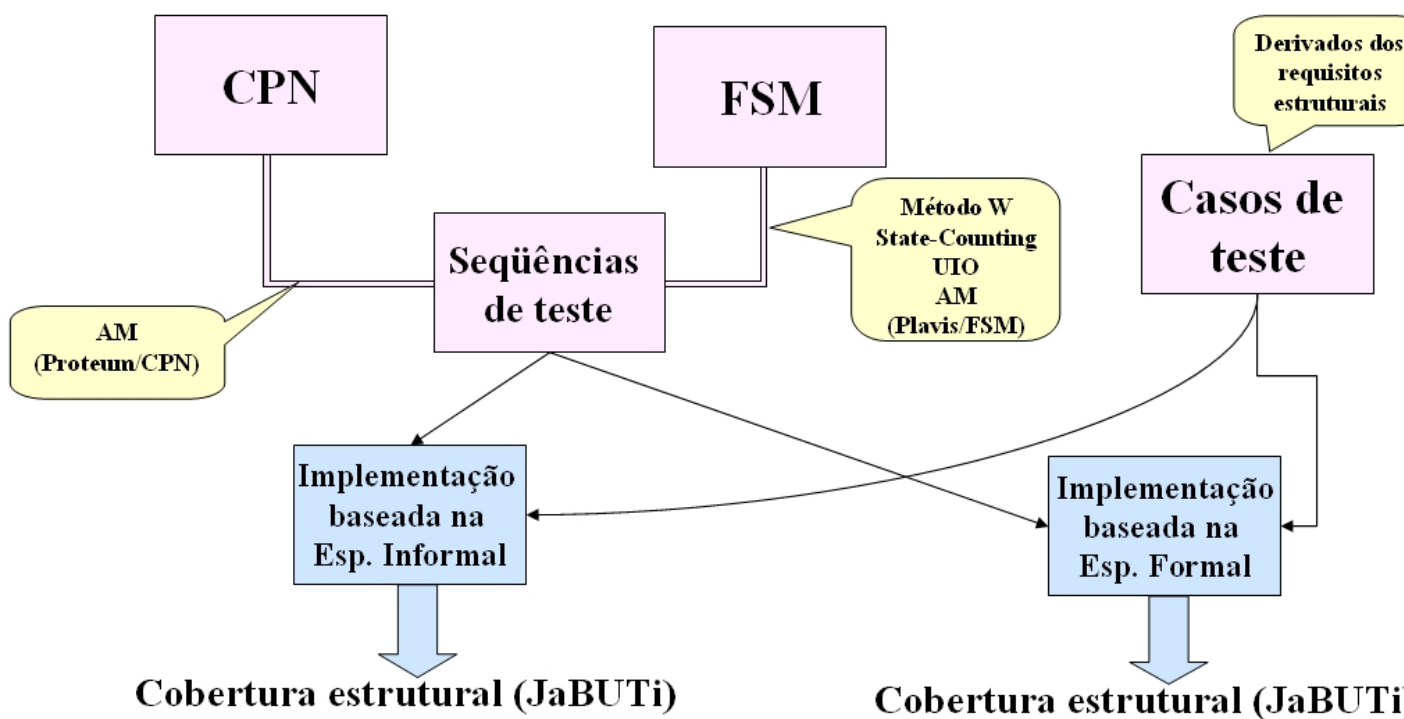

Figura 3.4: Processo de operação do estudo de caso utilizando o ConfCase

- Implementação baseada na especificação informal;

- Implementação baseada na especificação em MEF.

\subsubsection{Análise e Interpretação}

Como já foi explicado na Seção 3.2.1, o protocolo é semelhante a um chat, no qual os usuários podem interagir. É importante destacar que o comportamento do protocolo é descrito nos modelos formais em termos da visão de um único usuário, o qual é denominado Usuário A. Seus potencias parceiros são denominados Usuário B e Usuário C. Sendo assim, todas as ações ocorridas e, posteriormente, as seqüências de teste geradas, são referentes ao conhecimento do Usuário A.

\subsubsection{Implementação derivada da especificação informal}

Essa implementação é desenvolvida com base na especificação do protocolo, representada pela linguagem natural. A especificação completa e original pode ser encontrada em http://fmt.cs.utwente.nl/ConfCase (Côte de Resyste Project, 1999).

\section{Análise de cobertura dos requisitos estruturais}

Como pode ser observado na Tabela 3.1, o conjunto de teste derivado do método $W$ obtém a maior cobertura estrutural, satisfazendo $98 \%$ dos elementos requeridos pelo critério todos-nós. O conjunto de teste adequado para o critério Análise de Mutantes para MEF cobre $96 \%$ e o para RPC $90 \%$ dos requisitos de teste exigidos para o mesmo 
critério. As coberturas obtidas pelos conjuntos de teste adequados aos critérios SC e UIO são exatamente as mesmas, para os 3 critérios de teste estrutural analisados.

Tabela 3.1: Cobertura em \% referente aos critérios estruturais - implementação baseada na especificação informal

\begin{tabular}{|c|c|c|c|c|c|c|}
\hline \hline Critério de teste & $W$ & $\boldsymbol{S C}$ & $\boldsymbol{U I O}$ & AM(MEF) & AM(RPC) & Estruturais \\
\hline \hline todos-nós & 98 & 92 & 92 & 96 & 90 & 100 \\
\hline todas-arestas & 94 & 88 & 88 & 90 & 84 & 100 \\
\hline todos-usos & 89 & 82 & 82 & 81 & 73 & 100 \\
\hline
\end{tabular}

Todos os elementos requeridos cobertos por qualquer um dos conjuntos de teste analisados, também são cobertos pelo conjunto referente ao $W$ e os que não são satisfeitos por este conjunto, também não podem ser satisfeitos com a aplicação dos outros 4 .

$\mathrm{O}$ método $W$ não cobre, apenas, os elementos requeridos que não fazem parte do comportamento normal do protocolo. São eles: i) Um usuário que não faz parte da lista de potenciais parceiros tentar interagir com o Usuário A; ii) Troca de eventos entre usuários participando de conferências diferentes.

Os conjuntos de teste derivados dos métodos State-Counting e UIO não cobrem os requisitos que não são cobertos pelo conjunto de testes derivado do método $W$, além disso ambos não contêm sequiências que exercitam os comportamentos referentes ao usuário A, como: i) o usuário A tentar entrar duas vezes na mesma conferência; ii) o usuário A tentar enviar uma mensagem a uma conferência sem antes ter entrado nela; iii) o usuário A tentar sair de uma conferência sem antes ter entrado nela. A cobertura obtida pelo State-Counting é reflexo de uma de suas características, que é a de não completar a MEF artificialmente. Se fosse aplicada a hipótese de completude, a cobertura obtida pelo conjunto de teste derivado do SC seria a mesma obtida pelo conjunto derivado do Método $W$.

Com a aplicação do conjunto de testes derivado do critério AM, para MEF, é possível revelar um erro que não é manifestado com a aplicação dos outros conjuntos, inclusive dos estruturais. Esse erro é referente a um comportamento é equivalente, mas que na implementação está representado de maneira distinta. Ele é observado quando o usuário A recebe uma mensagem de um de seus potenciais parceiros que não está participando daquela conferência. Entretanto, o usuário que enviou a mensagem pode estar inserido em dois contextos: i) o usuário nunca executou a primitiva join(), ou seja, não entrou naquela conferência em qualquer momento, ou; ii) o usuário entrou na conferência, por meio de uma primitiva join() e, em um outro momento, antes do envio da mensagem, deixou de participar daquela conferência, executando um leave(). Esse comportamento não foi executado por nenhuma sequiência pertencente aos outros conjuntos de teste. 
A união de todos os elementos requeridos não cobertos pelos métodos já citados compõe o conjunto dos elementos que não são cobertos pelo conjunto de testes derivado do critério Análise de Mutantes para RPC.

Baseado nesses resultados, é possível perceber que os elementos requeridos que não fazem parte do comportamento normal do protocolo não podem ser cobertos com a aplicação de nenhum dos conjuntos de teste derivados dos modelos formais. Dessa forma levantam-se dois pontos: o primeiro é com relação à implementação. Deve-se notar que a implementação, tratando dos aspectos que não fazem parte do comportamento normal do protocolo, contém mais informação do que aquela representada na MEF. Tais comportamentos, ausentes na MEF, representam situações normais mas que podem ocorrer na execução do sistema.

O segundo ponto é referente aos modelos formais, em especial, à MEF, da qual foram derivados quatro conjuntos de teste. Analisa-se agora a adequação da MEF, já que essa só trata do comportamento normal do protocolo. Por meio da análise da especificação informal, percebe-se que o modelo reflete, adequadamente, o comportamento normal do sistema, entretanto, também, não há referências ao comportamento que não faz parte do fluxo normal. Sendo assim, pode-se afirmar que mesmo tendo sido concebida, analisada e aprovada por um grupo de profissionais e pesquisadores que compõem o projeto Plavis, erros e inconsistências ainda podem ocorrer. Da maneira como a máquina é apresentada, essa não seria adequada, nem mesmo, para a geração automática de código, já que características importantes não são tratadas.

\section{Análise de custo da aplicação dos conjuntos de teste}

O custo de aplicação dos conjuntos de teste é medido analisando o tamanho do conjunto de teste (número de casos de teste que compõem o conjunto) e o número de casos de teste necessários para satisfazer os critérios estruturais, tratados, aqui, como casos de teste efetivos. Na Tabela 3.2 estão representados esses valores.

Tabela 3.2: Custo de aplicação - implementação baseada na especificação informal

\begin{tabular}{|c|c|c|}
\hline \hline Conjunto de teste & Tamanho Total & Afetaram a cobertura \\
\hline \hline$W$ & 1455 & 11 \\
\hline $\boldsymbol{S} \boldsymbol{C}$ & 320 & 7 \\
\hline $\boldsymbol{U I O}$ & 28 & 8 \\
\hline AM(MEF) & 20 & 6 \\
\hline AM(RPC) & 9 & 7 \\
\hline Estruturais & 8 & 8 \\
\hline
\end{tabular}


O número de casos de teste efetivos na cobertura dos requisitos estruturais é muito semelhante, entre todos os conjuntos, entretanto, quando analisa-se o percentual de casos de teste do conjunto efetivo observa-se a grande disparidade, principalmente na comparação entre os pares de conjuntos $W-\mathrm{AM}(\mathrm{MEF})$ e $\mathrm{SC}$ - UIO. O primeiro par obtém cobertura estrutural muito semelhante, entretanto o número de elementos contidos em cada um dos conjuntos é muito diferente: $W=1455$ sendo $0,75 \%$ de casos de teste efetivos, e o $\mathrm{AM}(\mathrm{MEF})=20$, tendo em torno de $30 \%$. Para o segundo par de conjuntos observa-se exatamente a mesma cobertura para os 3 critérios estruturais analisados, sendo necessário, praticamente, o mesmo número de casos de teste para alcançar tais coberturas, entretanto, o percentual de casos de teste efetivos, frente ao conjunto completo é bem diferente: $2 \%$ para o SC e $28 \% .78 \%$ dos casos de teste que compõem o conjunto referente a RPC são efetivos. 8 casos de teste, criados com base código fonte, são utilizados para satisfazer $100 \%$ dos elementos requeridos pelos 3 critérios analisados.

É possível perceber que, independente do tamanho do conjunto, o número de casos de teste efetivos é muito semelhante. Assim, afirma-se que há um conjunto de sequiências, chamadas aqui de básicas, que cobrem grande parte dos elementos requeridos. Percebe-se também que, independente da técnica, o número de casos de teste efetivos é semelhante. Intuitivamente, acredita-se que isso deve-se ao fato de que todos os conjuntos, bem como a implementação, foram derivados da especificação informal.

\subsubsection{Implementação derivada da especificação em MEF}

Essa implementação é desenvolvida de forma que os estados e as transições que compõem a MEF ficam explícitos no código fonte. Sendo assim, é possível observar que há um relacionamento direto entre elementos requeridos pelos critérios estruturais de teste com os estados e transições contidos na máquina.

\section{Análise de cobertura dos requisitos estruturais}

Assim como na outra implementação, o conjunto de teste derivado do método $W$ satisfaz o maior número de elementos requeridos pelos critérios estruturais. Os requisitos não cobertos pelo método $W$ são os mesmos para a implementação derivada da especificação informal e há um outro requisito que exige alguma interação de um usuário partindo de um estado diferente daqueles contidos na implementação e, conseqüentemente, na MEF.

A argumentação para o parágrafo acima é análoga à que foi colocada em relação aos elementos requeridos não cobertos na implementação derivada da especificação informal. Observa-se que os elementos requeridos que não são cobertos não referem-se ao comportamento normal do protocolo, incluindo aquele que é particular a esta implementação e também não é coberto. 
Como pode ser observado na Tabela 3.3, depois do conjunto $W$ o conjunto State-Counting é o que satisfaz o maior número de requisitos estruturais. É interessante destacar que nessa segunda implementação, o número de requisitos de teste cobertos por esse critério não é o mesmo que o obtido com a aplicação do método UIO.

Tabela 3.3: Cobertura em \% referente aos critérios estruturais - implementação baseada na especificação formal

\begin{tabular}{|c|c|c|c|c|c|c|}
\hline \hline Critério de teste & $W$ & $\boldsymbol{S C}$ & $\boldsymbol{U I O}$ & AM(MEF) & AM(RPC) & Estruturais \\
\hline \hline todos-nós & 100 & 100 & 97 & 96 & 65 & 100 \\
\hline todas-arestas & 90 & 87 & 83 & 85 & 47 & 100 \\
\hline todos-usos & 82 & 79 & 66 & 70 & 32 & 100 \\
\hline
\end{tabular}

No conjunto de testes derivado do State-Counting não há nenhuma seqüência em que a primeira transição é diferente de um join do usuário A, no estado IDLE (estado em que o usuário A não está conectado). Isso implica em outro requisito não coberto que é o usuário tentar sair da conferência sem antes ter entrado nela.

O conjunto de testes derivado do método UIO não cobre os requisitos não cobertos pelo State-Counting. Além disso, outro elemento requerido que não é coberto refere-se a uma situação em que o usuário B envia uma mensagem para a conferência quando somente os usuários A e C estão conectados e também, uma outra mensagem, quando os usuários A, B e C estão conectados.

Nas seqüências de teste adequadas para o critério Análise de Mutantes para MEF não há nenhuma seqüência em que é possível cobrir o que o método $W$ não cobre. Além disso, não há seqüências que simulam o envio de uma mensagem pelo usuário C nas seguintes situações: i) quando apenas o usuário A está conectado na conferência e ii) quando os usuários A e C estão na mesma conferência. Para este último estado também não há nenhuma seqüência em que o usuário A deixa de participar da conferência. Também não há nenhuma seqüência que simule a situação em que os 3 usuários estão participando da mesma conferência e o usuário $\mathrm{C}$ executa a primitiva leave.

O conjunto de teste adequado para o critério Análise de Mutantes para Redes de Petri Coloridas é o que apresenta a menor cobertura dos requisitos estruturais para a implementação derivada da Máquina de Estado Finito. Os casos de teste desse conjunto não cobrem os requisitos que os outros métodos não cobrem além de não haver nenhuma sequiência em que o usuário B envia uma mensagem. Isso deve-se ao fato de que uma mensagem enviada pelo usuário C, por exemplo, já é suficiente para matar os mutantes referentes à troca de mensagens. Ainda com relação a este último critério, observa-se que nenhum evento é executado no estado em que os usuários A e C estão conectados, ou seja, nenhum caso de teste leva à implementação para tal estado. 
É possível observar que os elementos requeridos por essa implementação possuem uma relação direta com a MEF, o que explica a baixa cobertura obtida pelo conjunto derivado da RPC.

\section{Análise de custo da aplicação dos conjuntos de teste}

$\mathrm{Na}$ análise de custo de aplicação dos conjuntos de teste é possível perceber que o número de casos de teste efetivos é maior do que os que foram efetivos para a outra implementação. Isso deve-se ao fato dos requisitos de teste estarem relacionados, de forma mais direta, aos estados e transições contidos na MEF. Sendo assim, as seqüências geradas pelos métodos executam os requisitos de teste de maneira mais explícita. Pela análise da Tabela 3.4 é possível observar que, apesar do $W$ ser em torno de 4 vezes maior que o SC, suas coberturas são muito semelhantes e suas percentagens de aproveitamento são $11 \%$ contra $36 \%$ respectivamente. Já os conjuntos UIO e AM(MEF), comportam-se de maneira muito semelhante, apresentando o primeiro um aproveitamento de $79 \%$ e o segundo $80 \%$. O percentual de casos de teste efetivos para o critério AM aplicado para RPC fica em torno de $89 \%$, entretanto, a satisfação dos elementos estruturais de teste é considerada muito pequena. 16 casos de teste criados com base no código-fonte são necessários para satisfazer os critérios estruturais.

Tabela 3.4: Custo de aplicação - implementação baseada na especificação formal

\begin{tabular}{|c|c|c|}
\hline \hline Conjunto de teste & Tamanho Total & afetaram a cobertura \\
\hline \hline$W$ & 1455 & 155 \\
\hline $\boldsymbol{S C}$ & 320 & 115 \\
\hline $\boldsymbol{U I O}$ & 28 & 22 \\
\hline AM(MEF) & 20 & 16 \\
\hline AM(RPC) & 9 & 8 \\
\hline Estruturais & 16 & 16 \\
\hline
\end{tabular}

\subsubsection{Análise Comparativa}

Para ambas as implementações, o método $W$ obtém a maior cobertura estrutural, para os 3 critérios. Isso significa que qualquer elemento requerido por um dos critérios estruturais que é coberto por algum conjunto de teste, também é coberto pelo conjunto de teste derivado do método $W$. Há dois requisitos que ambas as implementações contêm e que não são cobertos por nenhum dos conjuntos de teste:

- Um usuário diferente daqueles pré-definidos (ou seja, aqueles que fazem parte da lista de potenciais parceiros) tentar interagir com o usuário sob o ponto de vista do qual a máquina é modelada (usuário A); 
- Troca de eventos entre usuários participando de conferências diferentes.

A implementação derivada da MEF ainda exige uma seqüência em que há uma ação partindo de um estado diferente daqueles existentes na implementação e, conseqüentemente, na máquina.

Constata-se que esses requisitos não fazem parte do comportamento normal do protocolo, e não são cobertos devido à maneira que os modelos formais são criados. Em nenhum deles há um estado de erro ou um usuário diferente de A, B e C. A máquina é desenvolvida sob o ponto de vista de um único usuário, que está sempre em uma única conferência; dessa forma, nenhum dos conjuntos de teste que são derivados dos modelos formais vai gerar uma seqüência em que a conferência de algum usuário é diferente daquela (única) definida. Como conseqüência disso, também, não há nenhuma seqüência em que o usuário A receba um evento de um usuário que não esteja na mesma conferência que ele, bem como que não esteja na lista dos seus potenciais parceiros.

A cobertura obtida pelos critérios derivados da MEF é semelhante, para as duas implementações, as diferenças de cobertura apenas reflete a completude do critério. A maior discrepância é observada na implementação derivada da especificação informal, quando o conjunto de teste da RPC é aplicado.

Observa-se que para a implementação derivada da especificação informal, a cobertura obtida por todos os conjuntos é muito semelhante, podendo ser considerada satisfatória, até mesmo para o conjunto de teste derivado da RPC. Acredita-se que isso deve-se ao fato de que o entendimento da especificação informal serviu de base para o desenvolvimento tanto do código, em Java, do protocolo, como dos modelos formais.

Com relação ao custo de aplicação dos conjuntos de teste, o número de casos de teste efetivos utilizados em cada uma das implementações é, significativamente, diferente. Conclui-se que esse fato é devido aos elementos de teste requeridos pela implementação derivada da MEF possuírem um relacionamento direto com a máquina e, conseqüentemente, os casos de teste que são derivados dessa máquina também estão relacionados com os elementos requeridos. Esse é um dos motivos que o conjunto de teste derivado na RPC é tão pequeno e, para a implementação derivada da MEF, obtém uma cobertura muito inferior à obtida para a implementação derivada da especificação informal. Outro fato é que o número de elementos de teste requeridos para a implementação derivada da MEF é o dobro daqueles exigidos para a implementação derivada da especificação informal. Entretanto, a proporção não é mantida, pois há um caso em que o número de casos de teste efetivos, chega a ser 12 vezes maior. 


\subsection{Estudo de Caso 2: Protocolo OBDH-EXP}

Este estudo de caso consiste na comparação de conjuntos de caso de teste derivados de uma especificação formal com critérios estruturais. Esta comparação é feita verificando a efetividade e o custo de se aplicar conjuntos de casos de teste derivados de uma especificação em Máquina de Estado Finito em uma implementação em Java. Os métodos para geração de seqüências de teste utilizados são: Método $W$, UIO e o critério Análise de Mutantes aplicado em MEF. Os critérios de teste estrutural utilizados são os critérios de fluxo de controle (todos-nós e todas-arestas) e de fluxo de dados (todos-usos). A seguir, para contextualização, faz-se uma descrição do Protocolo OBDH-EXP (extraída de INPE (2005)).

\subsubsection{Descrição do Protocolo}

Esse protocolo, desenvolvido no INPE, provê a comunicação entre dois equipamentos a bordo de satélites científicos, o computador principal, que é um computador de manipulação de dados a bordo $(\mathrm{OBDH})$ e um equipamento de carga útil científica (EXP). O computador principal fica a bordo do satélite; sua sigla OBDH vem de On-Board Data Handling e o experimento científico é chamado, de forma genérica, de EXP. Na Figura 3.5 é mostrada a arquitetura do protocolo.

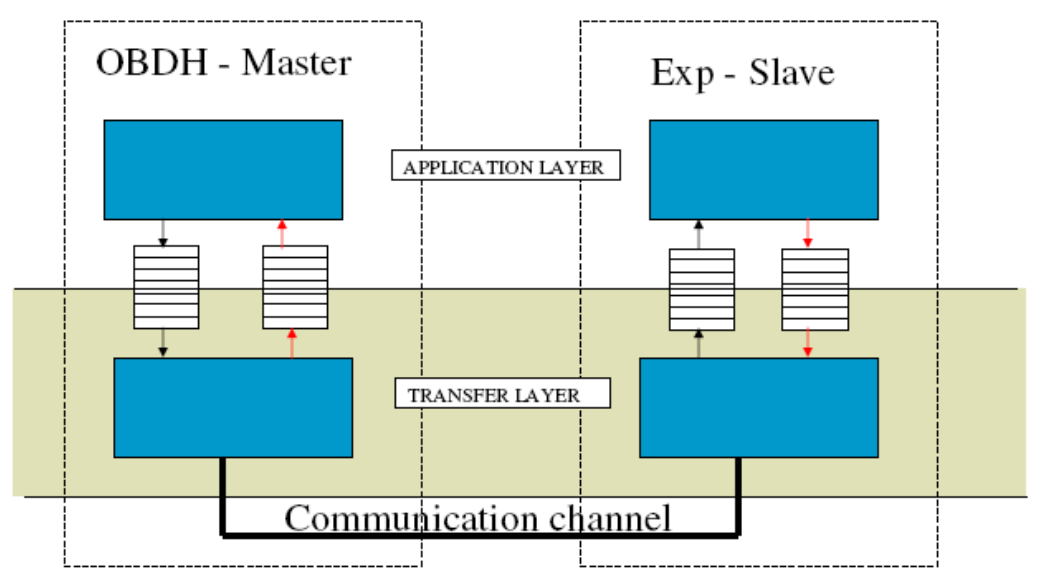

Figura 3.5: Arquitetura do protocolo OBDH-EXP

O EXP envia dados e respostas ao OBDH somente sob demanda. Ao reconhecer o comando, o EXP o executa e responde ao OBDH. Os comandos que podem ser reconhecidos e executados pelo EXP são: reinicialização (reset), reconfiguração, transmissão de dados, carga (load) de memória, descarga (dump) de memória, obtenção do tempo (clock), inicialização e interrupção de aquisição de dados, carga de parâmetros. Sempre que um comando não é reconhecido toda a mensagem é descartada. Se um byte do comando 
não chega dentro de 500 milisegundos toda a mensagem é descartada e o EXP volta a aguardar novo comando (Ambrosio, 2005). O formato da mensagem de comando recebida pelo EXP está representado na Figura 3.6, extraída de INPE (2005).

\begin{tabular}{|c|c|c|c|c|c|}
\hline 12 bits & 4 bits & 8 bits & 8 bits & & 8 bits \\
\hline SYNC & \begin{tabular}{|l} 
EXP \\
ID
\end{tabular} & TYPE & SIZE & DATA & CKS \\
\hline
\end{tabular}

Figura 3.6: Formato do comando enviado pelo $\mathrm{OBDH}$

O OBDH envia uma mensagem ao EXP que, quando recebe, trata cada um dos campos. A descrição de cada um dos campos contidos na mensagem é feita a seguir:

- SYNC: é uma palavra de 12 bits que é enviada ao EXP com o objetivo de indicar sincronismo. O valor desse campo é EB9;

- EXP ID: é uma palavra de 4 bits a qual identifica o experimento. Seu valor é o binário 0010, para o experimento em questão;

- TYPE: 8 bits que identificam o tipo do comando. A lista de comandos é apresentada adiante;

- SIZE: este é um campo opcional, de 8 bits, o qual depende do tipo do comando. Se o comando necessita transmitir dados esse campo deve ser usado para indicar o tamanho do dado que será transmitido no campo DATA;

- DATA: esse também é um campo opcional e depende do tipo do comando. Se o comando necessitar transmitir dados para o EXP esse campo pode ser usado várias vezes (até 38 bytes por comando);

- CKS: o checksum é uma palavra de 8 bits enviada para verificar a integridade da mensagem.

Os comandos que podem estar presentes no campo TYPE estão descritos na Tabela 3.5. Nesta tabela é mostrado o nome do comando com seu respectivo tipo, descrição e a resposta que o EXP pode enviar após o recebimento (e reconhecimento) de cada um dos comandos.

Nas Figuras 3.7 e 3.8 estão as MEFs desenvolvidas para esse protocolo. Na primeira figura é ilustrada uma visão geral do protocolo, na segunda têm-se uma visão detalhada. Essas máquinas foram elaboradas e revisadas pelos membros do projeto Plavis. 


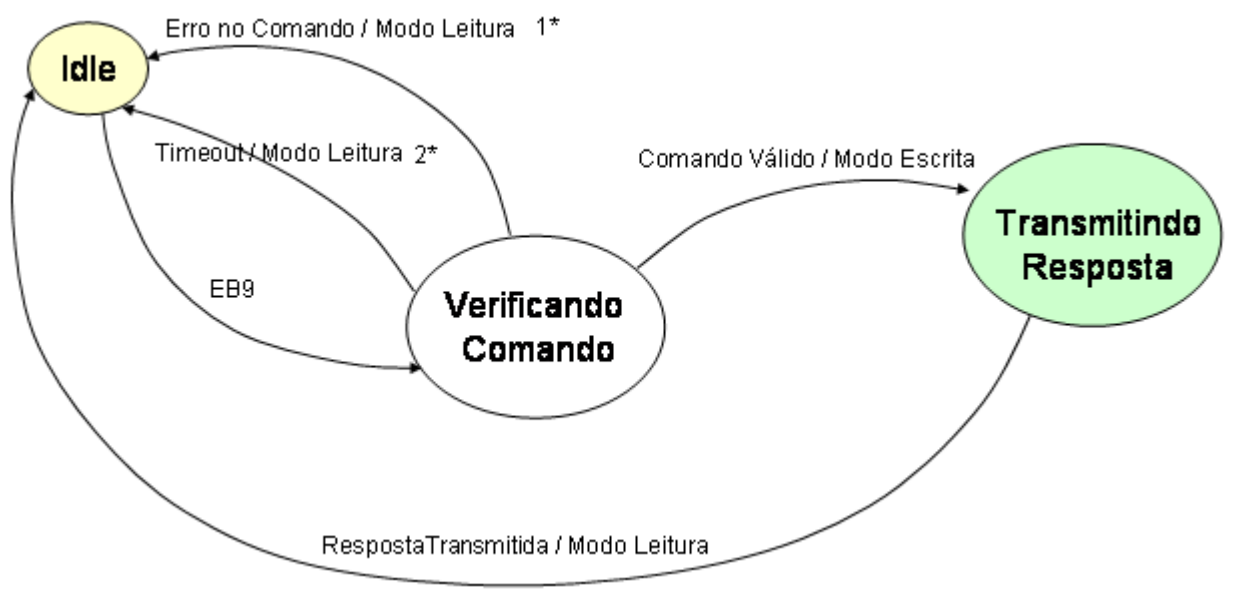

Figura 3.7: MEF do protocolo OBDH-EXP, visão macro

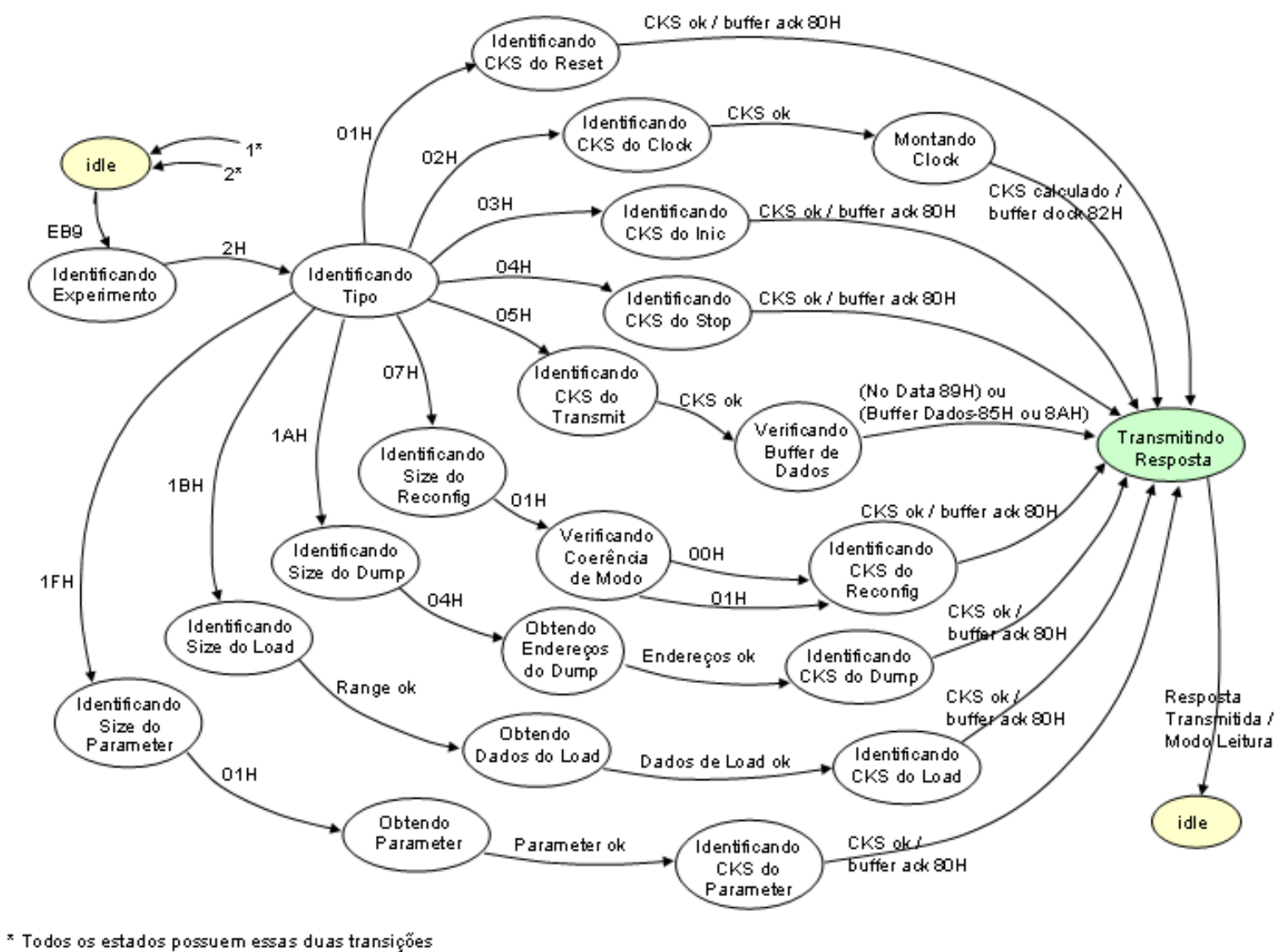

Figura 3.8: MEF do protocolo OBDH-EXP, visão detalhada 
Tabela 3.5: Descrição dos comandos enviados pelo OBDH

\begin{tabular}{|l|l|l|l|}
\hline \hline Nome do Comando & Tipo & Descrição & Resposta do EXP \\
\hline \hline Reinicialização & $01 \mathrm{H}$ & Reinicia o microcontrolador & $80 \mathrm{H}$ - Mensagem Recebida \\
\hline Obtenção do tempo & $02 \mathrm{H}$ & Solicita dados do relógio & $82 \mathrm{H}$ - Dados do Clock \\
\hline $\begin{array}{l}\text { Inicia aquisição de da- } \\
\text { dos }\end{array}$ & $03 \mathrm{H}$ & Ativa a aquisição dos dados & $80 \mathrm{H}$ - Mensagem Recebida \\
\hline $\begin{array}{l}\text { Pára aquisição de da- } \\
\text { dos }\end{array}$ & $04 \mathrm{H}$ & $\begin{array}{l}\text { Desativa a aquisição de da- } \\
\text { dos }\end{array}$ & $80 \mathrm{H}$ - Mensagem Recebida \\
\hline Transmissão de dados & $05 \mathrm{H}$ & $\begin{array}{l}\text { Solicita a transmissão dos } \\
\text { dados }\end{array}$ & $\begin{array}{l}85 \mathrm{H} \text { - Transmite o pacote de } \\
\text { dados ou 89H - quando não } \\
\text { dá dados para transmitir }\end{array}$ \\
\hline Reconfiguração & $07 \mathrm{H}$ & $\begin{array}{l}\text { Modifica o valor do modo de } \\
\text { operação.Especifica esse va- } \\
\text { lor no campo Data }\end{array}$ & $80 \mathrm{H}$ - Mensagem Recebida \\
\hline Descarga de memória & $1 \mathrm{AH}$ & $\begin{array}{l}\text { Solicita a carga de dados na } \\
\text { memória. Esse comando é } \\
\text { transmitido ao OBDH como } \\
\text { resposta de um comando de } \\
\text { transmissão de dados }\end{array}$ & $80 \mathrm{H}$ - Mensagem Recebida \\
\hline Carga de memória & $1 \mathrm{BH}$ & $\begin{array}{l}\text { Carrega na memória do mi- } \\
\text { crocontrolador até 36 bytes } \\
\text { de dados }\end{array}$ & $\begin{array}{l}\text { O EXP identifica os ti- } \\
\text { pos parâmetros recebidos e } \\
\text { executa-os }\end{array}$ \\
\hline Carga de parâmetros & $1 \mathrm{FH}$ - Mensagem Recebida Recebida \\
\hline
\end{tabular}

É necessário observar que pela especificação, depois que foi solicitado um comando de descarga de memória (1AH), o próximo comando de transmissão de dados $(05 \mathrm{H})$ provoca a transmissão de um buffer do tipo 8AH. No entanto, essa ação (preparação do buffer 8AH) é realizada pela Aplicação e não pelo Protocolo. Para isso, supõe-se que a Aplicação esteja correta. Assim, do estado "Verificando Buffer de Dados" para o estado "Transmitindo Resposta", um dos eventos que pode ocorrer é "Buffer Dados-85H ou 8AH", sendo que no caso do comando de descarga de memória deve ser um 8AH. Assim, a saída esperada quando ocorre uma descarga de memória seguida de uma transmissão deve ser "forçada" (editada) para identificar que essa seqüência de eventos está correta.

\subsubsection{Definição do estudo de caso}

Em seguida é feita uma breve definição do estudo de caso, seguindo o modelo proposto por Wohlin et al. (2000). 
- Analisar três conjuntos de casos de teste derivados de uma Máquina de Estado Finito aplicado em uma implementação em Java.

- Para o propósito de avaliar o quanto um conjunto de teste gerado baseado em uma especificação formal consegue cobrir os requisitos exigidos pelos critérios estruturais e qual é o custo de se aplicar, na implementação, esse conjunto de teste.

- Com respeito à efetividade e custo

- Do ponto de vista da cobertura dos requisitos de teste estrutural

- No contexto da exploração do uso de conjuntos de teste derivados de especificações formais aplicados em duas implementações Java, do Protocolo OBDH-EXP.

\subsubsection{Planejamento}

O estudo de caso está inserido no contexto do projeto Plavis. O objeto de estudo escolhido é um protocolo de comunicação (descrito na Seção 3.3.1), denominado OBDH-EXP. Esse protocolo foi escolhido como objeto de estudo por pertencer ao contexto explorado no projeto Plavis bem como neste trabalho, que são as aplicações espaciais.

O intuito do procedimento descrito a seguir é verificar se os conjuntos de teste gerados baseados em uma especificação formal são sempre adequados em relação aos critérios estruturais e se há diferença de custo na aplicação dos conjuntos de teste derivados de uma especificação formal e conjuntos de testes derivados de requisitos estruturais. Para isso são gerados três conjuntos de teste derivados de uma MEF e um outro conjunto derivado diretamente dos requisitos estruturais.

O estudo de caso é composto dos seguintes materiais:

- Uma especificação informal (em linguagem natural), do OBDH-EXP;

- Uma especificação formal do OBDH-EXP representada por uma Máquina de Estado Finito;

- Uma implementação do protocolo de comunicação, desenvolvida com base na especificação informal;

- Uma ferramenta de apoio para a geração dos casos de teste baseados na especificação em MEF (Plavis/FSM);

- Uma ferramenta de apoio para análise de cobertura, de implementações Java, dos critérios estruturais alvo deste trabalho (JaBUTi);

- Um emulador do OBDH; 
- Um cabo serial RS-232 usado para a comunicação entre os emuladores.

As seqüências de teste foram inseridas, manualmente, no emulador do OBDH. Como sabe-se, a atividade de teste, quando executada manualmente, está sujeita a erros, o que, nesse caso, pode colocar em risco a validade do estudo de caso.

\subsubsection{Operação}

Nesta Seção é descrita a forma como este estudo de caso foi conduzido. Com o auxílio da ferramenta Plavis/FSM são criados os conjuntos de caso de teste referentes aos métodos $W$, UIO e Análise de Mutantes. Para que esses conjuntos pudessem ser gerados, a máquina foi particionada levando em consideração cada um dos comandos executados pelo OBDH. O particionamento da máquina foi necessário pois, devido ao tamanho da máquina, a ferramenta não conseguia gerar os casos de teste, já que esse número era muito elevado. Dessa forma, obtém-se 9 máquinas, as quais são inseridas na ferramenta para posterior geração dos conjuntos. Tal divisão também pode colocar em risco a validade do estudo pois a execução dos métodos requer que a máquina seja completada artificialmente, gerando assim casos de teste repetidos.

As sequiências de teste foram inseridas, manualmente, no emulador do OBDH, que comunica-se com o EXP por meio de um uma linha serial, conectada por um cabo RS-232. A execução das seqüências foi monitorada pela ferramenta JaBUTi. O processo pelo qual o estudo de caso foi conduzido está ilustrado na Figura 3.9.

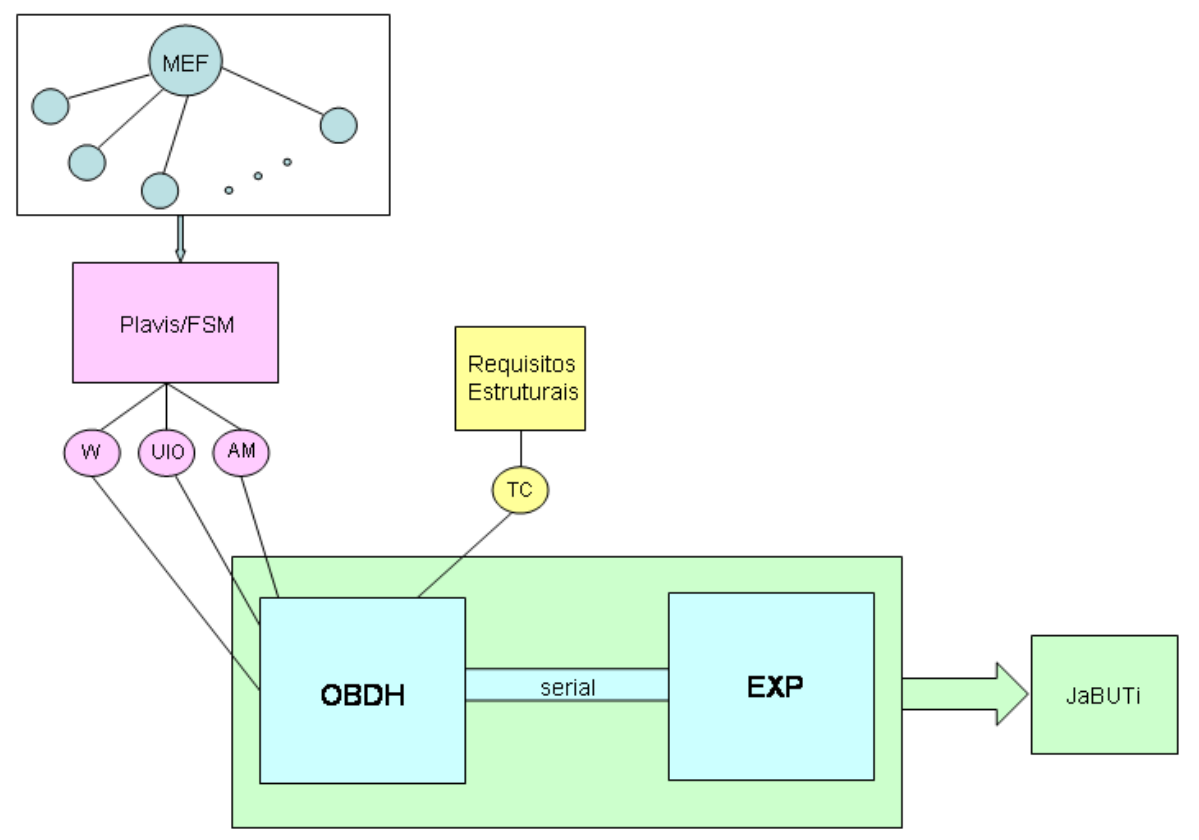

Figura 3.9: Processo de operação do estudo de caso utilizando o OBDH-EXP 


\subsubsection{Coleta de Dados}

Os dados coletados nesse estudo de caso foram:

- A cobertura dos elementos requeridos pelos critérios estruturais todos-nós, todas-arestas e todos-usos com a aplicação dos conjuntos de teste referentes a:

- Método $W$

- Unique Input-Output;

- Análise de Mutantes (MEF);

- O custo, em termos do número de casos de teste utilizados, de aplicar cada um dos conjuntos de teste, citados acima, na implementação do protocolo.

\subsubsection{Análise e Interpretação}

Assim como foi feito para o primeiro estudo de caso, a análise e interpretação dos resultados é dividida em análise de cobertura dos requisitos estruturais e análise de custo.

\section{Análise de cobertura dos requisitos estruturais}

Por meio da análise da Tabela 3.6 observa-se que o comportamento obtido pelos três conjuntos de teste é semelhante. Analisando a especificação e a implementação entende-se o porquê dessa semelhança. A especificação trata da troca de mensagens entre o computador de bordo e o experimento científico e na implementação é possível observar, claramente, a declaração de cada um dos comandos em seus comportamentos normais e em uma situação de erro qualquer. Assim, qualquer um dos conjuntos de teste gera, obviamente, um conjunto de seqüências que representam o comportamento normal e uma seqüência, qualquer, que leva a uma combinação de entradas resultando em um comando errado.

A especificação trata apenas da troca de mensagens, não definindo como essas mensagens serão enviadas ou recebidas. Já na implementação é necessário que tal definição seja concretizada. Para efeitos de avaliação e estudo essa diferença é desconsiderada, tratando todos os elementos requeridos referentes à comunicação serial como elementos não executáveis.

Também não é possível simular o timeout (transição presente em todos os estados) em todas as situações, pois o emulador não permite tal entrada.

A representação de erros no comando (também presente em todas as transições da MEF) não é comprometida pelo emulador, entretanto, esses erros estão representados na implementação de maneira pré-definida, sendo reconhecidos e/ou tratados em poucas situações, como por exemplo: erro de tipo de experimento, erro de checksum apenas. Um 
erro no comando de sincronização, por exemplo, simplesmente é ignorado, não prosseguindo no recebimento do comando mas também não informando tal erro. Devido a isso, não é possível cobrir, nem mesmo por meio do conjunto de teste derivado dos requisitos estruturais, $100 \%$ dos elementos requeridos, ao menos, pelo critério todos-nós.

A cobertura obtida com a aplicação do conjunto de testes criados com base nos requisitos estruturais é: $85 \%, 78 \%, 64 \%$ para os critérios todos-nós, todas-arestas e todos-usos, respectivamente.

Tabela 3.6: Cobertura em \% referente aos critérios estruturais

\begin{tabular}{|l|c|c|c|c|}
\hline \hline Critério de teste & $W$ & AM(MEF) & UIO & Estruturais \\
\hline \hline todos-nós & 80 & 80 & 78 & 85 \\
\hline todas-arestas & 74 & 74 & 73 & 78 \\
\hline todos-usos & 59 & 59 & 56 & 64 \\
\hline
\end{tabular}

\section{Análise de custo da aplicação dos conjuntos de teste}

Assim como foi feito no primeiro estudo de caso, o custo de se aplicar um conjunto de teste é medido pelo tamanho total do conjunto e o número de casos de teste efetivos. Alguns casos de teste que compõe os conjuntos, não são aplicáveis. Esses casos de teste que não se aplicam referem-se a combinações dos comandos de entrada que não podem ser simulados no emulador do OBDH. A percentagem de casos de teste aplicáveis é de $67 \%$ para o conjunto derivado do critério AM, $72 \%$ para o conjunto $W$ e $82 \%$ para o conjunto derivado do UIO. Dos 1752 casos de teste do conjunto $W$, apenas 28 foram efetivos, o que corresponde a 1,6\% de casos de teste efetivos. Esse número reflete as diferenças entre a especificação e a implementação. Percebe-se que esses dois artefatos estão representados em níveis de abstração muito diferentes. Da maneira que se apresenta a especificação, ela não seria adequada para a geração de código e nem para o teste de conformidade, pois expressa o comportamento do protocolo num nível de abstração muito alto. Na Tabela 3.7 estão mostrados esses números. O conjunto derivado do UIO é o menor, sendo que $20 \%$ dos seus casos de teste foram efetivos. O conjunto derivado da AM contém $7 \%$ de casos de teste efetivos. Como a cobertura obtida pelos 3 conjuntos foi considerada equivalente, constata-se que, para esse caso, o conjunto de teste que apresenta a melhor relação de custo/benefício (efetividade e custo) de aplicação é o conjunto derivado do UIO pois é o menor conjunto de teste e que apresenta o maior número de casos de teste efetivos. Foram elaborados e utilizados 4 conjuntos de teste com base nos requisitos estruturais. 
Tabela 3.7: Custo de aplicação, em número de casos de teste efetivos

\begin{tabular}{|c|c|c|c|}
\hline \hline Conjunto de teste & Tamanho Total & Aplicáveis & Influenciaram na cobertura \\
\hline \hline$W$ & 2431 & 1752 & 28 \\
\hline AM(MEF) & 702 & 470 & 34 \\
\hline $\boldsymbol{U I O}$ & 147 & 121 & 25 \\
\hline Estruturais & 4 & 4 & 4 \\
\hline
\end{tabular}

\subsection{Considerações Finais}

Neste capítulo foram mostrados os dois estudos de caso desenvolvidos durante este trabalho de mestrado. Foram explorados métodos de geração de seqüências de teste, baseados em modelos formais, afim de compará-los com critérios de teste estrutural. O objetivo da comparação é analisar o custo e a eficácia (em termos de cobertura de requisitos estruturais) de aplicar conjuntos de teste derivados de modelos formais em implementações em Java.

No primeiro estudo de caso o objeto de estudo foi um protocolo de conferência, semelhante a um chat. O estudo foi composto de duas especificações do problema por meio de modelos formais, sendo um deles uma MEF e o outro uma RPC. A partir desses modelos foram derivados os conjuntos de teste referentes aos critérios: $W$, SC, UIO e AM (adequados à primeira técnica) e AM adequado para RPC. Cada um desses conjuntos de teste foi aplicado em duas implementações do protocolo, uma foi desenvolvida baseada na especificação informal e a outra foi baseada na especificação em MEF. Observou-se que nenhum dos conjuntos de teste conseguiu cobrir os elementos requeridos pelo teste estrutural que não fazem parte do comportamento normal do protocolo. Questionou-se a adequação dos modelos gerados frente à implementação dos problemas. Pôde-se observar que, nem sempre, os modelos formais e o código fonte são semelhantes. Além disso, concluiu-se que um modelo formal, às vezes elaborado e revisado por um grupo de pessoas, pode ainda sim ser incompleto frente às características exigidas por uma implementação.

O objeto de estudo utilizado no segundo estudo de caso pertence ao contexto de aplicações espaciais. É um protocolo de comunicação, desenvolvido e utilizado pelo INPE. Consiste de um protocolo que provê a comunicação entre dois equipamentos a bordo de satélites científicos, sendo um o computador principal (OBDH) e o outro um equipamento de carga útil científica (EXP). Em linhas gerais, o estudo de caso foi composto da implementação em Java e da especificação em MEF desse protocolo. Com base na especificação foram gerados conjuntos de teste referentes aos métodos $W$, UIO e AM. O número de casos de teste gerados por esses métodos foi bem diferente, assim como o número de casos de teste efetivos. Entretanto, a cobertura dos requisitos estruturais alcançada, foi 
muito semelhante. Considerou-se que, para esse caso, o conjunto derivado do UIO apresentava a melhor relação custo/benefício já que gerou o menor conjunto de teste, com o maior número de casos de teste efetivos e cobertura semelhante a dos outros conjuntos. Novamente foi questionada a adequação da MEF já que nenhum dos conjuntos de teste conseguiu cobrir $100 \%$ dos elementos requeridos, ao menos, pelo critério todos-nós. Entretanto, ressaltasse que a análise foi prejudicada devido a inserção manual dos casos de teste bem como ao uso do emulador, que limitava a inserção de algumas seqüências de teste geradas.

Com isso observa-se a deficiência de alguns métodos que não conseguem cobrir, de maneira satisfatória, requisitos importantes, bem como revelar a presença de alguns defeitos, caracterizando sua insuficiência, bem como a dos critérios estruturais. Tal insuficiência sugere o aspecto complementar entre ambos. Conclui-se também que há uma deficiência nos modelos que, mesmo gerados, analisados e revisados por um grupo de pessoas, ainda sim são insuficientes com relação à completude e ao nível de abstração em que se apresentam. Alguns dos modelos não seriam adequados para a geração automática de código, devido ao seu alto nível de abstração. Sendo assim, ressalta-se a necessidade de um ambiente integrado de ferramentas de teste na qual estão integrados os modelos, a partir dos quais seriam gerados os casos de teste automaticamente, e a implementação, na qual será analisada a cobertura.

No próximo capítulo são apresentadas as conclusões deste trabalho bem como a identificação de trabalhos a serem realizados futuramente. 


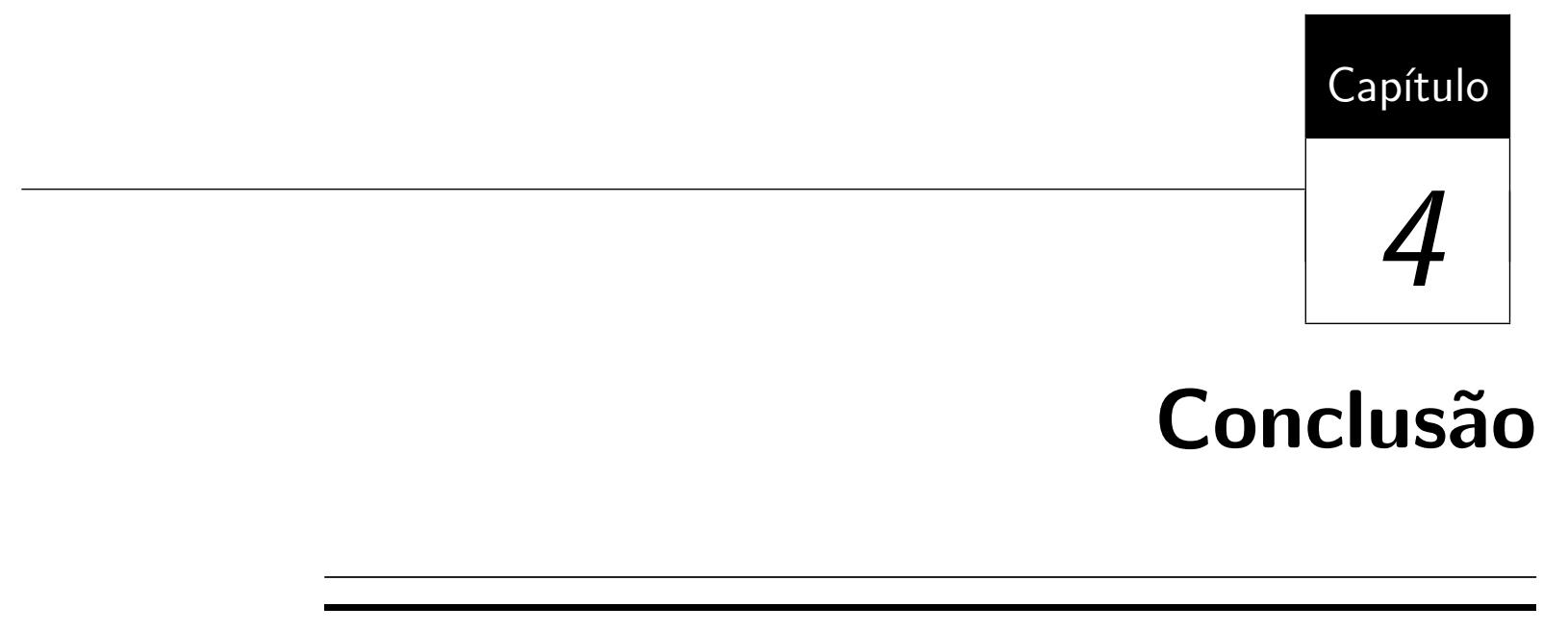

\subsection{Considerações Iniciais}

Neste trabalho foi investigada a relação entre critérios de teste estruturais e métodos de geração de seqüências baseados em modelos formais, com o objetivo de analisar como eles se relacionam e como poderiam ser usados em conjunto a fim de compor uma estratégia de teste. A análise foi feita em termos de eficiência e custo sendo conduzida por meio de dois estudos de caso. Os estudos de caso, além da comparação entre os critérios, permitiu que se avaliasse a própria problemática de instaurar-se uma estratégia de teste baseada em modelos sob o ponto de vista das técnicas e ferramentas utilizadas.

Pela análise dos resultados pôde-se observar que, nem sempre, os modelos formais e o código fonte são equivalentes. Além disso, concluiu-se que um modelo formal, às vezes elaborado e revisado por um grupo de pessoas, pode ainda sim ser incompleto frente às características exigidas por uma implementação. Observa-se, também, a deficiência de alguns métodos que não conseguem cobrir, de maneira satisfatória, requisitos importantes, bem como revelar a presença de alguns defeitos, caracterizando sua insuficiência, bem como a dos critérios estruturais. Tal insuficiência sugere o aspecto complementar entre ambos. Assim, seria possível se pensar em formas de otimização das seqüências geradas, de modo a diminuir sua cardinalidade, sem que se perca efetividade.

Conclui-se também que há uma deficiência nos modelos que, mesmo gerados, analisados e revisados por um grupo de pessoas, ainda sim são insuficientes com relação à 
completude e ao nível de abstração em que se apresentam. Alguns deles não seriam adequados, nem mesmo, para a geração automática de código. Sendo assim, ressalta-se a necessidade de um ambiente integrado de ferramentas de teste na qual estão integrados os modelos, a partir dos quais seriam gerados os casos de teste automaticamente, e a implementação, na qual será analisada a cobertura.

Sabe-se que a investigação realizada ainda não é suficiente sendo necessária a realização de mais estudos de casos e, principalmente, a inclusão de outras técnicas.

\subsection{Contribuições}

Dentre as contribuições deste trabalho destacam-se as constatações referentes à:

- deficiência de alguns métodos que geram um grande número de casos de teste e, entretanto, não conseguem alcançar uma cobertura satisfatória, bem como revelar alguns defeitos;

- deficiência dos modelos que, mesmo quando desenvolvidos e revisados por um grupo de pessoas, ainda apresentam-se de maneira superficial, muitas vezes não sendo, nem mesmo, adequados para a geração automática de código;

- insuficiência dos métodos de geração. Insuficiência, também, dos critérios baseados em cobertura, o que sugere o aspecto complementar entre eles;

- inadequação de alguns critérios de geração, que podem criar um número de seqüência não gerenciável;

- necessidade de um ambiente integrado de ferramentas de teste que possibilitem a integração entre modelos (de geração) e implementações (para análise de cobertura);

- realização dos dois estudos de caso que proporcionaram dados para as comparações entre os critérios.

\subsection{Trabalhos Futuros}

Neste trabalho de mestrado foi investigada a relação entre critérios estruturais e métodos de geração de sequiências derivados de modelos formais. Entretanto, sabe-se que a investigação realizada ainda não é suficiente sendo necessária a realização de mais estudos de casos e, principalmente, a inclusão de outras técnicas. Destacam-se os seguintes pontos:

- estudos de caso devem ser conduzidos em situações semelhantes, cada um deles possuindo o mesmo conjunto de artefatos; 
- a condução dos estudos de caso deve ser feita tendo as duas implementações: uma baseada no modelo formal e a outra na especificação informal;

- deve-se, também, incluir nessa análise os critérios potenciais-usos;

- expandir o estudo usando modelos como Redes de Petri, Statecharts e SDL;

- criação de uma estratégia e um ambiente de teste baseado em modelos. 



\section{Referências}

Acree, A. T. On Mutation. Tese de Doutoramento, Scholl of Information and Computer Science, Georgia Institute of Technology, Atlanta/GA - USA, 1980.

Ambrosio, A. M. Cofi - uma abordagem combinando teste de conformidade e injeção de falhas para validação de software em aplicações espaciais. Tese de Doutoramento, Instituto Nacional de Pesquisas Espaciais - INPE, Sâo José dos Campos/SP, 2005.

Barbosa, E. F.; Maldonado, J. C.; Vincenzi, A. M. R. Towards the determination of sufficient mutant operators for c. Software Testing, Verification and Reliability Journal, v. 11, n. 2, p. 113-136, 2001.

Barbosa, E. F.; Maldonado, J. C.; Vincenzi, A. M. R.; Delamaro, M. E.; Souza, S. R. S.; Jino, M. Introdução ao teste de software. Minicurso apresentado no $14^{\circ}$ Simpósio Brasileiro de Engenharia de Software (SBES'2000). João Pessoa, PB/Brasil, 2000.

Barroca, L.; McDermid, J. A. Formal methods: Use and relevance for the development of safety-critical systems. The Computer Journal, v. 35, n. 6, p. 579-599, 1992.

Belinfante, A.; Brinksma, E.; Feenstra, J.; Tretmans, J.; de Vries, R. G. Côte de resyste - automatic model-based testing of communication protocols. Mobile Communications in Perspective - 7th Annual CTIT Workshop, University of Twente, The Netherlands, pages: 49 - 51, published in 2001, 2001.

Binder, R. V. Testing object-oriented systems: Models, patterns, and tools. 1st. ed. Addison Wesley, 1999.

BLRC Software tools for interoperability testing of network protocols, especially for voip products. Online, disponível em http://blrc.edu.cn/research/seeproject.php3? projectid=6 - último acesso em 17/03/2005, 2005. 
Briand, L. C.; Labiche, Y.; Wang, Y. Using simulation to epirically investigate test coverage criteria based on statechart. In: Proceedings of the $26^{\text {th }}$ International Conference on Software Engineering (ICSE'2004), Edinburgh/Scotland, UK: IEEE Computer Society Press, 2004.

Candolo, M. A. P.; Simão, A. S.; Maldonado, J. C. MGASet - Uma ferramenta para apoiar o teste e validação de especificações baseadas em Máquinas de Estado Finito. In: Anais do $15^{\circ}$ Simpósio Brasileiro de Engenharia de Software, Rio de Janeiro/RJ Brasil, 2001, p. 386-391.

Chaim, M. L. Poke-Tool - Uma ferramenta para suporte ao teste estrutural de programas baseado em análise de fluxo de dados. Dissertação de Mestrado, DCA/FEEC/UNICAMP, Campinas/SP - Brasil, 1991.

Chow, T. S. Testing software design modeled by finite-state machine. IEEE Transactions on Software Engineering, v. 4, n. 3, p. 178-187, 1978.

Corporation IBM, D. P. D. Hipo: A design aid and documentation technique. 1974.

Côte de Resyste Project Conferece protocol case study. Online, disponível em http: //fmt.cs.utwente.nl/ConfCase - último acesso em 04/11/2006, 1999.

Delamaro, M. Mutação de interface: Um critério de adequação interprocedimental para o teste de integração. Tese de Doutoramento, IFSC/USP, 1997.

Delamaro, M. E. Proteum - um ambiente de teste baseado na análise de mutantes. Dissertação de Mestrado, ICMC/USP, São Carlos, SP, 1993.

Delamaro, M. E.; Maldonado, J. C. Proteum: A tool for the assesment of test adequacy for C programs. In: Conference on Performability in Computing Systems (PCS'96), New Brunswick/NJ - USA, 1996, p. 79-95.

Delamaro, M. E.; Maldonado, J. C.; Mathur, A. P. Interface Mutation: An approach for integration testing. IEEE Transactions os Software Engineering, v. 27, n. 3, p. 228-247, 2001.

DeMillo, R. A. Hints on test data selection: Help for the practicing programmer. IEEE Computer, v. 11, n. 4, p. 34-43, 1978.

DeMillo, R. A. Mutation analysis as a tool for software quality assurance. In: Anais da COMPSAC80, Chicago/IL - USA, 1980. 
DeMillo, R. A. Software testing and evaluation. The Benjamin/Cummings Publishing Company Inc, 1987.

Design/CPN Design/cpn. Online, disponível em http://www.daimi.au.dk/ designCPN/ - último acesso em 18/12/2006, 2006.

Fabbri, S. C. P. F. A análise de mutantes no contexto de sistemas reativos: uma contribuição para o desenvolvimento de estratégias de teste e validação. Tese de Doutoramento, IFSC/USP, 1996.

Fabbri, S. C. P. F.; Maldonado, J. C.; Masiero, P. C.; Delamaro, M. E. Análise de mutantes baseadas em máquinas de estado finito. In: Anais do $11^{\text {th }}$ Simpósio Brasileiro de Redes de Computadores, Campinas/SP - Brasil, 1993.

Fabbri, S. C. P. F.; Maldonado, J. C.; Masiero, P. C.; Delamaro, M. E. Mutation analysis for finite state machines. In: Proceedings of $5^{\text {th }}$ International Symposium on Software Reliability Engineering (ISSRE'94), Monterey/CA - USA, 1994, p. 220-229.

Fabbri, S. C. P. F.; Maldonado, J. C.; Sugeta, T.; Masiero, P. C. Mutation testing applied to validate specifications based on statecharts. In: Proceedings of $10^{\text {th }}$ International Symposium on Software Reliability Engineering (ISSRE'99), Boca Raton/Florida - USA, 1999, p. 210-219.

Frankl, P. G.; Weyuker, E. J. A data flow testing tool. In: Proceedings of IEEE Softfair II Conference on Software Development Tools, Techniques, and Alternatives,, 1985, p. 46-53.

Frankl, P. G.; Weyuker, E. J. A formal analysis of the fault-detecting ability of testing methods. IEEE Transactions on Software Engineering, v. 19, n. 3, p. 202-213, 1993.

Frankl, P. G.; Weyuker, E. J. Testing software to detect and reduce risk. Journal of Systems and Software, v. 53, n. 3, p. 275-286, 2000.

Fujiwara, S.; Bochmann, G. V.; Khendek, F.; Amalou, M.; Ghedamsi, A. Test selection based on finite state models. IEEE Transactions on Software Engineering, v. 17, n. 6, 1991.

Gane, C.; Sarson, T. Structured system analysis: Tool and techniques. New Jersey USA: Prentice-Hall, 1979.

Gargantini, A. Conformance testing. In: Model-Based Testing of Reactive Systems, 2004, p. 87-111. 
Gill, A. Introduction to the theory of Finite State Machines. New York - USA: McGraw-Hill, 1962.

Gönenç, G. A method for design of fault-detection experiments. IEEE Transactions on on Computer, v. C-19, n. 6, p. 551-558, 1970.

Grahlmann, B. The pep tool. In: Tool Presentations of ATPN'977 (Application and Theory of Petri Nets), 1997.

Harel, D. Statecharts: A visual formalism for complex systems. Science of Computer Programming, v. 8, p. 231-274, 1987.

Harrold, M. J. Testing: A roadmap. In: 22th International Conference on Software Engineering - Future of SE Track, ACM Press, 2000, p. 61-72.

Heiner, M. Ped - a hierarchical petri net editor. Online, disponível em http: //www-dssz.informatik.tu-cottbus.de - último acesso em 17/03/2005, 2005.

Horgan, J. R.; Mathur, A. P. Assessing testing tool in research and education. IEEE Software, v. 9, n. 3, p. 61-69, 1992.

IEEE Ieee standard glossary of software engineering terminology. Standard 610.12, Institute of Electric and Electronic Engineers, 1990.

INPE EXP-OBDH communication protocol definition - a case study for plavis. Technical Report M13-IF-009, Instituto Nacional de Pesquisas Espaciais (INPE), São José dos Campos/SP, 2005.

Jackson, M. System development. New Jersey: Prentice-Hall International Englewood Cliffs, 1983.

Jensen, K. An Introduction to the Theoretical Aspects of Coloured Petri Nets. In: de Bakker, J.; de Roever, W.-P.; Rozenberg, G., eds. A Decade of Concurrency, London, UK: Springer-Verlag, p. 230-272, 1994.

Jensen, K. An introduction to the practical use of coloured petri nets. In: Advanced Courses on Petri Nets: Lecture Notes in Computer Science, Enschede - The Netherlands: Springer-Verlag, 1996, p. 237-292.

Jensen, K. Coloured petri nets. basic concepts, analysis methods and practical use. Springer-Verlag, three Volumes, 1997. 
Jorge, R. F.; Vincenzi, A. M. R.; Delamaro, M. E.; Maldonado, J. C. Teste de mutação: Estratégias baseadas em equivalência de mutantes para redução do custo de aplicação. In: Anais do XXVII Latin-American Conference on Informatics - CLEI'2001, Merida - Venezuela, 2001.

Luo, G.; Petrenko, A.; Bochmann, G. Selecting test sequences for partially-specified nondeterministic finite state machines. Relatório técnico, Department d'IRO, Université de Montreál, 1994.

Maldonado, J. C. Critérios potenciais usos: Uma contribuição ao teste estrutural de software. Tese de Doutoramento, DCA/FEE/UNICAMP, Campinas, SP - Brasil, 1991.

Maldonado, J. C. Critérios de teste de software: Aspectos teóricos, empíricos e de automatização. Concurso de Livre Docência - ICMC-USP, 1997.

Maldonado, J. C.; Barbosa, E. F.; Vincenzi, A. M. R.; Delamaro, M. E. Evaluating n-selective mutation for c programs: Unit and integration testing. In: Anais do Mutation 2000 Symposium, San Jose/CA - USA, 2000a.

Maldonado, J. C.; Delamaro, M. E.; Fabbri, S. C. P. F.; Simão, A. S.; Sugeta, T.; Masiero, P. C. Proteum: A family of tools to support specification and program testing based on mutation. In: Mutation 2000 Symposium - Tool Session, San Jose/CA - USA: Kluwer Academic Publishers, 2000b, p. 113-116.

Martins, E.; Sabião, S. B.; Ambrósio, A. M. Condata: a tool for automating specification-based test case generation for communication systems. Software Quality Journal, v. 8, n. 4, p. 303-319, 1999.

Mathur, A. P.; Wong, W. E. Evaluation of the cost of alternative mutation strategies. In: VII Simpósio Brasileiro de Engenharia de Software, Rio de Janeiro/RJ - Brasil, 1993, p. 320-335.

Mealy, G. H. A method for synthesizing sequential circuits. Bell System Technical Journal, v. 35, p. 1045-1079, 1955.

Moore, E. F. Gedanken-experiments on sequential machines. In: Automata Studies, Princeton/NJ, 1956, p. 129-153.

Mresa, E. S.; Bottaci, L. Efficiency of mutation operators and selective mutation strategies: an empirical study. The Journal of Software Testing, v. 9, n. 4, p. 205-232, 1999. 
Murata, T. Properties, analysis and applications. In: Proceedings of the IEEE, 1989, p. $541-580$.

Myers, G. J.; Sandler, C.; Badgett, T.; Thomas, T. M. The art of software testing. 2nd. ed. John Wiley \& Sons, 2004.

Nakazato, K. K. Módulos de geração de seqüências de teste baseadas em Máquinas de Estado Finito. Dissertação de Mestrado, ICMC/USP, São Carlos/SP - Brasil, 1995.

Nakazato, K. K.; Maldonado, J. C.; Fabbri, S. C. P. F.; Masiero, P. C. Aspectos teóricos e de implementação de critérios de geração de seqüências de teste baseados em máquina de estados finitos. Relatório Técnico 25, ICMC/USP, São Carlos/SP, 1994a.

Nakazato, K. K.; Maldonado, J. C.; Fabbri, S. C. P. F.; Masiero, P. C. Propriedades das máquinas de estados finitos relevantes para critérios de geração de seqüências de teste. Relatório Técnico 27, ICMC/USP, São Carlos/SP, 1994b.

Nakazato, K. K.; Maldonado, J. C.; Fabbri, S. C. P. F.; Masiero, P. C. Seqüências básicas de máquinas de estado finito. Relatório Técnico 28, ICMC/USP, São Carlos/SP, 1994c.

Ntafos, S. C. A comparison of some structural testing strategies. IEEE Transactions on Software Engineering, v. 14, n. 6, p. 868-874, 1988.

Offutt, A. J.; Lee, A.; Rothermel, G.; Untch, R. H.; Zapf, C. An experimental determination of sufficient mutant operators. ACM Transactions on Software Engineering Methodology, v. 5, n. 2, p. 99-118, 1996.

Peterson, J. L. Petri Nets theory and modelling of systems. Eaglewood Cliffs/NJ USA: Prentice-Hall, 1981.

Petrenko, A.; Bochmann, G.; Yao, M. On fault coverage of tests for finite state specifications. Computer Network and ISDN Systems, v. 29, n. 1, p. 81-106, 1996.

Petrenko, A.; Yevtushenko, N. On test derivation from partial specifications. In: FORTE/PSTV 2000: Proceedings of the FIP TC6 WG6.1 Joint International Conference on Formal Description Techniques for Distributed Systems and Communication Protocols (FORTE XIII) and Protocol Specification, Testing and Verification (PSTV XX), Deventer, The Netherlands, The Netherlands: Kluwer, B.V., 2000, p. 85-102.

Petrenko, A.; Yevtushenko, N. Testing from partial deterministic fsm specifications. IEEE Transactions on Computers, v. 54, p. 1154-1165, 2005. 
Pressman, R. S. Software engineering - a practitioner's approach. 6th. ed. McGraw-Hill, 2005.

Rapps, S.; Weyuker, E. J. Data flow analysis techniques for program test data selection. In: Proceedings of the $6^{\text {th }}$ International Conference on Software Engineering (ICSE'1982), Tokio - Japan: IEEE Computer Society Press, 1982, p. 272-278.

Rapps, S.; Weyuker, E. J. Selectiong software testing data using data flow information. IEEE Transactions os Software Engineering, v. 11, n. 4, p. 367-375, 1985.

Roch, S.; Stark, P. H. Manual of INA - integrated net analyser, version 2.2. Humboldt-Universität zu Berlin, Institut für Informatik, 1999.

Sabnari, K. K.; Dahbura, A. Sa protocol test generation procedure. Computer Network and ISDN Systemsg, v. 15, n. 4, p. 285-297, 1988.

Simão, A. S. Proteum-rs/pn: Uma ferramenta para validação de redes de petri baseada na análise de mutantes. Dissertação de Mestrado, ICMC/USP, São Carlos/SP - Brasil, 2000.

Simão, A. S. Teste e validação de Redes de Petri coloridas usando análise de mutantes. Exame Geral de Qualificação para Doutoramento, ICMC/USP, São Carlos/SP - Brasil. 2002.

Simão, A. S. Aplicação de análise de mutantes no contexto do teste e validação de redes de Petri Coloridas. Tese de Doutoramento, ICMC/USP, São Carlos/SP - Brasil, 2004.

Simão, A. S.; Ambrósio, A. M.; Fabbri, S. C. P. F.; Amaral, A. S. M. S.; Martins, E.; Maldonado, J. C. Plavis/fsm: an environment to integrate fsm-based testing tools. In: Sessão de Ferramentas do $19^{\circ}$ Simpósio Brasileiro de Engenharia de Software (SBES'2005), Uberlândia/MG - Brasil, 2005.

Sommerville, I. Engenharia de software. 6th ed. Addison-Wesley, 2003.

Souza, S. R. S. Avaliação do custo e eficácia do critério análise de mutantes na atividade de teste de software. Dissertação de Mestrado, ICMC/USP, São Carlos/SP - Brasil, 1996.

Sugeta, T. Proteum-rs/st: Uma ferramenta para apoiar a validação de especificações statecharts baseada na análise de mutantes. Dissertação de Mestrado, ICMC/USP, São Carlos/SP - Brasil, 1999. 
Sze, S.; Lyu, M. Atacobol: A cobol test coverage analisys tool and its applications. In: Proceedings of $11^{\text {th }}$ International Symposium of Software Reliabitity Engineering (ISSRE'2000), San Jose/CA - USA, 2000, p. 327-335.

Tan, Q. M.; Petrenko, A.; Bochmann, G. A test generation tool for specifications in the form of state machines. In: Proceedings of the International Communication Conference (ICC'96), Session on advanced tools and technologies for developing high integrity software systems, Dallas/Texas - USA, 1996, p. 225-229.

Terpstra, R.; Pires, L.; Heerink, L.; Tretmans, J. Testing theory in practice: A simple experiment. 1996.

Disponível em citeseer.ist.psu.edu/terpstra96testing.html

Varpaaniemi, K.; Halme, J.; Hiekkanen, K.; Pysyssalo, T. Prod reference manual. Digital Systems Laboratory, Department of Computer Science, Kelsinki University of Technology, Otaniemi, Finlândia, 1995.

Vincenzi, A. M. R. Orientação a objeto: Definição, implementação e análise de recursos de teste e validação. Tese de Doutoramento, ICMC/USP, São Carlos, SP - Brasil, 2004.

Vincenzi, A. M. R.; Maldonado, J. C.; Barbosa, E. F.; Delamaro, M. E. Unit and integration testing strategies for c programs using mutation-based criteria. Journal of Software Testing, Verification and Reliability, v. 11, n. 4, p. 249-268, 2001.

Vincenzi, A. M. R.; Wong, W. E.; Delamaro, M. E.; Maldonado, J. C. Jabuti: A coverage analysis tool for java programs. In: Anais do $17^{\circ}$ Simpósio Brasileiro de Engenharia de Software (SBES'2003), Sessão de Ferramentas, Manaus/AM - Brasil, 2003, p. 79-84.

Wing, J. M. A specifier's introduction to formal methods. IEEE Computer, v. 23, n. 9, p. 8-22, 1990.

Wohlin, C.; Runeson, P.; Höst, M.; Ohlsson, M. C.; Regnell, B.; Wesslén, A. Experimentation in Software Engineering: an Introduction. Kluwer Academic Publishers, 2000.

Wong, W. E.; Maldonado, J. C.; Mathur, A. P. Software quality and productivity theory, practice, education and training, cáp. Mutation versus All-Uses: An Empirical Evaluation of Cost, Strength, and Effectiveness Hong Kong, 1994.

Yano, T. Estudo do teste de mutação em programas funcionais SML. Dissertação de Mestrado, ICMC/USP, São Carlos/SP - Brasil, 2004. 
Zhu, H. A formal analysis of the subsume relation between software test adequacy criteria. IEEE Transactions on Software Engineering, v. 22, n. 4, p. 248-255, 1996. 

Apêndice

$A$

\section{Rede de Petri Colorida - Protocolo de Conferência}

Neste apêndice mostra-se a Rede de Petri Colorida, do Protocolo de Conferência, utilizada no estudo de caso 1, mostrado no Capítulo 3. Essa RPC foi desenvolvida no contexto do projeto Plavis.

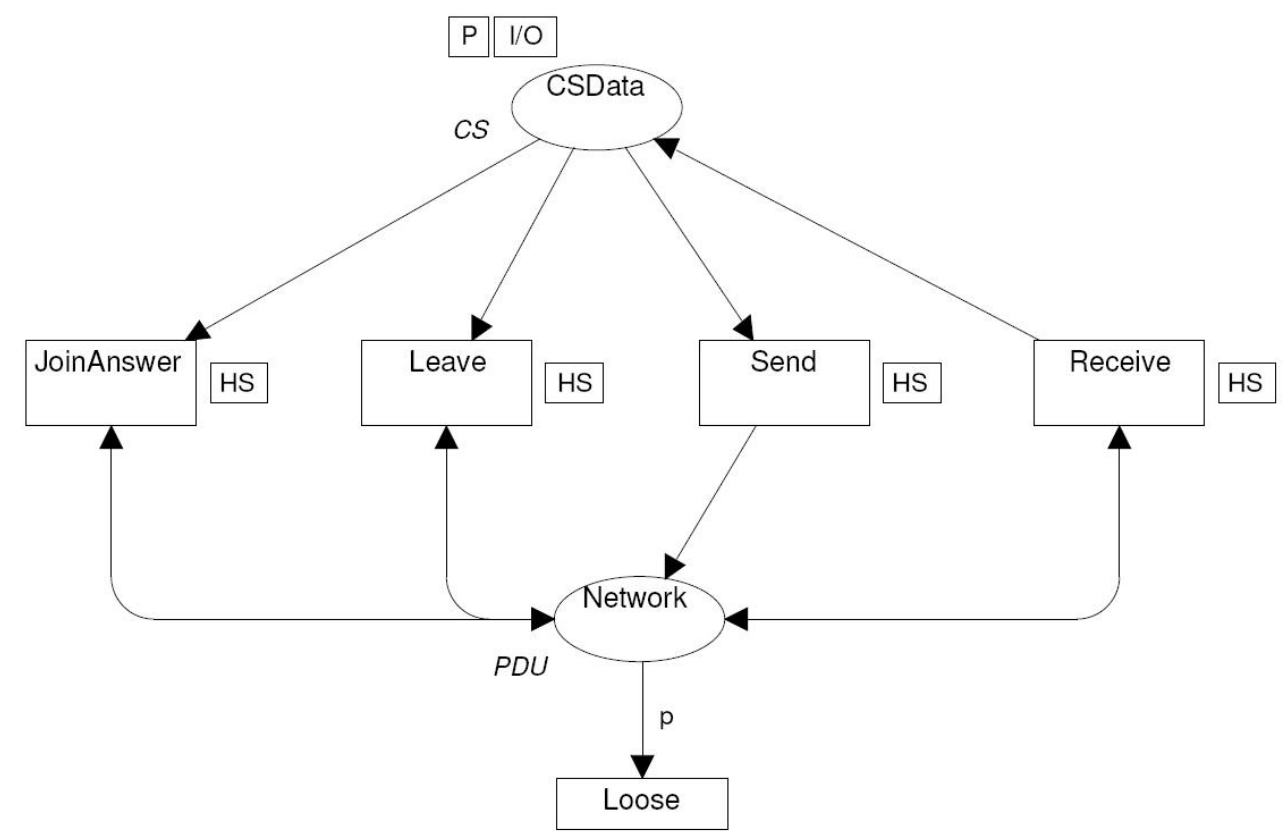

Figura A.1: RPC do Protocolo de Conferência - Página $C P E$ 


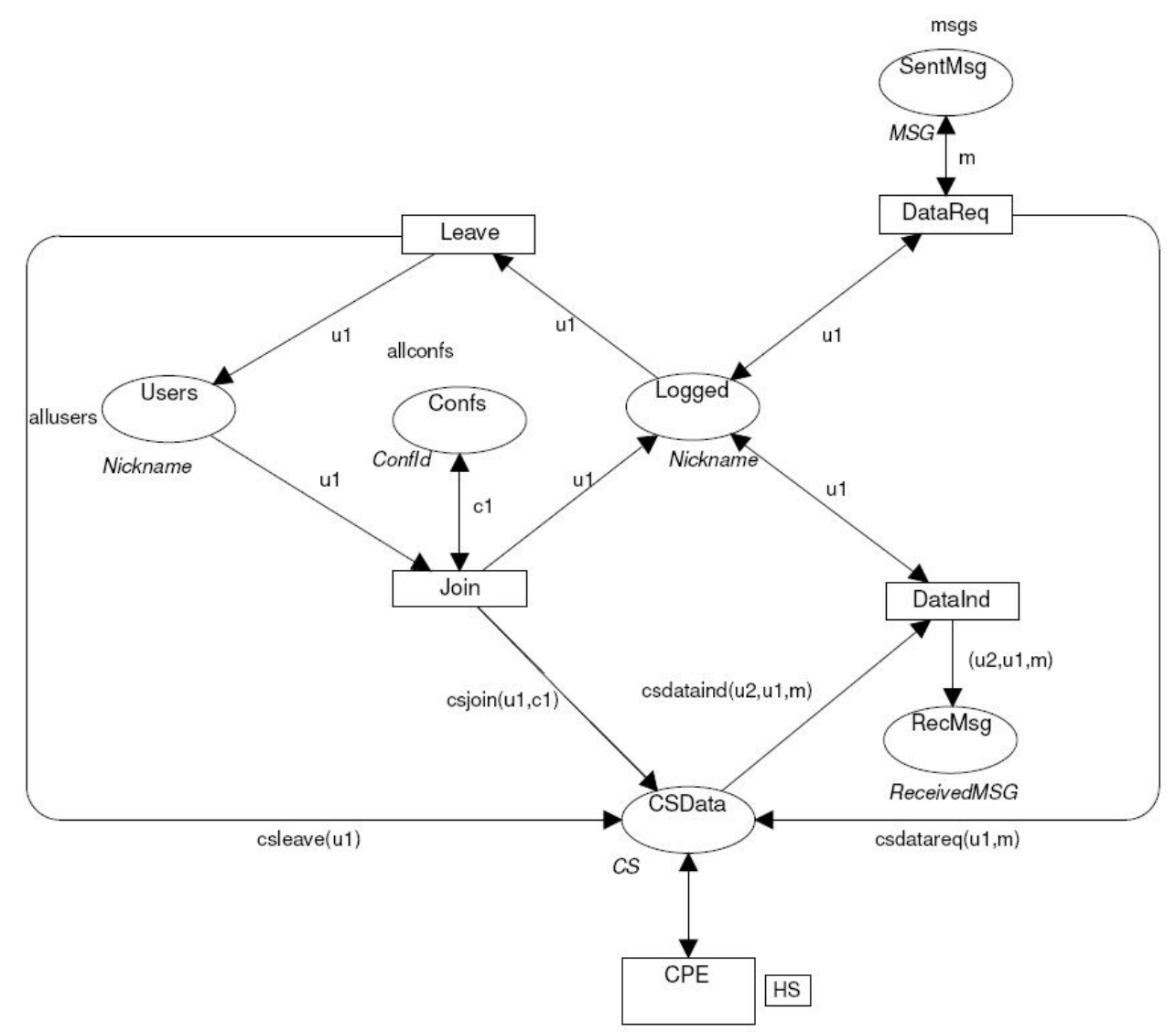

Figura A.2: RPC do Protocolo de Conferência - Página CSAP

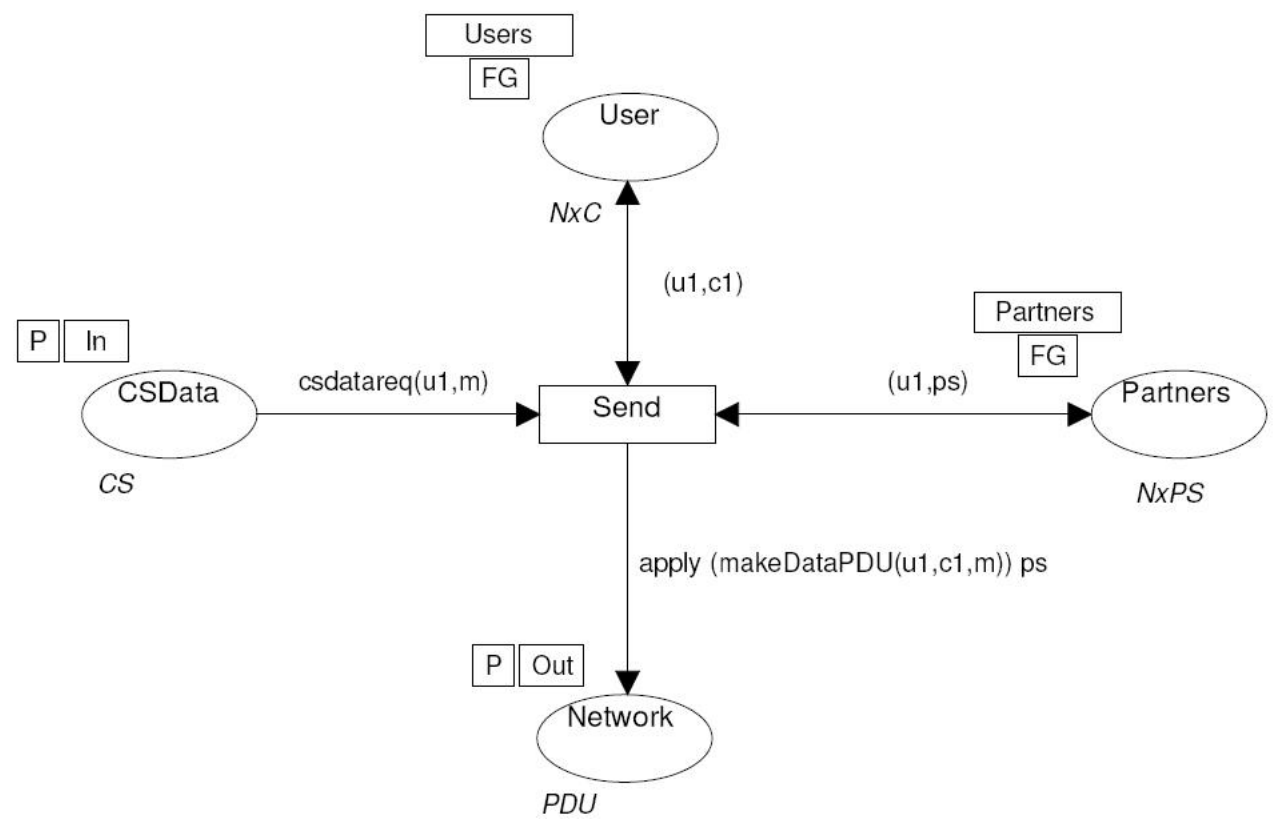

Figura A.3: RPC do Protocolo de Conferência - Página Send 


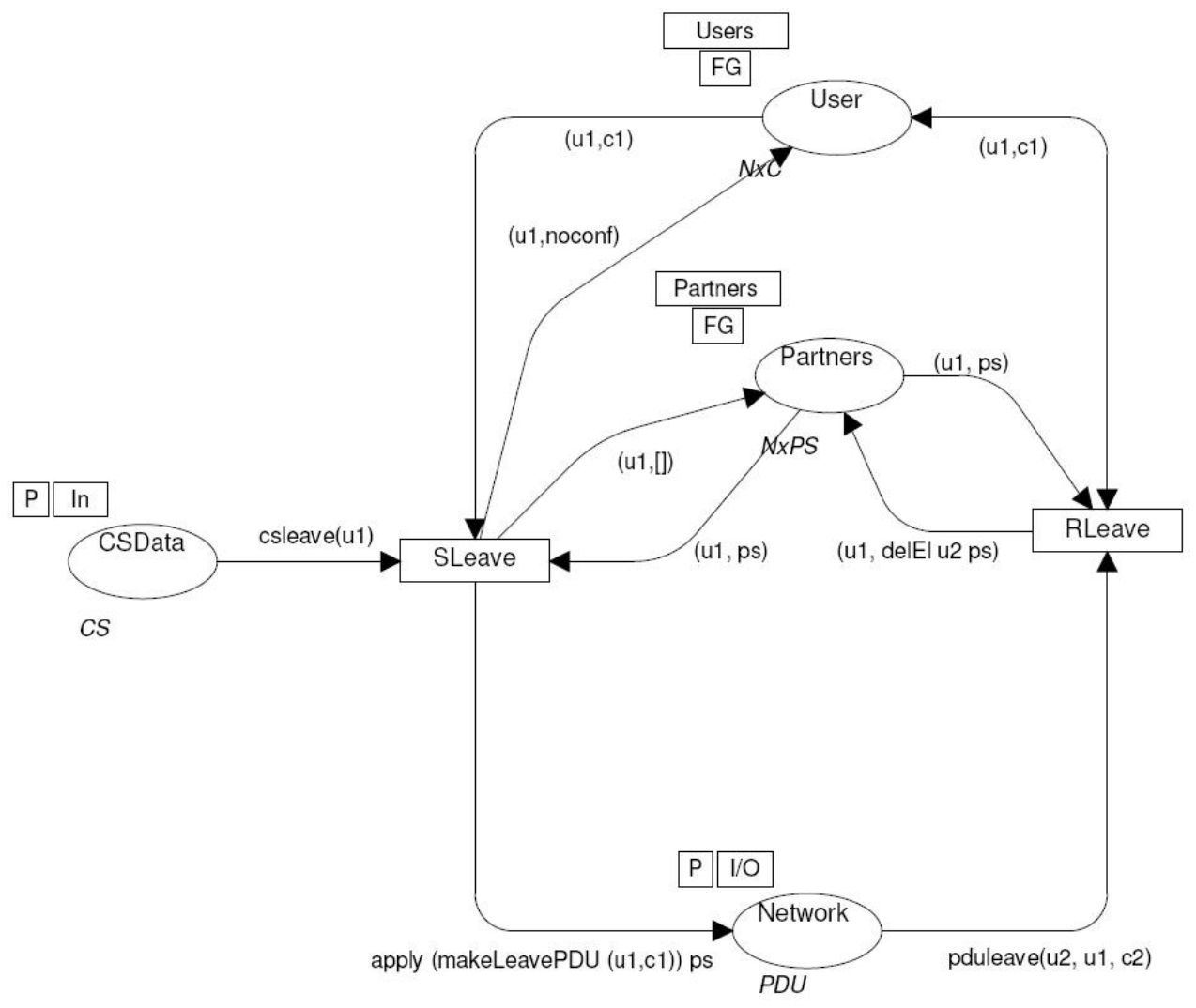

Figura A.4: RPC do Protocolo de Conferência - Página Leave

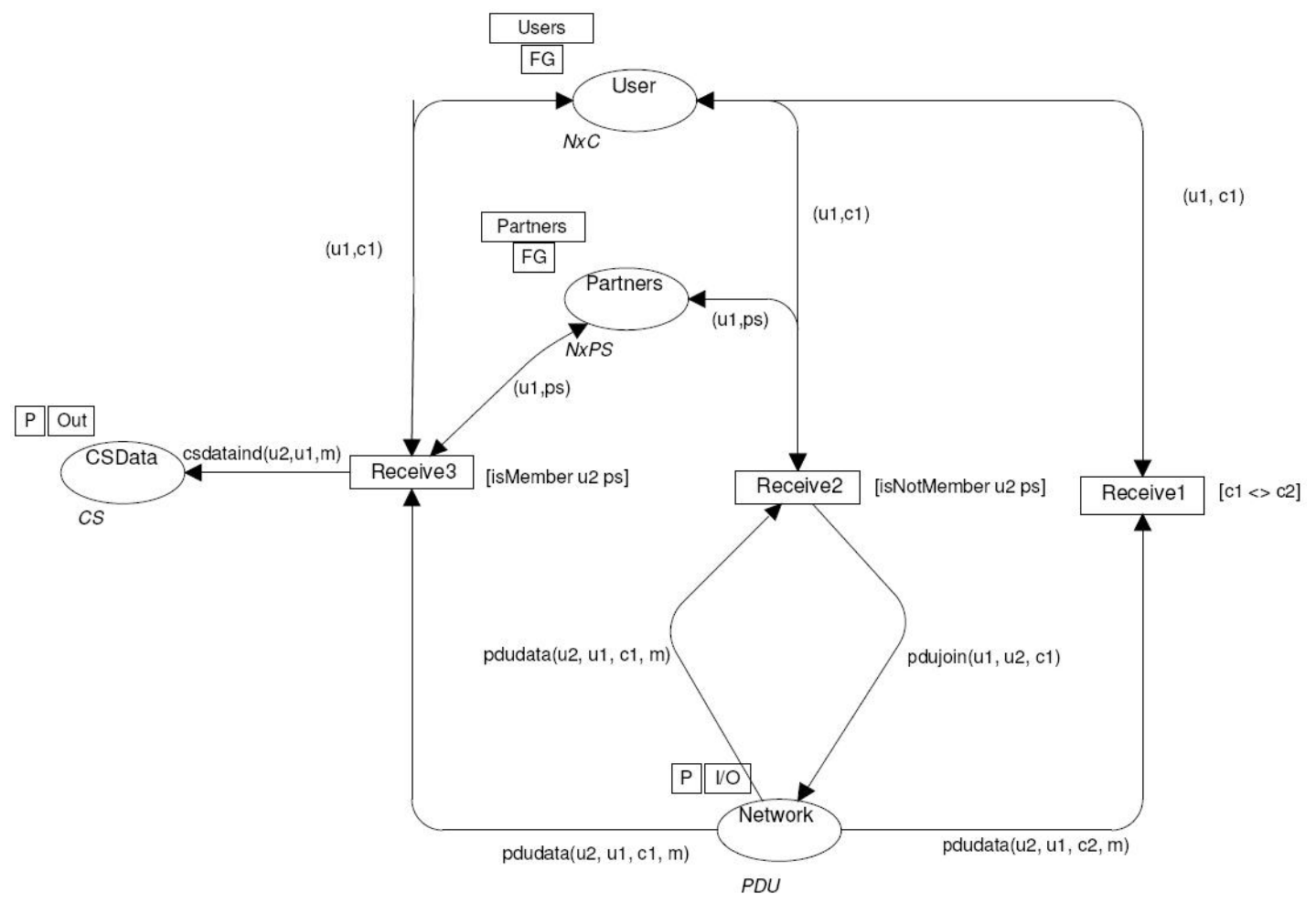

Figura A.5: RPC do Protocolo de Conferência - Página Receive 


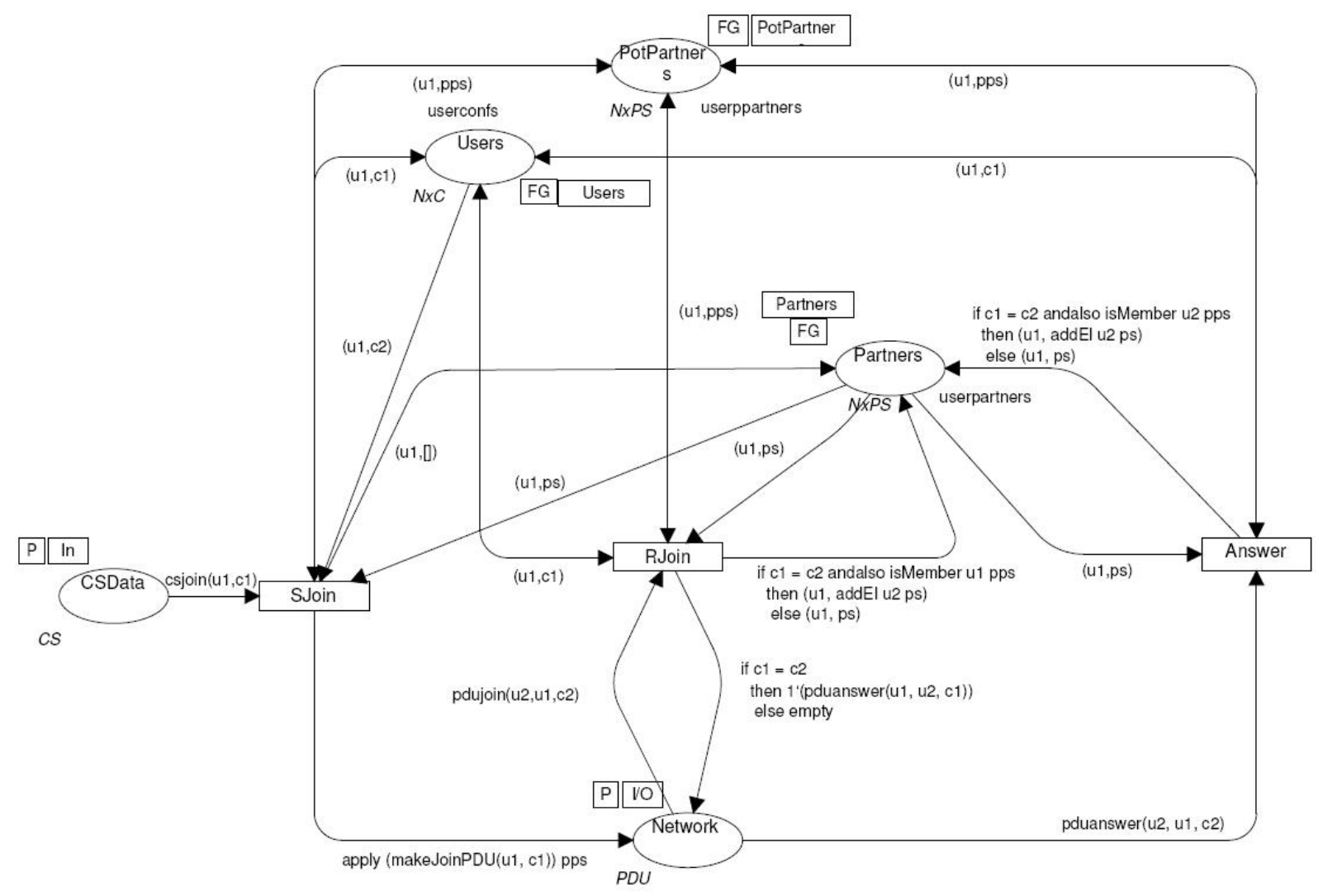

Figura A.6: RPC do Protocolo de Conferência - Página JoinAnswer 